\title{
Representações Hierárquicas de Vocábulos de Línguas Indígenas Brasileiras: Modelos Baseados em Mistura de Gaussianas
}

\section{Lianet Sepúlveda Torres}

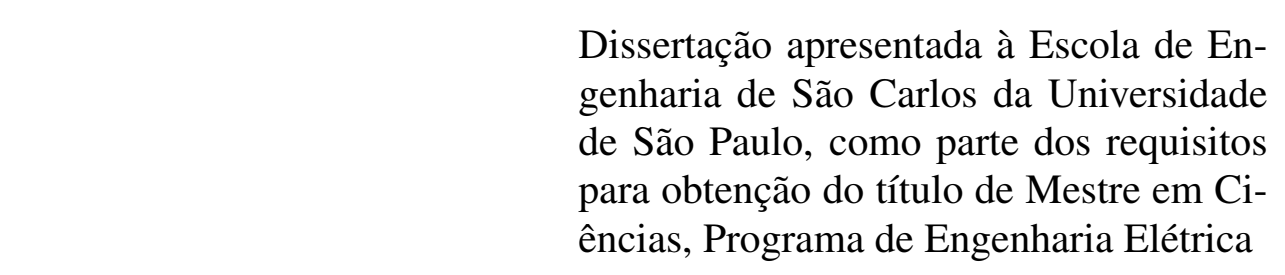

ÁREA DE CONCENTRAÇÃO: Processamento de Sinais e Instrumentação. ORIENTADOR: Prof. Dr. José Carlos Pereira 
AUTORIZO A REPRODUÇÃO E DIVULGAÇÃO TOTAL OU PARCIAL DESTE TRABALHO, POR QUALQUER MEIO CONVENCIONAL OU ELETRÔNICO, PARA FINS DE ESTUDO E PESQUISA, DESDE QUE CITADA A FONTE.

Ficha catalográfica preparada pela Seção de Tratamento da Informação do Serviço de Biblioteca - EESC/USP

\footnotetext{
Sepúlveda Torres, Lianet

Representações hierárquicas de vocábulos de linguas indígenas brasileiras : modelos baseados em mistura de Gaussianas / Lianet Sepúlveda Torres ; orientador José Carlos Pereira. -- São Carlos, 2010.

Dissertação (Mestrado-Programa de Pós-Graduação em Engenharia Elétrica e Área de Concentração em Processamento de Sinais e Instrumentação) -- Escola de Engenharia de São Carlos da Universidade de São Paulo, 2010 .

1. Processamento de sinais acústicos. 2. Processamento digital de voz. 3. Línguas indígenas. I. Título.
} 
FOLHA DE JULGAMENTO

Candidato(a): Ingeniero Informático LIANET SEPÚLVEDA TORRES.

Dissertação defendida e julgada em 08/12/2010 perante a Comissão Julgadora:
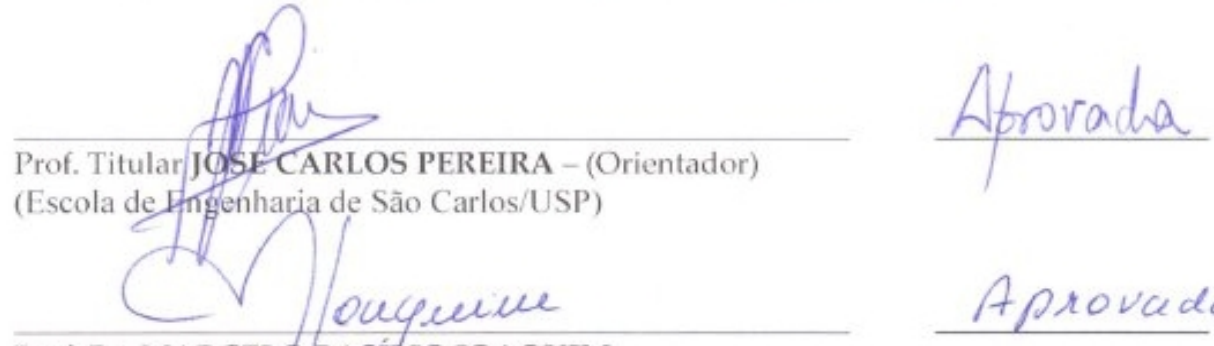

Prof. Dr. MARCELQ/BASTILIO JOAQUIM

(Escola de Engentiarla de São Carlos/USP)
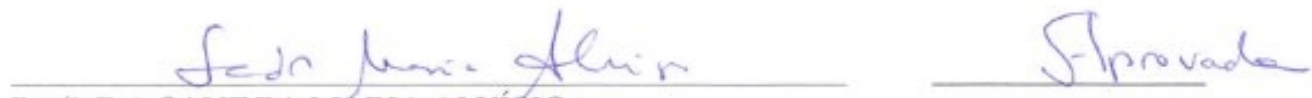

Prof". Dra. SANDRA MARIA ALUÍSIO

(Instituto de Ciências Matemáticas e de Computação/USP)
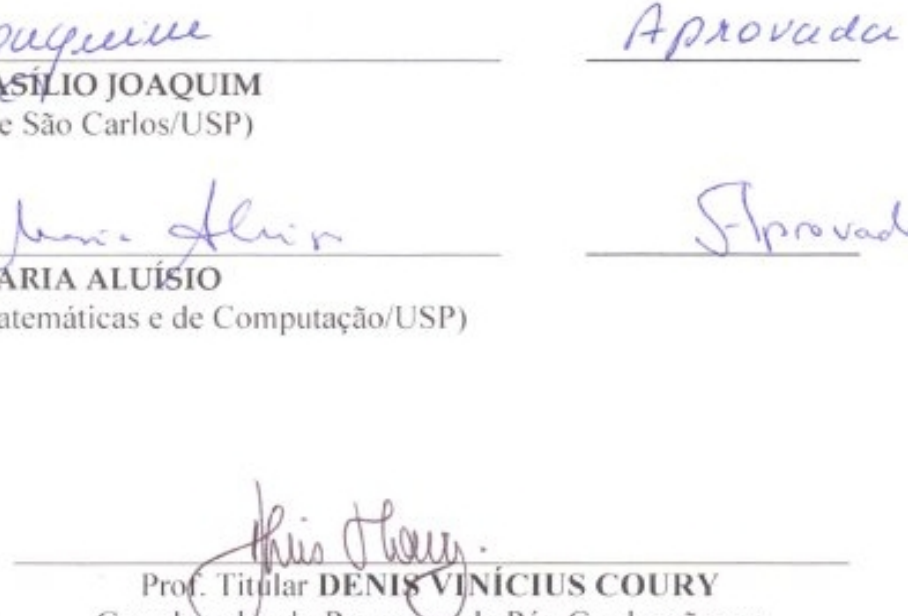

Coordenadorr do Progranta de Pós-Graduação em

Engenharia Elétrica

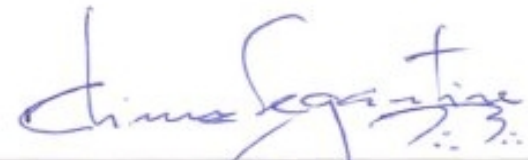

Prof. Associado PAULO CÉSAR LIMA SEGANTINE

Presidente da Comissão da Pós-Graduação da EESC 
Dedicatória

Aos meus pais pelo exemplo e a confiança,

A Lian por todo seu amor. 
A Lian (Mi jevi) por acreditar sempre em nosso amor, por ser minha força, pela paciência, pelo apoio, pelos momentos difíceis e pelas muitas alegrias. Todas minhas conquitas são compartilhadas.

Agradeço aos meus pais pelo apoio até nas decisões mais difíceis, pela confiança e a constante preocupação. Apesar da distância, sempre me acompanham. Por me ensinar o que é realmente importante na vida e por me incentivar a continuar estudando. A meu irmão que adoro tanto. Esta conquista é para vocês em troca dos anos não compartidos.

A Esperanza e Felipe por serem meus pais no Brasil. Muito obrigada pela ajuda, a confiança o carinho e a oportunidade de me reunir com Lian. A Indara e Orieta obrigada pela força, por assumirem as tarefas domésticas para que eu possa terminar meu trabalho. Muito obrigada!!!

Agradeço ao Prof. José Carlos Pereira pelo apoio, a confiança e a generosidade.

Um agradecimento especial ao pessoal do laboratório "internacional” Eugenia, Edwin, Soledad, Anderson, Paulo, Regina, Jamile, Julian e Alan que me receberam e me apoiaram sempre. Obrigada pelo apoio, a amizade, os palpites profissionais, os momentos de descontração e pela oportunidade de aprender diferentes versões do espanhol e dificilmente o português.

A Eugenia por ser como uma irmã, pelo carinho, pelo exemplo de luta, pela guia durante estes dois anos, pela preocupação. Agradeço por ter encontrado uma argentina como tu aqui no Brasil. Obrigada ao Silvio (Chuchu) por me receber em sua casa e me ajudar.

“Aos maricas”!!! Amilcar, Guido e Giovani, obrigada pelos cafés, as largas conversas, os churrascos e o mais importante pela amizade incondicional. Amilcar, muito obrigada pelas frases matutinas de português, ainda não aprendi falar "A xícara caiu no chão sujo da chácara...”

A Edwin por ser meu palpiteiro. Agradeço cada um dos conselhos recebidos, tua ajuda foi crucial neste trabalho.

A Regina (Rejina) e Adilson por seu esforço. Muito obrigada pelo apoio, a preocupação e as horas falando de tudo e nada. Obrigada pelas aulas de português!!!

Aos cubanos de São Carlos, Karel (Poeta), Katiuska, Peko, Michel, Rosangela, Lita, Miquel e aos argentinos, por tantas madrugadas de salsa, cerveja, risadas e discussões políticas. 
Aos professores que contribuíram com minha formação e que me ajudaram nestes anos, Prof. José Carlos Pereira, Prof. Rodrigo Guido, Prof. Carlos Maciel, Prof. Marcelo BJ, Prof. Jean Claude M'Peko, Prof. Suely Oliveira. A professora Sandra por confiar em mim e me dar a oportunidade de trabalhar com ela.

A CAPES pelo apoio financeiro e ao Programa de Engenharia Elétrica que me aceitou e ajudou em cada uma de minhas dificuldades.

Agradeço ao pessoal da secretaria, Jussara e Marisa, que sempre estiveram dispostas a me ajudar. Meu agradecimento ao pessoal de apoio técnico, Roseli e João, por arrumar meus problemas urgentes na hora. A Vera, pelo café, a Dair, a Rui, e a Zé por sua cordialidade. As faxineiras, aos seguranças, a todos, meus agradecimentos por fazer nossas vidas mais amenas.

Agradeço a minhas primas Ana, Alicia, Eva e Mariela pela ajuda e a preocupação nestes anos longe da minha família.

Agradeço a minha família de Cuba, meus avos (Mima, Papi, tia Berta), minhas tias (Sandra, Elita, Lourdes, Maria) e os meus primos, pela constante preocupação e pelo carinho. Os que já não estão (Mimi, Pipo e Ferna), minha lembrança. Estão todos no meu coração. A família do Lian muito obrigada pela preocupação e a Fina por suas soluções alternativas nos momentos mais complicados.

Um agradecimento especial para meus amigos de Cuba, para esses amigos de tantos anos que estão sempre no meu coração.

A Alexandra e Walcir muito obrigada pela ajuda e pela amizade incondicional.

A Terezinha por ter me apoiado e recebido na sua casa no primeiro ano em São Carlos.

Enfim, a cada pessoa que encontrei nestes anos, me apoiando, me criticando, me incentivando,

Muito Obrigada 


\section{Sumário}

Lista de Figuras

$\begin{array}{lll}\text { Lista de Tabelas } & \text { xv }\end{array}$

$\begin{array}{ll}\text { Lista de Símbolos } & \text { xvii }\end{array}$

Lista de Siglas

Resumo $\quad$ xxi

$\begin{array}{ll}\text { Abstract } & \text { xxiii }\end{array}$

1 Introdução 1

2 Fundamentos Teóricos 5

2.1 Vozes Indígenas $\ldots \ldots \ldots \ldots \ldots$

2.2 Estimativas da função de distribuição de probabilidade (PDF) . . . . . . . . . 11

2.3 Modelo baseado em mistura de gaussianas $(\mathrm{GMM}) \ldots \ldots$. . . . . . . . . 17

2.3.1 Algoritmo Maximização da Expectância (EM) . . . . . . . . . . . . . 19

2.4 Medidas de Similaridade . . . . . . . . . . . . . . . . . . . . . . . . . 20

2.5 Divergência Kulback-Leibler $(\mathrm{KL}) \ldots \ldots$. . . . . . . . . . . . . . . 23

2.5 .1 Simetrização da divergência KL . . . . . . . . . . . . . . . . 25

2.5.2 Estimativa da divergência KL entre GMM . . . . . . . . . . . 28

2.6 Agrupamento Hierárquico . . . . . . . . . . . . . . . . . . 31

2.6.1 Métodos aglomerativos tradicionais . . . . . . . . . . . . 32

3 Materiais e Métodos $\quad 37$

3.1 Banco de dados . . . . . . . . . . . . . . . . . . . 37

3.2 Arquitetura do algoritmo proposto . . . . . . . . . . . . . . . 39

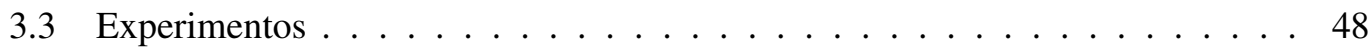

3.3.1 Experimentos na estimativa de PDF . . . . . . . . . . . . . . . . 49 
3.3.2 Experimentos do cálculo da distância entre os modelos . . . . . . . . . 51

4 Resultados e Discussões

4.1 Resultados dos sinais simulados . . . . . . . . . . . . . . . . . . 55

4.2 Resultados das palavras das línguas indígenas. . . . . . . . . . . . . . . . 59

5 Conclusões e Sugestões $\quad 77$

5.1 Trabalhos futuros . . . . . . . . . . . . . . . . . . . . . 79

$\begin{array}{ll}\text { Referências Bibliográficas } & 81\end{array}$ 


\section{Lista de Figuras}

FIGURA 2.1 Tronco Linguístico Tupi $\ldots \ldots \ldots \ldots$

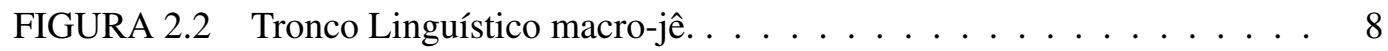

FIGURA 2.3 Família de línguas isoladas. . . . . . . . . . . . . . . . . 9

FIGURA 2.4 Relações entre métricas de distância usadas para simetrizar a divergência KL . . . . . . . . . . . . . . . . . . . . 27

FIGURA 2.5 Exemplo de representação de um dendrograma. . . . . . . . . . . . . 32

FIGURA 3.1 Diferentes etapas do sistema proposto. . . . . . . . . . . . . . . . . . 40

FIGURA 3.2 Operações realizadas no módulo de Pré-processamento. . . . . . . . 41

FIGURA 3.3 Sinal original e sinal pré-processado. . . . . . . . . . . . . . . . . . 41

FIGURA 3.4 Operações realizadas no módulo PDF . . . . . . . . . . . . . . . . . 42

FIGURA 3.5 Operações realizadas no módulo Medida. . . . . . . . . . . . . . . . 46

FIGURA 3.6 Histograma dos sinais gerados a partir de duas distribuições gaussianas. 50

FIGURA 4.1 Estimativa do GMM que representa a PDF, envoltória da mistura e o histograma dos sinais simulados nos 3 experimentos desenvolvidos. . . . . . . 58

FIGURA 4.2 Critério BIC na seleção do número ótimo de gaussianas que integram a mistura dos sinais simulados. . . . . . . . . . . . . . . . . . . . 59

FIGURA 4.3 Estimativa do GMM que representa a PDF da palavra água dita por 10 línguas indígenas brasileiras. . . . . . . . . . . . . . . 60

FIGURA 4.4 Estimativa do GMM que representa a PDF da palavra criança dita por 10 línguas indígenas brasileiras. 
FIGURA 4.5 Estimativa do GMM que representa a PDF da palavra fogo dita por 10 línguas indígenas brasileiras. . . . . . . . . . . . . . . . 62

FIGURA 4.6 Estimativa do GMM que representa a PDF da palavra olho dita por 10 línguas indígenas brasileiras. . . . . . . . . . . . . . . . 63

FIGURA 4.7 Estimativa do GMM que representa a PDF da palavra osso dita por 10 línguas indígenas brasileiras. . . . . . . . . . . . . . . . . . . 64

FIGURA 4.8 Estimativa do GMM que representa a PDF da palavra sangue dita por 10 línguas indígenas brasileiras. . . . . . . . . . . . . . . 65

FIGURA 4.9 Dendrograma do lote da palavra água, calculado usando a divergência KL. . . . . . . . . . . . . . . . . . . . . . . . . . . . 68

FIGURA 4.10 Dendrograma do lote da palavra criança, calculado usando a divergência KL. . . . . . . . . . . . . . . . . . . . . . . . . 68

FIGURA 4.11 Dendrograma do lote da palavra fogo, calculado usando a divergência

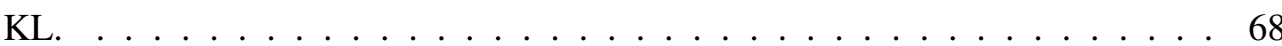

FIGURA 4.12 Dendrograma do lote da palavra olho, calculado usando a divergência

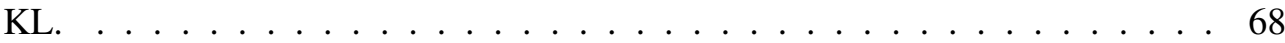

FIGURA 4.13 Dendrograma do lote da palavra osso, calculado usando a divergência KL . . . . . . . . . . . . . . . . . . . . . . . 68

FIGURA 4.14 Dendrograma do lote da palavra sangue, calculado usando a divergência KL. . . . . . . . . . . . . . . . . . . . . . . . . 68

FIGURA 4.15 Dendrograma do lote da palavra água, calculado usando a distância Bhattacharyya . . . . . . . . . . . . . . . . . 70

FIGURA 4.16 Dendrograma do lote da palavra criança, calculado usando a distância

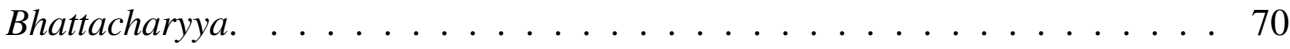

FIGURA 4.17 Dendrograma do lote da palavra fogo, calculado usando a distância Bhattacharyya . . . . . . . . . . . . . . . . . 70

FIGURA 4.18 Dendrograma do lote da palavra olho, calculado usando a distância

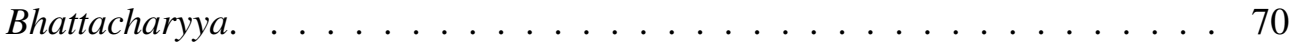


FIGURA 4.19 Dendrograma do lote da palavra osso, calculado usando a distância Bhattacharyya . . . . . . . . . . . . . . . . . . 70

FIGURA 4.20 Dendrograma do lote da palavra sangue, calculado usando a distância

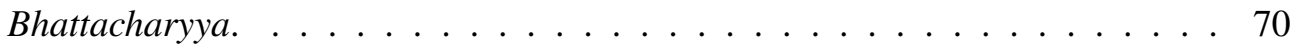

FIGURA 4.21 Dendrograma do lote da palavra água, calculado usando a distância Chi-quadrado de Pearson. . . . . . . . . . . . . . . . . . . . . . 71

FIGURA 4.22 Dendrograma do lote da palavra criança, calculado usando a distância Chi-quadrado de Pearson. . . . . . . . . . . . . . . . . . . . . . 71

FIGURA 4.23 Dendrograma do lote da palavra fogo, calculado usando a distância Chi-quadrado de Pearson. . . . . . . . . . . . . . . . . . . . . . 71

FIGURA 4.24 Dendrograma do lote da palavra olho, calculado usando a distância Chi-quadrado de Pearson. . . . . . . . . . . . . . . . . . . . . . . . 71

FIGURA 4.25 Dendrograma do lote da palavra osso, calculado usando a distância Chi-quadrado de Pearson. . . . . . . . . . . . . . . . . . . . . . . . 71

FIGURA 4.26 Dendrograma do lote da palavra sangue, calculado usando a distância Chi-quadrado de Pearson. . . . . . . . . . . . . . . . . . . . . 71

FIGURA 4.27 Dendrograma do lote da palavra água, calculado usando a distância Jensen-Shannon. . . . . . . . . . . . . . . . . . . . . . 72

FIGURA 4.28 Dendrograma do lote da palavra criança, calculado usando a distância Jensen-Shannon. . . . . . . . . . . . . . . . . . . . . 72

FIGURA 4.29 Dendrograma do lote da palavra fogo, calculado usando a distância Jensen-Shannon. . . . . . . . . . . . . . . . . . . . . . . . 72

FIGURA 4.30 Dendrograma do lote da palavra olho, calculado usando a distância Jensen-Shannon. . . . . . . . . . . . . . . . . . . . . . . . . 72

FIGURA 4.31 Dendrograma do lote da palavra osso, calculado usando a distância Jensen-Shannon. . . . . . . . . . . . . . . . . . . . . . . . 72

FIGURA 4.32 Dendrograma do lote da palavra sangue, calculado usando a distância Jensen-Shannon. . . . . . . . . . . . . . . . . . . . . . . 72

FIGURA 4.33 Dendrograma do lote da palavra água, calculado usando a distância C2. 73 xiii 
FIGURA 4.34 Dendrograma do lote da palavra criança, calculado usando a distância

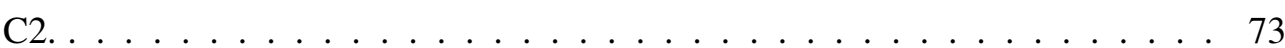

FIGURA 4.35 Dendrograma do lote da palavra fogo, calculado usando a distância C2. 73 FIGURA 4.36 Dendrograma do lote da palavra olho, calculado usando a distância C2. 73 FIGURA 4.37 Dendrograma do lote da palavra osso, calculado usando a distância C2. 73 FIGURA 4.38 Dendrograma do lote da palavra sangue, calculado usando a distância

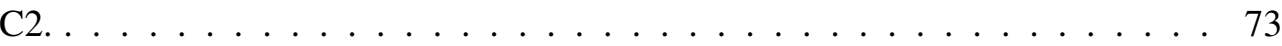




\section{Lista de Tabelas}

TABELA 2.1 Características das abordagens propostas para estimar a PDF de um

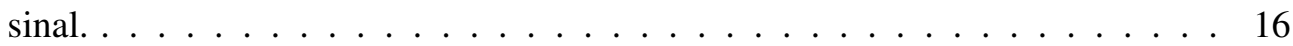

TABELA 2.2 Medidas de distância mais comummente empregadas entre GMM. . . 23

TABELA 2.3 Métodos para estimar a divergência KL entre GMM. Cumprimento das propriedades da KL. . . . . . . . . . . . . . . . . . . . 31

TABELA 3.1 Línguas e dialetos armazenados na base de dados do Museu do Índio. 38

TABELA 3.2 Palavras selecionadas para analisar no presente estudo. . . . . . . . . 38

TABELA 4.1 Parâmetros que descrevem as misturas dos sinais simulados de comprimento igual a 1000 amostras. . . . . . . . . . . . . . 56

TABELA 4.2 Cálculo do erro quadrático médio, da divergência KL, da distância de Bhattacharyya, da divergência Chi-quadrado de Pearson, da distância JensenShannon e da distância C2 entre o histograma dos dados e o GMM. . . . . . . 57 


\section{Lista de Símbolos}

$p_{i} \quad$ Probabilidade de cada célula $i$ no histograma $\ldots \ldots \ldots \ldots \ldots \ldots \ldots \ldots \ldots \ldots \ldots \ldots \ldots$

$k_{i} \quad$ Número de ocorrências dos pontos do sinal em cada célula do histograma . . . 12

$F \quad$ Família de funções de distribuição de probabilidades $\ldots \ldots \ldots \ldots \ldots \ldots \ldots \ldots$

k K-ésimo componente gaussiano que pertence a mistura de gaussianas . . . . . 17

$m_{\mathbf{k}}$ Média de cada componente gaussiano $\mathbf{k} \ldots \ldots \ldots \ldots \ldots \ldots \ldots \ldots \ldots \ldots \ldots \ldots$

$\sigma_{\mathbf{k}} \quad$ Desvio padrão de cada componente gaussiano $\mathbf{k} \ldots \ldots \ldots \ldots \ldots \ldots \ldots \ldots \ldots$

$p_{\mathbf{k}} \quad$ Probabilidade de ocorrência de cada componente gaussiano $\mathbf{k} \ldots \ldots \ldots \ldots \ldots 17$

$\Theta \quad$ Vetor que contêm os parâmetros da mistura de gaussianas $\ldots \ldots \ldots \ldots \ldots \ldots$

$f(x, \Theta) \quad$ Definição da função de mistura de gaussianas..................... 17

$\Lambda(X, \Theta) \quad$ Função de máxima verossimilhança da mistura.................. 18

$\lambda(X, \Theta) \quad$ Logaritmo da função de máxima verossimilhança da mistura $\ldots \ldots \ldots \ldots 18$

$\Theta_{k} \quad$ Conjunto de parâmetros estimados em uma iteração do EM . . . . . . . . . . 19

$p_{k}^{(i-1)}$ Probabilidade de ocorrência da gaussiana k, estimada na iteração $i-1$ do algoritmo EM . ................................... 19

$m_{k}^{(i-1)}$ Média da gaussiana k, estimada na iteração $i-1$ do algoritmo EM . . . . 19

$\sigma_{k}^{(i-1)}$ Desvio Padrão da gaussiana k, estimado na iteração $i-1$ do algoritmo EM 19

$p^{(i)}(k \mid n) \quad$ Probabilidade de pertinência, passo Expectância do algoritmo EM ..... 19

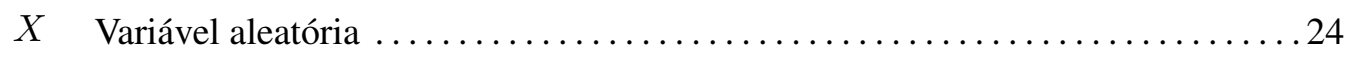

$H(X) \quad$ Entropia de Shannon da variável aleatória discreta $X \ldots \ldots \ldots \ldots \ldots 24$

$\chi \quad$ Alfabeto de eventos da variável aleatória discreta $X \ldots \ldots \ldots \ldots \ldots \ldots \ldots 24$

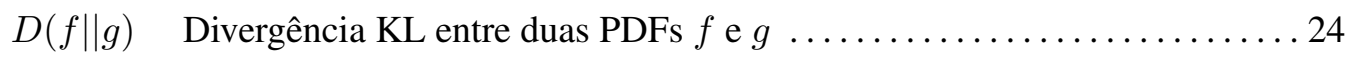

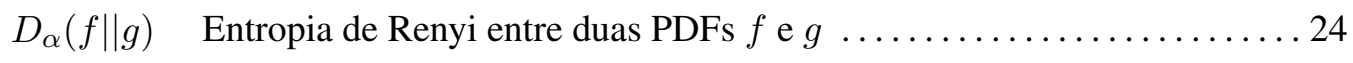

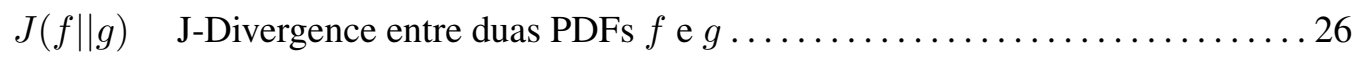

$W(f \| g) \quad$ Função weighted average entre duas PDFs $f$ e $g \ldots \ldots \ldots \ldots \ldots \ldots 26$

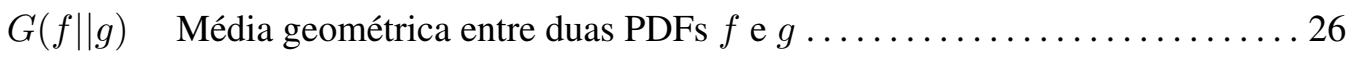




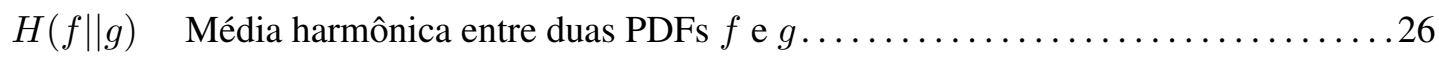

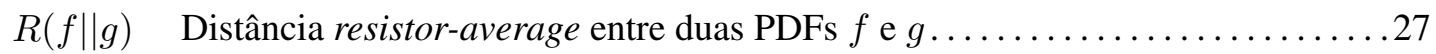

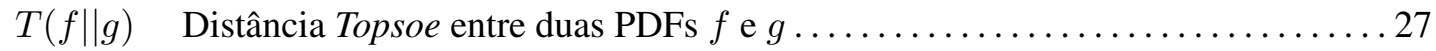

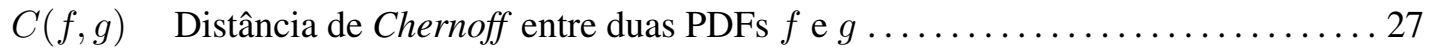

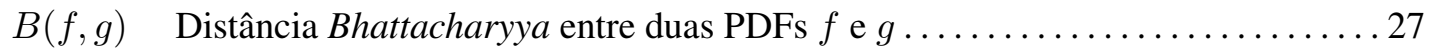

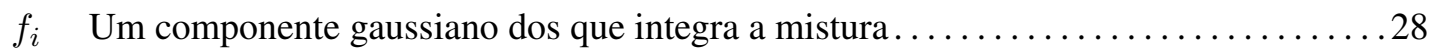

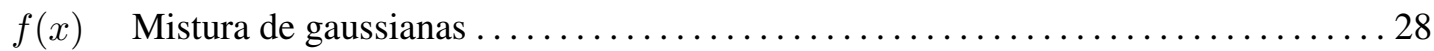

$\Delta=d(i, j) \quad$ Matrix de distância .................................... 33

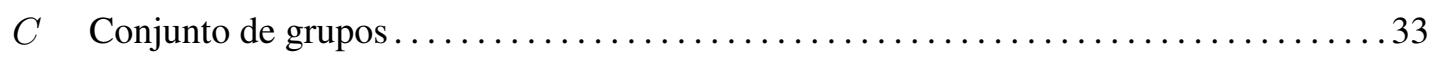

$l\left(\Theta^{k}\right) \quad$ Estimativa do logaritmo da verossimilhança na iteração $\mathrm{k} \ldots \ldots \ldots \ldots \ldots \ldots . \ldots 4$

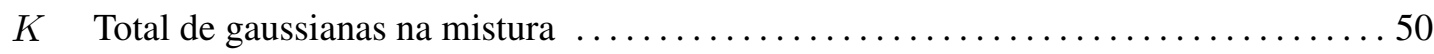

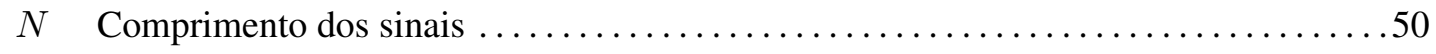

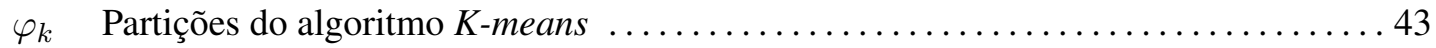

$N_{\varphi_{k}} \quad$ Total de elementos em cada partição do algoritmo $K$-means $\ldots \ldots \ldots \ldots \ldots \ldots 44$ 


\section{Lista de Siglas}

FUNAI Fundação Nacional do Índio . . . . . . . . . . . . . . . . . . . . . . .

PDF Função de Distribuição de Probabilidade .......................... 2

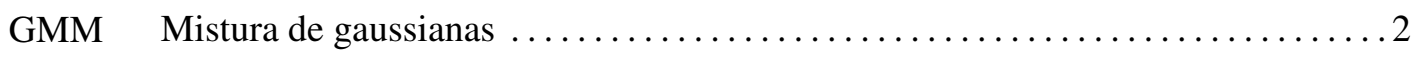

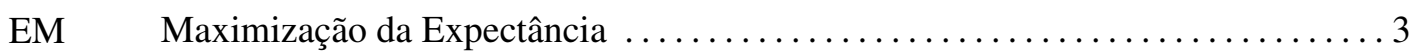

KL Kullback Leibler ...........................................

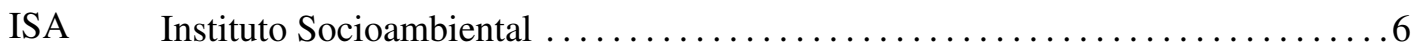

HMM Hidden Markov Models .................................... 10

GGD Generalized Gamma Distribution ............................ 13

VAD Voice Ativity Detenction .................................... 13

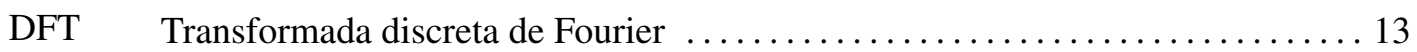

SNR Relação sinal-ruído ...................................... 14

EMD Earth Movers Distance ..................................... 22

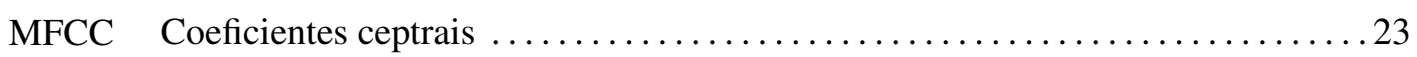

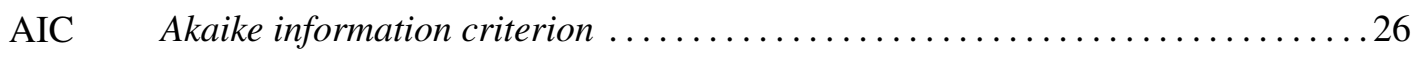

WAVE Waveform audio format, um tipo de codificação de áudio sem perdas . ....... 38

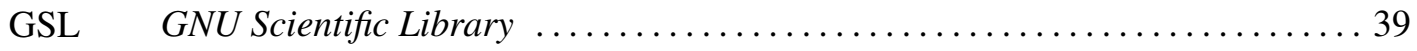

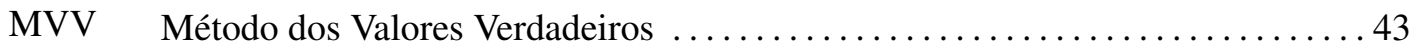

MVA Método dos Valores Iniciais Aleatórios $\ldots \ldots \ldots \ldots \ldots \ldots \ldots \ldots \ldots \ldots \ldots$

MM Método dos Momentos ......................................... 43

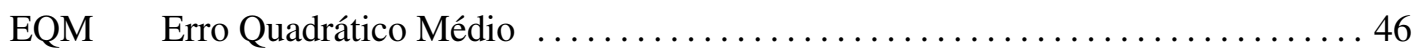

BIC Bayesian Information Criterion ................................ 50 


\section{Resumo}

Sepúlveda Torres, Lianet. Representações Hierárquicas de Vocábulos de Línguas Indígenas Brasileiras: Modelos Baseados em Mistura de Gaussianas. 2010. 110 f. Dissertação (Mestrado). Escola de Engenharia de São Carlos, Universidade de São Paulo, São Carlos, 2010.

Apesar da ampla diversidade de línguas indígenas no Brasil, poucas pesquisas estudam estas línguas e suas relações. Inúmeros esforços têm sido dedicados a procurar similaridades entre as palavras das línguas indígenas e classificá-las em famílias de línguas. Seguindo a classificação mais aceita das línguas indígenas do Brasil, esta pesquisa propõe comparar palavras de 10 línguas indígenas brasileiras. Para isso, considera-se que estas palavras são sinais de fala e estima-se a função de distribuição de probabilidade (PDF) de cada palavra, usando um modelo de mistura de gaussianas (GMM). A PDF foi considerada um modelo para representar as palavras. Os modelos foram comparados utilizando medidas de distância para construir estruturas hierárquicas que evidenciaram possíveis relações entre as palavras. Seguindo esta linha, a hipótese levantada nesta pesquisa é que as PDFs baseadas em GMM conseguem caracterizar as palavras das línguas indígenas, permitindo o emprego de medidas de distância entre elas para estabelecer relações entre as palavras, de forma que tais relações confirmem algumas das classificações. Os parâmetros do GMM foram calculados utilizando o algoritmo Maximização da Expectância (em inglês, Expectation Maximization (EM)). A divergência Kullback Leibler (KL) foi empregada para medir semelhança entre as PDFs. Esta divergência serve de base para estabelecer as estruturas hierárquicas que ilustram as relações entre os modelos. A estimativa da PDF, baseada em GMM foi testada com o auxílio de sinais simulados, sendo possível confirmar que os parâmetros obtidos são próximos dos originais. Foram implementadas várias medidas de distância para avaliar se a semelhança entre os modelos estavam determinadas 
pelos modelos e não pelas medidas adotadas neste estudo. Os resultados de todas as medidas foram similares, somente foi observada alguma diferença nos agrupamentos realizados pela distância C2, por isso foi proposta como complemento da divergência KL. Estes resultados sugerem que as relações entre os modelos dependem das suas características, não das métricas de distância selecionadas no estudo e que as PDFs baseadas em GMM, conseguem fazer uma caracterização adequada das palavras. Em geral, foram observados agrupamentos entre palavras que pertenciam a línguas de um mesmo tronco linguístico, assim como se observou uma tendência a incluir línguas isoladas nos agrupamentos dos troncos linguísticos. Palavras que pertenciam a determinada língua apresentaram um comportamento padrão, sendo identificadas por esse tipo de comportamento. Embora os resultados para as palavras das línguas indígenas sejam inconclusivos, considera-se que o estudo foi útil para aumentar o conhecimento destas 10 línguas estudadas, propondo novas linhas de pesquisas dedicadas à análise destas palavras.

Palavras-chaves: mistura de gaussianas, divergência KL, agrupamento hierárquico, dendrograma, línguas indígenas. 


\section{Abstract}

Sepúlveda Torres, Lianet. Hierarchical representations of words of Brazilian Indigenous Languages: Models Based on Gaussian Mixture. 2010. 110 p. Dissertation (Master's). School of Engineering-University of São Paulo, São Carlos, 2010.

Although there exists a large diversity of indigenous languages in Brazil, there are few researches on these languages and their relationships. Numerous efforts have been dedicated to search for similarities among words of indigenous languages to classify them into families. Following the most accepted classification of Brazilian indigenous languages, this research proposes to compare words of 10 Brazilian indigenous languages. The words of the indigenous languages are considered speech signals and the Probability Distribution Function (PDF) of each word was estimated using the Gaussian Mixture Models (GMM). This estimation was considered a model to represent each word. The models were compared using distance measures to construct hierarchical structures that illustrate possible relationships among words. The hypothesis in this research is that the estimation of the PDF, based on GMM can characterize the words of indigenous languages, allowing the use of distance measures between the PDFs to establish relationships among the words and confirm some of the classifications. The Expectation Maximization algorithm (EM) was implemented to estimate the parameters that describe the GMM. The Kullback Leibler (KL) divergence was used to measure similarities between two PDFs. This divergence is the basis to establish the hierarchical structures that show the relationships among the models. The PDF estimation, based on GMM was tested using simulated signals, allowing confirming the useful approximation of the original parameters. Several distance measures were implemented to prove that the similarities among the models depended on the model of each word, and not on the distance measure adopted in this study. The results of all measures were similar, however, as the clustering results of the C2 
distances showed some differences from the other clusters, C2 distance was proposed to complement the KL divergence. The results suggest that the relationships between models depend on their characteristics, and not on the distance measures selected in this study, and the PDFs based on GMM can properly characterize the words. In general, relations among languages that belong to the same linguistic branch were illustrated, showing a tendency to include isolated languages in groups of languages that belong to the same linguistic branches. As the GMM of some language families presents a standard behavior, it allows identifying each family. Although the results of the words of indigenous languages are inconclusive, this study is considered very useful to increase the knowledge of these types of languages and to propose new research lines directed to analyze this type of signals.

Keywords: Gaussian Mixture Models, KL divergence, hierarchical clustering, dendogram, indigenous languages. 


\section{Capítulo 1}

\section{Introdução}

As línguas dos povos descrevem a história, a cultura, o desenvolvimento natural e as características individuais de cada pessoa. O estudo das línguas de nossos antepassados contribuem para a compreensão dos fundamentos de nossas origens. Muitas línguas desapareceram, perdendo-se com elas informações relevantes relacionadas com a espécie humana (Crystal, 2000). O estudo das línguas indígenas ajuda a entender a história migratória da humanidade. A grande maioria das línguas indígenas faladas atualmente no mundo estão, de fato, ameaçadas de extinção, devido à globalização dos valores econômicos, sociais e culturais (Maia, 2006).

Segundo a Fundação Nacional do Índio (FUNAI), o Brasil é um dos países em que há maior diversidade de línguas no mundo. Atualmente, existem cerca de 225 comunidades indígenas, as quais falam 180 línguas diferentes e estão distribuídas do norte ao sul do território brasileiro.

Estudos linguísticos mostraram que algumas destas línguas são semelhantes entre si, evidenciando influências mutuas, origens comuns e processos de diversificação que ocorreram ao longo do tempo (Nolazco et al., 2005; Rodrigues, 1986). Conhecer o vasto repertório destas línguas e suas relações tem sido um desafio para os linguistas. Contudo, considerando origens comuns, os linguistas constroem famílias de línguas, estabelecendo similaridades entre elas. A classificação mais aceita de troncos linguísticos e famílias de linguísticas para as línguas indígenas brasileiras foi publicada em Rodrigues (1986) e mostra diversas relações de semelhanças entre este tipo de línguas.

$\mathrm{Na}$ literatura, uma das técnicas mais comuns para comparar palavras de línguas indígenas consiste em estudar o comportamento estatístico tanto de vogais como de consoantes (Maia et al., 1998). Em geral, estes trabalhos se concentram em procurar o conjunto de fonemas com 
maior ocorrência em cada língua, assim como aqueles fonemas com características articulatórias similares entre várias línguas indígenas. Em Maia et al. (1998), foram estudadas algumas similaridades entre línguas indígenas brasileiras e de outras nações.

A linguística também dedicou e continua dedicando vários estudos ao que chama de classificação genética das línguas indígenas. Nesta classificação, o linguista compara listas de palavras de línguas diferentes para ver se pertencem a uma mesma família. Compara também listas de palavras de uma mesma família com outras palavras que pertencem a outras famílias para ver se há semelhanças suficientes para considerar que tais famílias pertencem a um mesmo tronco linguístico (Francheto, 1999).

Embora tais trabalhos apresentem resultados bastante expressivos, ainda há muito a fazer em termos de estudar as diferentes línguas indígenas. Contudo, à medida que as línguas forem sendo descritas, novas bases de dados poderão ser construídas, o que propiciará a obtenção de mais resultados sobre o comportamento dos sons vocálicos e consonantais nas línguas do mundo (Cândido e Ribeiro, 2007), além de encontrar novas classificações e relações entre este tipo de línguas.

Seguindo esta linha e motivados pela diversidade linguística existente no Brasil, no presente trabalho se levanta a seguinte questão de pesquisa: Utilizar métodos de processamento digital de sinais de fala para analisar similaridades entre línguas indígenas brasileiras serviria de suporte para as classificações e relações publicadas em Rodrigues (1986)?

\section{Proposta de Solução}

Em aplicações dedicadas ao processamento digital de sinais de fala é comum a estimativa da função de distribuição de probabilidade (PDF) (Gazor e Zhang, 2003b), produzindo uma representação compacta do sinal, que depende de um reduzido número de parâmetros e possibilita o uso de medidas de similaridades, com a finalidade de comparar estes modelos. Esta estimativa constitui uma alternativa muito eficiente para pesquisar as propriedades dos sinais, além de ser muito utilizada em algoritmos dedicados à classificação (Archambeau e Verleysen, 2003).

Existem basicamente três abordagens para estimar a PDF de um sinal: paramétrica, nãoparamétrica e semiparamétrica (Erdogmus e Principe, 2006). Neste trabalho, propõe-se estimar a PDF das palavras usando uma abordagem semiparamétrica, baseada em uma mistura de gaussianas (GMM). Os modelos baseados em mistura de gaussianas têm sido muito usados devido 
à precisão na aproximação dos dados e à simplicidade na estimativa dos parâmetros usando o algoritmo Maximização da Expectância (EM) (Huber et al., 2008; Lan et al., 2006).

Na literatura, existem diversas alternativas para calcular similaridade entre modelos baseados em PDFs. Uma das medidas de divergência mais usada é a entropia relativa, mais conhecida como divergência Kullback Leibler (KL) (Cover e Thomas, 1991). A divergência KL é um coeficiente assimétrico que avalia separação ou disparidade entre duas PDFs. Esta divergência é usada em diferentes sistemas dedicados ao reconhecimento de fala ou de imagem (Hershey e Olsen, 2007). Segundo Hershey e Olsen (2007) é necessário modificar a divergência KL, com a finalidade de construir uma medida de distância entre as PDFs. O termo "modificar" se refere à operação de simetrização da divergência KL. O uso da divergência KL é muito difundido em diversas áreas da ciência, sendo muito natural a sua utilização entre GMM, em aplicações de reconhecimento de fala e de imagem (Hershey e Olsen, 2007).

Em Scalassara et al. (2009a) o uso da divergência KL para sinais de fala, considerando uma abordagem estocástica, obteve resultados muito interessantes na diferenciação de vozes normais e patológicas. $\mathrm{O}$ autor mostrou o uso desta divergência, para medir semelhanças entre PDFs, como uma medida promissora, mas reporta que seu resultado depende da exatidão na estimativa da PDF dos sinais.

A hipótese levantada nesta pesquisa é que as PDFs baseadas em GMM conseguem caracterizar as palavras das línguas indígenas, permitindo o emprego de medidas de distância entre elas para estabelecer relações entre as palavras, de forma que tais relações confirmem algumas das classificações realizadas em Rodrigues (1986).

\section{Objetivos e Resultados Esperados}

O principal objetivo deste trabalho é definir um modelo para representar vocábulos pertencentes a línguas indígenas brasileiras e empregar medidas de distância entre os modelos para construir estruturas hierárquicas que evidenciem possíveis relações entre os vocábulos a serem estudadas.

Nossa abordagem considera as palavras das línguas indígenas como sinais de fala e pretende estimar as PDFs destas palavras usando uma mistura de gaussianas. A PDF, baseada em GMM é o modelo selecionado para representar as palavras das línguas indígenas. A comparação entre estes modelos é realizada empregando a divergência KL.

Mais especificamente, tem-se como objetivos: (a) considerar as limitações do algoritmo 
EM na sua implementação para obter uma aproximação adequada dos parâmetros da mistura, (b) propor um método computacional para estimar a divergência KL entre GMM e utilizar uma função eficiente para simetrizar esta divergência, e (c) verificar se as relações encontradas entre os modelos dependem da divergência KL ou dos modelos estimados para cada vocábulo.

Dentre as principais contribuições do trabalho, destaca-se a implementação de um algoritmo para comparar as palavras. Primeiramente, as PDFs baseadas em GMM são estimadas através da implementação do método EM. Este método calcula os parâmetros que descrevem a mistura. As principais limitações do EM são superadas no desenvolvimento do algoritmo, dado que se considera que elas influenciam no desempenho do mesmo. Após a estimativa das PDFs, o sistema calcula a divergência KL entre os modelos para formar a matriz de distância que será empregada como critério de similaridade. Finalmente, o sistema implementa um algoritmo de agrupamento hierárquico, baseado na matriz KL, para construir os dendrogramas. Estes dendrogramas mostram as principais relações entre os modelos estimados. Estas relações podem ser consideradas como possíveis associações entre as palavras indígenas utilizadas na presente pesquisa. As palavras das línguas indígenas selecionadas para análise pertencem a 10 línguas indígenas do Brasil. Estas línguas são faladas atualmente no território brasileiro e a sua documentação está na base de dados do Museu do Índio do Brasil ${ }^{1}$.

Neste estudo não se espera encontrar relações definitivas entre as palavras indígenas analisadas. Consideramos esta pesquisa como uma alternativa para encontrar novas ideias que contribuam com o conhecimento destas línguas, possibilitando a implementação de trabalhos futuros, em que exista uma integração de profissionais de diversas áreas que dediquem esforços ao estudo de línguas indígenas brasileiras.

O presente trabalho está organizado em 5 capítulos. O Capítulo 2 descreve os fundamentos teóricos, que sustentam os métodos implementados, além disso inclui uma revisão bibliográfica, na qual são tratados alguns dos trabalhos que utilizam as técnicas desenvolvidas nesta pesquisa para diversas aplicações. No Capítulo 3, Materiais e Métodos, é apresentado o banco de dados que foi analisado e as implementações realizadas, fornecendo uma explicação detalhada do algoritmo. No Capítulo 4, são apresentados e discutidos os resultados alcançados. Finalmente, no Capítulo 5, se mostram as conclusões obtidas e os trabalhos futuros.

\footnotetext{
${ }^{1}$ http://www.museudoindio.org.br/
} 


\section{Capítulo 2}

\section{Fundamentos Teóricos}

Este capítulo apresenta os fundamentos teóricos necessários para o desenvolvimento do trabalho. O capítulo é dividido em quatro seções. Na primeira seção é descrito o panorama das línguas indígenas que existem hoje no Brasil, algumas de suas características e os diferentes grupos linguísticos identificados. Também se descrevem trabalhos dedicados a resgatar estas línguas. Depois é apresentada a teoria relacionada com os métodos de estimativa da função distribuição de probabilidade (PDF), junto com as principais abordagens responsáveis pelo cálculo da PDF, além disso, são comentados diversos estudos nos quais estes métodos têm sido empregados. Na terceira parte do capítulo são abordadas algumas das métricas utilizadas para medir divergência entre modelos, especialmente o uso da divergência Kullback Leibler (KL) como medida de similaridade e suas características fundamentais. Por último, apresenta-se uma introdução da teoria relacionada com os métodos de agrupamento hierárquico.

\subsection{Vozes Indígenas}

A língua é o meio mais eficiente para transmitir nossas culturas. A sociedade em geral perde quando alguma das línguas de nossos antepassados morre, mas são os membros das diferentes comunidades quem perdem mais quando a língua desaparece. O termo "a língua morre" se refere a uma língua que desaparece. Segundo Cristófaro-Silva (2002) há pelo menos três casos concretos de morte de línguas. O primeiro caso está relacionado às situações em que o pesquisador não pôde investigar o processo de desaparecimento da língua porque havia apenas um ou simplesmente uns poucos falantes vivos. O segundo caso está relacionado à opressão política imposta aos falantes de uma determinada língua, os quais deixam de falar a língua com 
o objetivo de não serem identificados como membros de uma comunidade específica. O último caso está relacionado com aquela língua que deixa de ser usada coloquialmente e é mantida apenas em situações de ritual. Nos casos anteriores o processo de desaparecimento das línguas ocorre em um curto espaço de tempo, impossibilitando a descrição deste processo. Cada povo tem se adaptado a circunstâncias únicas e as línguas destes povos as expressam (Nolazco et al., 2005). Por isso, é importante dedicar esforços à preservação e ao estudo das línguas de nossos antepassados.

Estima-se que existam hoje no mundo pelo menos 5 mil povos indígenas, somando cerca de 350 milhões de pessoas. O Brasil é um país onde há uma grande diversidade de línguas indígenas, muitas delas em perigo de extinção. Segundo os dados do Instituto Socioambiental $(\text { ISA })^{1}$, atualmente no território brasileiro se encontram 233 povos, falantes de mais de 180 línguas diferentes. A maior parte dessa população distribui-se por milhares de aldeias, situadas no interior de 653 terras indígenas, de norte a sul do território brasileiro.

Dentre as cerca de 180 línguas indígenas que existem no Brasil, algumas são semelhantes entre si mais do que outras, revelando origens comuns e processos de diversificação ocorridos ao longo do tempo. Os linguistas expressam as semelhanças e as diferenças entre elas através da ideia de troncos e famílias linguísticas. Quando se fala em tronco, tem-se em mente línguas cuja origem comum está situada há milhares de anos, sendo as semelhanças entre elas muito sutis (Seki, 2000). O termo família se refere a "línguas que têm uma origem comum; em que houve uma língua-mãe que em tempos antigos, pertencia a uma etnia só” (Francheto, 1999).

No Brasil, a classificação em troncos e famílias linguísticas indígenas mais aceita foi publicada por Rodrigues (1986). O estudo define dois grandes troncos: o tupí e o macro-jê e mais 20 famílias linguísticas que não apresentam um suficiente grau de similaridade para que possam ser agrupadas em um tronco. Estas 20 famílias são denominadas de línguas isoladas, as quais não são parecidas com nenhuma outras das línguas conhecidas e integram grupos individuais.

Na Figura 2.1, são mostradas as línguas que integram o tronco tupí, que é o maior e mais falado. Como se observa na figura, este tronco inclui dez famílias e cada família agrupa várias línguas; em alguns casos existem diferentes dialetos. A família tupí-guarani caracteriza-se por grande dispersão geográfica: suas línguas são faladas em diferentes regiões do Brasil e também em outros países da América do Sul (Bolívia, Peru, Venezuela, Guiana Francesa, Colômbia, Paraguai e Argentina). As demais famílias do tronco tupí estão todas localizadas no território

\footnotetext{
${ }^{1}$ http://www.socioambiental.org/
} 


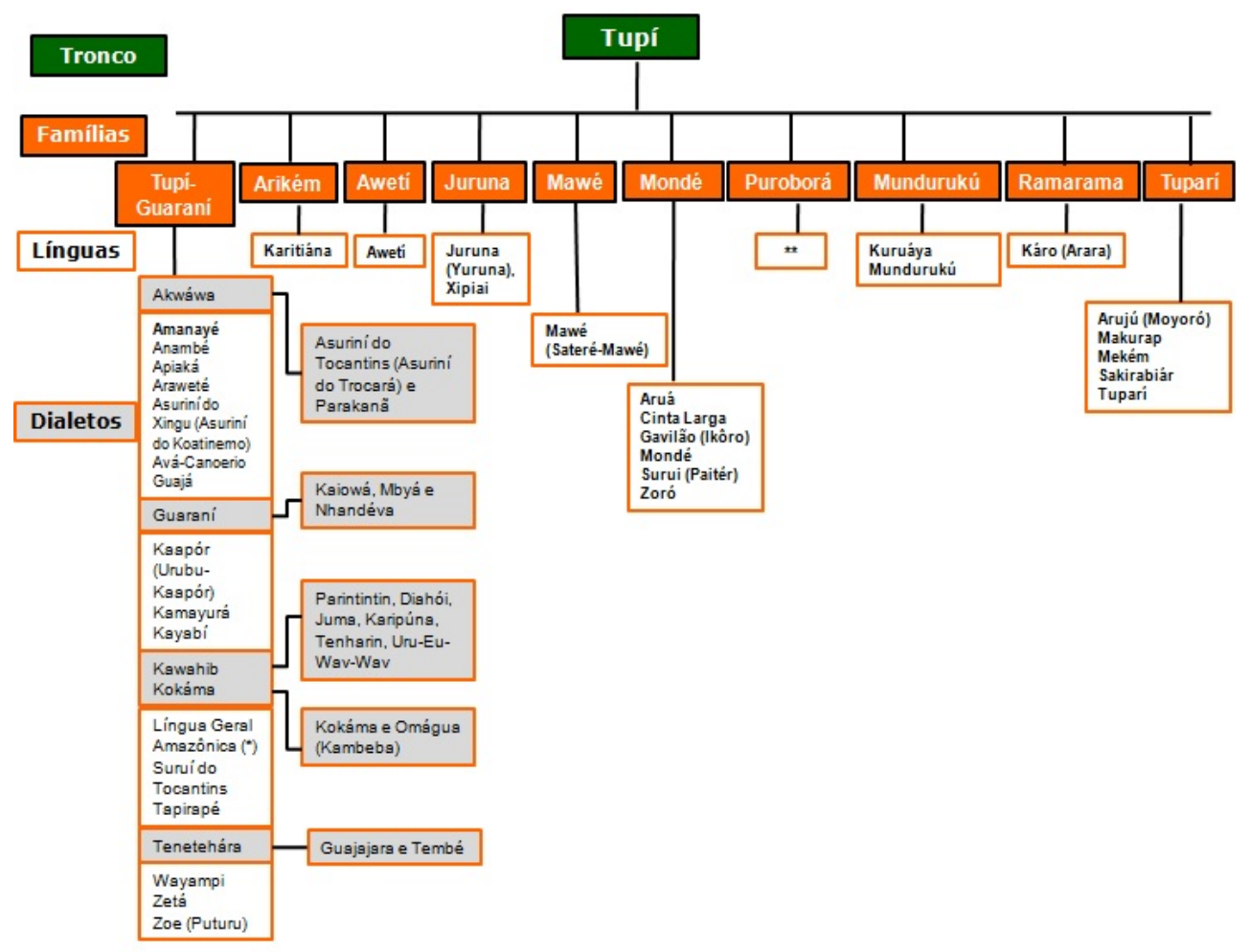

Figura 2.1: Tronco Linguístico Tupi. (*) Língua Geral Amazônica (Nheengatu). É Amazônica para distinguir da outra Língua Geral, a Paulista, agora já extinta. (**) Puruborá é um povo para cuja língua há documentos dos anos 20 e dos anos 50. Imagem modificada de http://pib.socioambiental.org/pt/c/no-brasil-atual/línguas/troncos-e-famílias

brasileiro, ao sul do Rio Amazonas (Seki, 2000).

Na Figura 2.2, é mostrado o tronco macro-jê que está representado por 9 famílias e é considerado um tronco grande e importante. A família jê é a maior, constituída por várias línguas e dialetos. Em geral, as línguas deste tronco são faladas no Centro-Oeste, no sul, no Pará e na Amazônia meridional e são exclusivamente brasileiras (Seki, 2000; Francheto, 1999).

Na Figura 2.3, são ilustradas as famílias de línguas isoladas. Estas famílias não formam troncos, pois "constituem tipos linguísticos únicos" (Seki, 2000). Cada uma destas famílias estão integradas por um conjunto de línguas e encontram-se espalhadas por todo o território brasileiro (Francheto, 1999).

O número existente de línguas indígenas brasileiras representa uma grande diversidade linguística, que respeita tanto a organização dos sistemas de sons quanto a estrutura gramatical (Seki, 2000). Atualmente, busca-se no Brasil praticar uma política de preservação e defesa das línguas indígenas, combatendo o preconceito, incentivando a pesquisa e o estudo destas línguas (Francheto, 1999). 


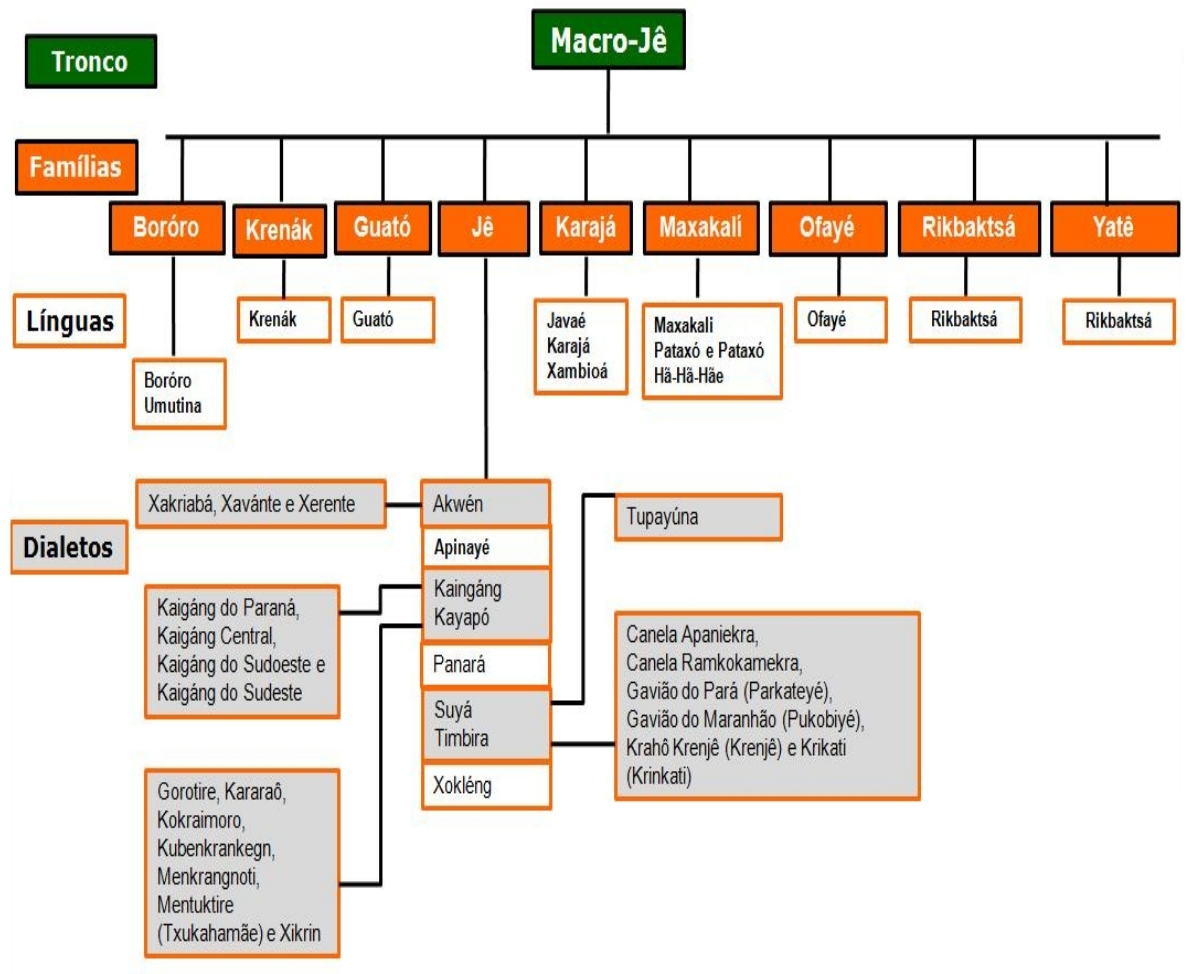

Figura 2.2: Tronco Linguístico macro-jê. Imagem modificada de http://pib.socioambiental.org/pt/c/no-brasil-atual/linguas/troncos-e-familias

Diversos trabalhos (Olson e Mielke, 2007; Parker, 2007; Nolazco et al., 2005; Kroeker, 2003) têm sido desenvolvidos na procura de resgatar algumas das informações das línguas de nossos antepassados e de alguns dos povos indígenas que ainda existem em diferentes pontos do mundo. A maioria dos trabalhos já realizados restringem-se à investigação dos segmentos vocálicos e, em número menor, são os que tratam dos segmentos consonantais. Em geral, os trabalhos revisados "constituem-se metodologicamente como tentativas de classificar tipologicamente os sistemas fonológicos das línguas com base no seu número de séries consoantes (oclusivas, nasais, fricativas, entre outras) ou de vogais (alta, baixas, anteriores posteriores, entre outras)"(Cândido e Ribeiro, 2007). Ainda são poucas as pesquisas dedicadas ao conhecimento de línguas indígenas ou aquelas línguas que descrevem o patrimônio linguístico de determinados povos, mas existem alguns exemplos isolados, mencionados abaixo.

O México é um dos países na América onde atualmente há ainda comunidades indígenas. As línguas Huestec e Náhuatl são bem conhecidas por serem as línguas do império Azteca e Maia, respectivamente. Estas línguas originalmente eram escritas como uma mistura de figuras e quando os espanhóis chegaram ao território mexicano uma das primeiras tarefas foi adaptá-las ao alfabeto espanhol. Geralmente, as palavras nestes tipos de línguas são extensas, incluindo 

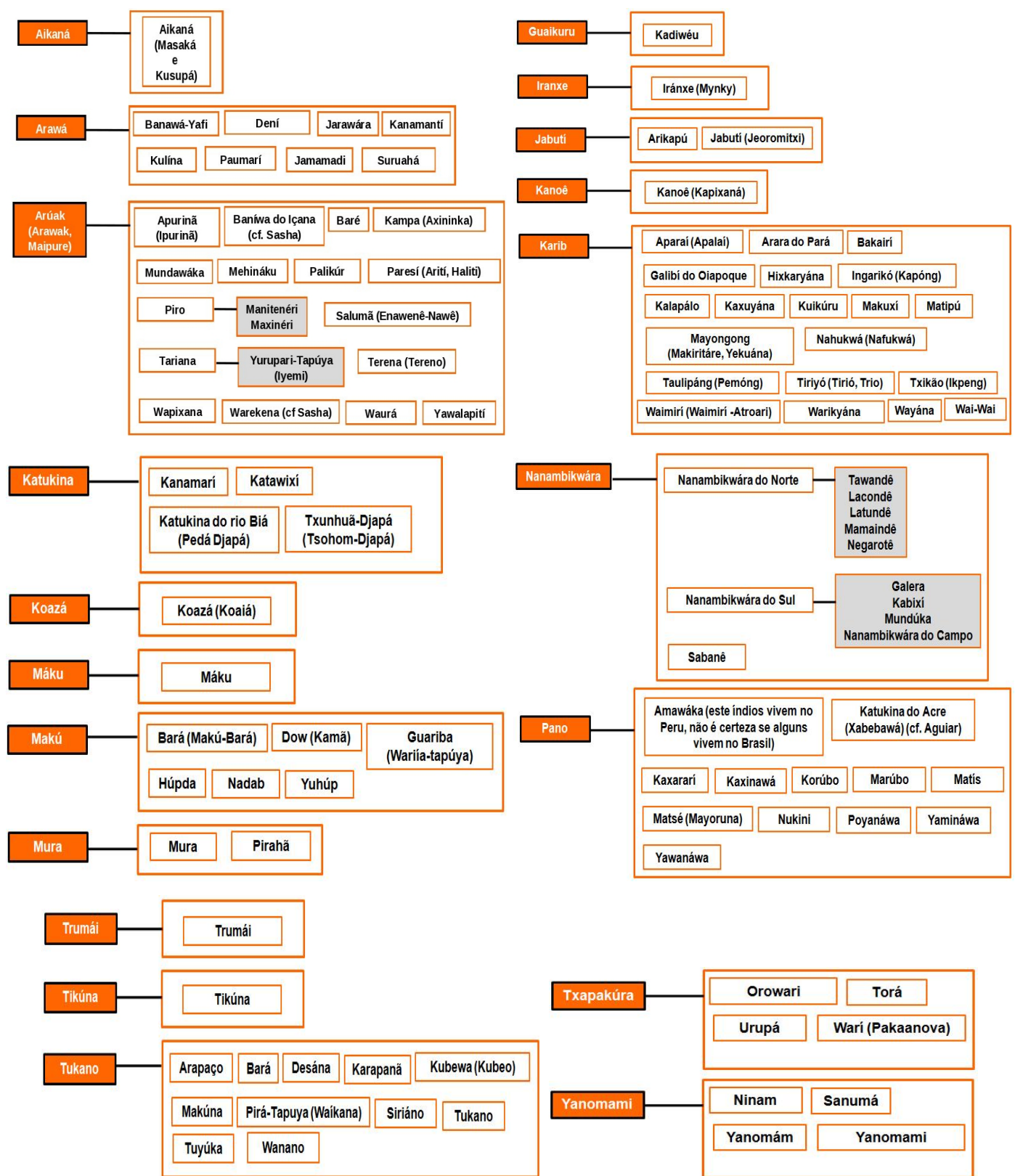

Figura 2.3: Família de línguas isoladas. Imagem modificada de http://pib.socioambiental.org/pt/c/no-brasil-atual/linguas/troncos-e-familias. 
muita informação e o número de palavras não é muito grande. Em Nolazco et al. (2005) foi criada uma base de dados com frases pertencentes as línguas Huestec e Náhuatl. Um sistema de reconhecimento automático da fala foi aplicado às palavras inseridas na base de dados, usando Hidden Markov Models (HMM) como modelo acústico das palavras, construindo um dicionario de pronunciação e mostrando todos os resultados obtidos para cada uma das línguas analisadas.

Parker (2007) teve como propósito documentar as principais características acústicas de uma variedade do Quéchua ${ }^{2}$ falado em Cusco, em Peru. O estudo apresenta os resultados de medição da duração e da intensidade, tanto das consoantes como das vogais, além de obter a frequência fundamental e os três primeiros formantes de cada uma das vogais que integram a língua. Um dos resultados principais do trabalho é a geração de um resumo das características mais interessantes e relevantes da fonética acústica do Quéchua falado em Cusco.

O trabalho de Olson e Mielke (2007) apresenta um estudo preliminar das propriedades acústicas das vogais que pertencem à língua Kagayanen. Kagayanen é um língua pouco conhecida no mundo, mais comum nas Filipinas (Olson e Mielke, 2007). O trabalho examina a estrutura dos formantes de cada vogal da língua com a finalidade de avaliar o comportamento fonético das vogais.

Ainda são muito poucas as línguas indígenas brasileiras que foram documentadas, sendo que diversos estudos (Kroeker, 2003; Seki, 2000; Maia et al., 1998) têm se dedicado a pesquisar o comportamento fonológico de algumas das línguas. Um dos trabalhos encontrados na literatura foi o de Kroeker (2003), o qual se dedica a estudar a língua Nambikuara. Esta língua é classificada como uma língua isolada, e se ilustra na Figura 2.3. No trabalho foi analisado o problema de condicionamento vocálico na língua Nambikuara examinando se a mudança de amplitude ou de extensão estimula a mudança do caráter da vogal. Primeiramente, foram estabelecidas as normas para as vogais Nambikuara, passando depois a observá-las em diversos ambientes para se analisar os fatores responsáveis pelas mudanças notadas no caráter das mesmas.

Após conhecer as características principais das línguas indígenas brasileiras, além dos estudos que abordam a análise deste tipo de línguas, na próxima seção são apresentados alguns dos métodos matemáticos e ferramentas propostas na literatura para a modelagem de sinais de

\footnotetext{
${ }^{2}$ Também chamado de Quíchua ou Quéchua, é uma importante língua indígena da América do Sul, ainda hoje falada por cerca de dez milhões de pessoas de diversos grupos étnicos da Argentina, Bolívia, Chile, Colômbia, Equador e Peru ao longo dos Andes (Parker, 2007).
} 
fala. Também serão comentadas as medidas de semelhanças mais usadas para comparar este tipo de modelos.

\subsection{Estimativas da função de distribuição de probabilidade (PDF)}

Atualmente, em aplicações dedicadas ao processamento de sinais de fala, tem sido interessante representar o sinal através de modelos. Em geral, estes modelos fornecem uma representação compacta do sinal, mantendo as informações mais relevantes dele (Shin et al., 2005). A estimativa da PDF de um sinal se considera uma parte essencial na eficácia de diversos algoritmos empregados para o processamento da fala (Shin et al., 2005; Gazor e Zhang, 2003b). Dependendo de um reduzido número de parâmetros, esta função descreve a distribuição de probabilidade que seguem os sinais. Por isso, modelos probabilísticos baseados na PDF do sinal são comumente usados para representar sinais de fala. O sucesso destas representações do sinal depende do modelo que tem sido definido.

Em áreas como aprendizado de máquina e processamento digital de sinais, a estimativa da PDF representa uma constante preocupação, devido ao fato dela proporcionar uma base sólida na construção de ferramentas de processamento de dados, contribuindo na seleção das características dos sinais. Além disso, esta estimativa é crucial em algoritmos de aprendizagem não supervisionado (em inglês, unsupervised learning), em métodos de inferência Bayesiana e em diferentes técnicas de classificação (Raykar, 2002).

Existem basicamente três abordagens para estimar a PDF de um sinal: paramétrica, nãoparamétrica e semiparamétrica (Scalassara et al., 2009b; Erdogmus e Principe, 2006; Gray e Moore, 2003). Estas alternativas são empregadas como soluções de diversos problemas, mas não existe um consenso universal na escolha destas abordagens para solucionar determinados problemas, por isso diversos estudos são dedicados ao emprego das alternativas em cada um dos problemas existentes (Gray e Moore, 2003). A seguir são comentadas as abordagens anteriores, assim como o uso delas em diversos sistemas dedicadas ao processamento de sinais.

\section{Abordagem não-paramétrica}

Os métodos não-paramétricos não fazem nenhuma consideração da distribuição de probabilidade dos dados. Em geral, estes métodos se caracterizam por conseguir uma estimativa adequada para qualquer conjunto de dados que recebem como entrada. Entretanto, essa vantagem é difícil de se obter, pelo fato do custo computacional ser intratável. A técnica não-paramétrica 
mais comumente usada é a estimativa da PDF através do histograma das amostras do sinal. Este método é pobre quando não é suficiente o número de amostras do sinal, neste caso, o método baseado em Kernel é o mais comumente utilizado (Gray e Moore, 2003). Neste documento o termo Kernel se refere a uma função simétrica, não necessáriamente positiva e cuja integral em todo o domínio $R$ é 1 .

$\mathrm{Na}$ estimativa não-paramétrica existem duas técnicas que são as mais conhecidas, uma delas é a estimativa do kernel (em inglês, Kernel density estimation) (Gray e Moore, 2003), e a outra é baseada em histogramas (Scalassara, 2009). Considerando a técnica de histogramas, pode-se ter células de tamanho fixo ou variável, conforme a distribuição local dos dados ou obtidas por janelas móveis retangulares. A grande dificuldade da técnica de histogramas é a determinação do comprimento das células (Ku e Kawasumi, 2008). Se, ao invés de uma janela retangular, fosse usada uma função diferente, o método passaria a ser chamado de estimativa do kernel (Erdogmus e Principe, 2006), em que se define uma função com as características mencionadas no parágrafo anterior.

Em Scalassara et al. (2009b) emprega-se a abordagem não-paramétrica baseada em histogramas, tanto para células de tamanho fixo como para as de tamanho variável, para estimar a PDF das amostras dos sinais vocálicos. Usando a estimativa do histograma, os autores calculam a entropia empregando diferentes métodos. Para estimar a PDF do sinal estudado em Scalassara et al. (2009b), divide-se essa função contínua em um reticulado com $i$ células igualmente espaçadas. Assim, a probabilidade $p_{i}$, de cada célula $i$ é estimada por $\frac{k_{i}}{N}$, sendo que $k_{i}$ é o número de ocorrências dos pontos do sinal em cada célula, $N$ é o total de amostras do sinal e $\Delta x$ é a largura da célula.

\section{Abordagem Paramétrica}

A abordagem paramétrica é geralmente usada quando a distribuição dos dados é conhecida antecipadamente ou quando os dados são simples de forma que permitam ser modelados usando uma distribuição conhecida, por exemplo gaussiana, Gamma, Laplace, etc (Gray e Moore, 2003). Para estimar os parâmetros da distribuição selecionada existem vários métodos, dentre os mais empregados encontram-se a estimativa de máxima verossimilhança e a estimativa Bayesiana (Viola et al., 1996). Esta abordagem às vezes é inapropriada devido ao fato dela considerar uma forma paramétrica para a distribuição que seguem os dados (Scalassara, 2009); resultando uma estimativa da PDF que somente será satisfatória se a suposição inicial da distribuição dos dados for correta (Gray e Moore, 2003). 
Considerando uma abordagem paramétrica, diversos estudos (Gopinath et al., 2008; Chang et al., 2006; Gazor e Zhang, 2003b) apresentam-se na literatura para estimar a PDF de sinais de fala. Nos trabalhos, dedicam-se inúmeros esforços na procura da distribuição de probabilidade que melhor se aproxima aos dados iniciais. Geralmente, a maioria dos algoritmos convencionais de processamento de sinais, que adotam modelos probabilísticos, assumem que a melhor aproximação do espectro da fala se consegue com a distribuição gaussiana (Shin et al., 2005).

Em Gazor e Zhang (2003b), com o objetivo de procurar a função de distribuição que aproximava os dados de forma mais exata, o sinal de fala foi representado em diversos domínios. O trabalho realiza alguns ensaios considerando a distribuição gaussiana, a Gamma e a Laplace, alcançando os melhores resultados quando é empregada a distribuição de Laplace. Os autores notaram que em ambientes em que a fala está combinada com trechos de silêncio a melhor aproximação da PDF se conseguia utilizando a distribuição Gamma Generalizada (em inglês, Generalized Gamma Distribution (GGD)) . Esta função combina no mesmo modelo a distribuição gaussiana, a Laplace e a Gamma.

Em Gopinath et al. (2008) foi proposta uma abordagem paramétrica para estimar a distribuição de probabilidade das vogais da língua Índia Malayalam. As funções de distribuição Normal, a LogNormal, a Gamma e a Weibull foram utilizadas para determinar a melhor estimativa da duração dos fonemas, usando o método Q-Q $\operatorname{plot}^{3}$. Diversos ensaios mostraram que a função Gamma garante a melhor aproximação da PDF dos fonemas.

Em Chang et al. (2006) se apresenta um algoritmo detector de atividade da voz (em inglês, Voice Ativity Detenction (VAD) $)^{4}$ baseado em múltiplos modelos estatísticos. O principal objetivo do trabalho foi descobrir as propriedades dos modelos estatísticos, que descrevem o espectro de um sinal de fala com ruído. Sabe-se que quase todos os algoritmos convencionais de VAD operam no domínio da frequência e assumem que a fala livre de ruído e o ruído são caracterizados por uma distribuição gaussiana (Chang et al., 2006). Pesquisas recentes (Gazor e Zhang, 2003a; Martin e Breithaupt, 2003) indicam que a PDF dos coeficientes da transformada discreta de Fourier (DFT), do sinal livre de ruído e do ruído são aproximadas de forma mais eficiente usando a distribuição Gamma e Laplace. No trabalho de Chang et al. (2006) propõe-se representar a distribuição de cada coeficiente discreto de Fourier usando, além da

\footnotetext{
${ }^{3}$ Q-Q plot, é uma técnica gráfica para determinar se dois conjuntos de dados provêm de populações com distribuições comuns.

${ }^{4}$ Voice Activity Detector (VAD), refere-se a o problema clássico de distinguir entre uma fala ativa e momentos de silencio e é aplicado por muitos sistemas de comunicação como codificação da voz (em inglês, speech coding), reconhecimento da fala (em inglês, speech recognition) e melhoria do sinal (em inglês, noise speech enhancement).
} 
distribuição gaussiana, a Laplace e a Gamma. Os diferentes modelos são avaliados usando o teste Kolmogorov-Smirnov ${ }^{5}$. Entre os principais resultados do trabalho de Chang et al. (2006) se destaca a conveniência em aplicar diferentes modelos estatísticos para representar a PDF dos coeficientes de Fourier de um sinal de fala com ruído, dependendo da relação sinal-ruído (SNR) que o sinal apresente. Além disso, se o modelo escolhido para aproximar a PDF é paramétrico, as funções de distribuição que se apresentam como fortes candidatas são a Laplace e Gamma.

\section{Abordagem semiparamétrica}

A abordagem semiparamétrica (misturas ou redes neurais) combina a flexibilidade da abordagem não-paramétrica e a eficiência na avaliação dos parâmetros da abordagem paramétrica (Ku e Kawasumi, 2008; Raykar, 2002). Estes modelos utilizam um número de funções base que são sempre menores que o conjunto de treinamento. Em geral, são caracterizados por procedimentos de otimização não lineares que às vezes encontram soluções localmente ótimas que dependem dos critérios de partida do algoritmo EM. Os modelos semiparamétricos conseguem aproximar qualquer tipo de dados, para isso é preciso que o número de componentes tenda ao infinito, mas se isso acontecer o custo computacional seria muito elevado.

Em Ku e Kawasumi (2008) foi proposta uma abordagem semiparamétrica para analisar a estacionaridade de um sinal usando o método de estimativa do kernel. A função de distribuição Gamma é embutida no kernel para estimar a melhor ordem do modelo e os coeficientes que o descrevem. Os parâmetros da função Gamma são estimados usando o método de máxima verossimilhança. Como resultados importantes do trabalho tem se o uso de uma abordagem semiparamétrica que reúne as vantagens das outras duas abordagens: paramétrica e não-paramétrica, obtendo um modelo de ordem inferior e estimando os coeficientes que melhor descrevem o modelo.

O uso dos modelos semiparamétricos baseados em GMM, tem se apresentado como uma ferramenta amplamente usada na estimativa da PDF de qualquer sinal. Em comparação com os conhecidos métodos paramétricos, esta ferramenta se mostra como a mais poderosa para estimar a família de funções de distribuição. Comparando-a com os métodos não-paramétricos propostos na literatura, como é o caso da estimativa do Kernel, o custo computacional desta técnica é menor (Lan et al., 2006). Embora o modelo baseado em GMM demande uma conside-

\footnotetext{
${ }^{5}$ teste Kolmogorov-Smirnov é usado para determinar se duas distribuições de probabilidade subjacentes diferem uma da outra ou se uma das distribuições de probabilidade subjacentes difere da distribuição em hipótese, em qualquer dos casos com base em amostras finitas.
} 
rável quantidade de parâmetros e, para obter uma estimativa da PDF robusta requer um grande conjunto de dados, este tem se convertido em uma abordagem muito usada para descrever a PDF de um sinal de fala de forma semiparamétrica (Shin et al., 2005).

Segundo Dustor e Szware (2009) os modelos baseados em GMM possuem a habilidade de capturar todas as flutuações ou variações da voz e como resultado podem modelar as propriedades fundamentais da fala de qualquer língua. Dustor e Szware (2009) apresentaram uma abordagem para reconhecimento automático da fala baseada em reconhecimento estatístico de padrões. Para a pesquisa foram escolhidas várias palavras de dez línguas de diferentes países. Neste caso, as palavras das línguas selecionadas são representadas como uma combinação linear de $M$ funções gaussianas, em que cada distribuição é especificada pelo vetor de médias $m_{i}$, a matriz de co-variância $C_{i}$ e a probabilidade de ocorrência $p_{i}$. O conjunto de parâmetros que descrevem o modelo é calculado usando o procedimento iterativo EM, que será descrito na Seção 2.3.1. Os testes foram desenvolvidos a partir das palavras selecionadas, destacando que o método é adequado para a identificação de cada uma das línguas envolvidas, porém o número de componentes gaussianas que pertencem à estimativa é decisivo para uma correta identificação.

Em Nan et al. (2009) apresenta-se uma modificação do algoritmo Tail-fitting ${ }^{6}$ O algoritmo, em vez de estar baseado no histograma dos dados, toma como base uma mistura de gaussianas. No trabalho, propõe-se calcular o número máximo de componentes da mistura usando o conceito de curtose ${ }^{7}$, provendo um critério de exatidão entre o modelo aproximado e os dados reais. Os parâmetros da mistura são estimados usando o algoritmo EM, e em cada iteração, o algoritmo atualiza o número de componentes gaussianos, assim como o número de parâmetros de cada componente através da medição da curtose e da máxima verossimilhança.

Em Chen et al. (2001), apresenta-se um método baseado em GMM para identificar diferentes acentos da língua Chinesa Mandarim. No trabalho, o número de componentes da mistura é treinado para obter a aproximação mais exata da estimativa. Diversos testes realizados indicaram que a escolha certa do número de componentes que integram a mistura pode contribuir na precisão do modelo para uma correta identificação dos diversos acentos das línguas. O estudo sugere que o modelo construido seja composto por 32 elementos para manter uma compensa-

\footnotetext{
${ }^{6}$ Tail-fitting é um método muito popular para separar o jitter determinístico do jitter aleatório.

${ }^{7}$ Curtose é uma medida de dispersão que caracteriza o "achatamento "da curva da função de distribuição. É normalmente definida como: $\frac{m_{4}(\mu)}{\sigma^{4}}-3$. em que $m_{4}(\mu)$ é o quarto momento central e $\sigma$ é o desvio-padrão
} 
ção entre exatidão da estimativa e custo computacional.

Considerando que a mistura de gaussianas é um modelo capaz de aproximar qualquer distribuição de probabilidade e que qualquer componente dos que integram a mistura pode representar o espectro de qualquer falante, Reynolds e Rose (1995) usaram este tipo de modelo para implementar um algoritmo dedicado à identificação do locutor independente do texto (em inglês, Text-independent Speaker Identification). Embora o trabalho destaca como crítico no treinamento do modelo baseado em GMM a escolha do número máximo de componentes que integram o modelo e a inicialização dos parâmetros, diversos ensaios mostraram que este tipo de modelo provê uma representação robusta para a difícil tarefa de identificar um falante, sobre um sinal de fala corrompido ou sem restrições.

Tabela 2.1: Características das diferentes abordagens, Não-Paramétrica, Paramétrica e Semiparamétrica, propostas para estimar a PDF de um sinal.

\begin{tabular}{|c|c|c|c|}
\hline & Não-paramétrica & Paramétrica & Semiparamétrica \\
\hline Características & $\begin{array}{l}\text { - Não considera a } \\
\text { distribuição dos } \\
\text { dados; } \\
\text { - Consegue uma } \\
\text { estimativa } \\
\text { adequada para } \\
\text { qualquer conjunto } \\
\text { de dados. }\end{array}$ & $\begin{array}{l}\text { - É usada quando a } \\
\text { distribuição dos dados é } \\
\text { conhecida ou quando os } \\
\text { dados são simples. }\end{array}$ & $\begin{array}{l}\text { - Combina a flexibilidade da } \\
\text { abordagem não-paramétrica } \\
\text { com a eficiência da avaliação } \\
\text { dos parâmetros da } \\
\text { abordagem paramétrica; } \\
\text { - Consegue aproximar } \\
\text { qualquer tipo de dados. }\end{array}$ \\
\hline Funções & $\begin{array}{l}\text { Janela retangular, } \\
\text { função Ganma e } \\
\text { gaussianas. }\end{array}$ & $\begin{array}{l}\text { Ganma, Laplace, } \\
\text { gaussianas e Weibull. }\end{array}$ & $\begin{array}{l}\text { - Misturas } \\
\text { - Redes Neurais }\end{array}$ \\
\hline $\begin{array}{l}\text { Métodos ou } \\
\text { Estimativa dos } \\
\text { parâmetros }\end{array}$ & $\begin{array}{l}\text { - Histograma; } \\
\text { - Estimativa do } \\
\text { Kernel. }\end{array}$ & $\begin{array}{l}\text { - Estimativa da máxima } \\
\text { verossimilhança; } \\
\text { - Estimativa Bayesiana. }\end{array}$ & $\begin{array}{l}\text { - Estimativa da máxima } \\
\text { verossimilhança (Algoritmo } \\
\text { EM). }\end{array}$ \\
\hline Considerações & $\begin{array}{l}\text { Tamanho das } \\
\text { células. }\end{array}$ & $\begin{array}{l}\text { Distribuição que melhor } \\
\text { aproxima os dados. }\end{array}$ & Cálculo dos parâmetros. \\
\hline Aplicações & $\begin{array}{l}\text { - Estimativa da } \\
\text { Entropia } \\
\text { (Scalassara et al., } \\
\text { 2009b). }\end{array}$ & $\begin{array}{l}\text { - PDF das vogais da } \\
\text { língua Índia Malayalam } \\
\text { (Gopinath et al., 2008); } \\
\text { - Detector da atividade } \\
\text { da voz (Chang et al., } \\
\text { 2006). }\end{array}$ & $\begin{array}{l}\text { - Estimar estacionaridade } \\
\text { de um sinal (Ku e Kawasumi, } \\
\text { 2008); } \\
\text { - Reconhecimento automático } \\
\text { da fala (Dustor e Szware, } \\
\text { 2009); } \\
\text { - Identificação de acentos da } \\
\text { língua chinesa Mandarim } \\
\text { (Chen et al., 2001). }\end{array}$ \\
\hline
\end{tabular}

Nesta seção, foram estudadas as três abordagens documentadas na literatura para estimar a 
PDF de um sinal, assim como vários trabalhos em que estas abordagens foram utilizadas. Na Tabela 2.1, é apresentado um resumo das principais características das abordagens existentes para estimar a PDF de um sinal, assim como alguns trabalhos em que estas abordagens têm sido empregadas. A seguir, é descrito o método para calcular a PDF, usando um modelo baseado em mistura de gaussianas, pois este é o modelo empregado no presente trabalho para representar as palavras que integram o vocabulário escolhido para análise.

\subsection{Modelo baseado em mistura de gaussianas (GMM)}

Considerando um sinal de fala como uma série temporal $x_{1}, \ldots, x_{N} \in R$ de comprimento $N$, a PDF do sinal pode ser aproximada por uma família $F$ de funções de distribuição de probabilidades em $R$. Em algoritmos dedicados à estimativa da PDF, o problema é encontrar a função de distribuição $f(x) \in F$ que melhor gere os dados de entrada.

A definição da família de funções $F$ adotada neste estudo é proposta por Tomasi (2004). O autor conseguiu fazer uma representação matemática descritiva que facilitou a implementação computacional do método. Nesta definição, $F$ é considerada como uma mistura de gaussianas, em que os componentes que integram a mistura apresentam a mesma estrutura matemática. Consegue-se identificar cada um dos elementos do GMM através de diferentes valores dos parâmetros. A Equação 2.1 mostra a forma da mistura de gaussianas

$$
f(x, \Theta)=\sum_{\mathbf{k}=1}^{K} p_{\mathbf{k}} g\left(x, m_{\mathbf{k}}, \sigma_{\mathbf{k}}\right)
$$

na qual $f(x, \Theta)$ representa a mistura, $p_{\mathbf{k}}$ é a probabilidade de ocorrência de cada gaussiana $k \mathrm{e}$

$$
g\left(x, m_{\mathbf{k}}, \sigma_{\mathbf{k}}\right)=\frac{1}{\sigma_{\mathbf{k}} \sqrt{2 \pi}} e^{-\frac{1}{2}\left(\frac{x-m_{\mathbf{k}}}{\sigma_{\mathbf{k}}}\right)^{2}}
$$

é o $k$-ésimo componente gaussiano que pertence à mistura, em que $\Theta=\left[\theta_{1}, \ldots, \theta_{K}\right]$ $=\left[\left(p_{1}, m_{1}, \sigma_{1}\right), \ldots,\left(p_{\mathbf{K}}, m_{\mathbf{K}}, \sigma_{\mathbf{K}}\right)\right]$ é um vetor de comprimento $K$ que contém a probabilidade $p_{\mathbf{k}}$, a média $m_{\mathbf{k}}$ e o desvio padrão $\sigma_{\mathbf{k}}$ de cada gaussiana (Tomasi, 2004).

A função $f$ na Equação 2.1 representa uma função de distribuição de probabilidade, então $f$ é positiva e $\int_{R} g\left(x, m_{\mathbf{k}}, \sigma_{\mathbf{k}}\right) d x=1$, desenvolvendo tem-se (Tomasi, 2004): 


$$
1=\int_{R} f(x, \Theta) d x=\int_{R} \sum_{\mathbf{k}=1}^{K} p_{\mathbf{k}} g\left(x, m_{\mathbf{k}}, \sigma_{\mathbf{k}}\right) d x=\sum_{\mathbf{k}=1}^{K} p_{\mathbf{k}} \int_{R} g\left(x, m_{\mathbf{k}}, \sigma_{\mathbf{k}}\right) d x=\sum_{\mathbf{k}=1}^{K} p_{\mathbf{k}} .
$$

Então $p_{k} \geq 0$ e $\sum_{\mathbf{k}=1}^{K} p_{\mathbf{k}}=1$. O principal problema do algoritmo é estimar os parâmetros $\Theta$ que especificam o modelo e que melhor caracterizam o sinal $x$.

Diversas técnicas estão disponíveis para estimar os parâmetros de uma mistura de Gaussianas (McLachlan e Krishnan, 1997). Em Azzalini e Capitanio (1999) se recomenda usar os métodos Newton-Raphson ou método quasi-Newton, no entanto o método mais utilizado na literatura e mais estabelecido é o método de máxima verossimilhança (Reynolds e Rose, 1995). O objetivo deste último método é encontrar, a partir dos dados de entrada, os parâmetros que maximizam a verossimilhança da mistura $\Lambda(X, \Theta)$ (Nan et al., 2009; Archambeau e Verleysen, 2003; Reynolds e Rose, 1995).

A função de verossimilhança para uma mistura de gaussianas é:

$$
\Lambda(X, \Theta)=\prod_{n=1}^{N} \sum_{k=1}^{K} p_{k} g\left(x_{n}, m_{k}, \sigma_{k}\right)
$$

O logaritmo da função de verossimilhança $\lambda(X, \Theta)$ definida na Equação 2.3 é

$$
\lambda(X, \Theta)=\sum_{n=1}^{N} \log \sum_{k=1}^{K} p_{k} g\left(x_{n}, m_{k}, \sigma_{k}\right) .
$$

Infelizmente, a Equação 2.3 é uma função não linear dos parâmetros $\Theta$ e não existe uma expressão analítica para maximizá-la. Desta forma, esta estimativa pode ser obtida de forma iterativa usando um caso especial do algoritmo EM (Nan et al., 2009; Reynolds e Rose, 1995). Este algoritmo é considerado a ferramenta padrão para o cálculo da máxima verossimilhança em GMM (Marques, 2009). A seguir é descrito o algoritmo EM responsável pelo cômputo dos parâmetros que descrevem a mistura de gaussianas. 


\subsubsection{Algoritmo Maximização da Expectância (EM)}

O algoritmo EM (McLachlan e Krishnan, 1997) é um procedimento iterativo para estimar a máxima verossimilhança em problemas de dados incompletos. O EM se converteu em uma ferramenta padrão no contexto estatístico (McLachlan e Peel, 2000; McLachlan e Krishnan, 1997) não só envolvendo problemas de dados incompletos, como também problemas que podem ser tratados de forma similar como é o caso de estimativas de misturas. Segundo Nasser et al. (2006) EM é uma técnica frequentemente empregada para obter as PDF tanto em forma univariada como multivariada.

Neste trabalho, é descrito o algoritmo EM que foi proposto por Tomasi (2004) para estimar os parâmetros de uma mistura de gaussianas. Tomasi (2004) desenvolveu um caso especial deste algoritmo para estimar a PDF, de um conjunto de pontos, baseada em GMM.

A ideia básica do algoritmo EM é começar com um modelo inicial de parâmetros $\Theta_{0}$, para estimar um novo modelo descrito pelo conjunto de parâmetros $\Theta_{1}$, de forma que $p\left(x \mid \Theta_{1}\right) \geq$ $p\left(x \mid \Theta_{0}\right)$, incrementando a máxima verossimilhança em cada iteração (Nan et al., 2009). O modelo inicial $\Theta_{0}$ se converte no modelo $\Theta_{K}$ que melhor aproxima a distribuição dos dados quando a condição de convergência é alcançada.

Cada iteração do algoritmo EM consiste em dois processos: Expectância e Maximização. No passo Expectância se aproxima a PDF desejada, usando como entrada os parâmetros $p_{k}^{(i-1)}$, $m_{k}^{(i-1)}$ e $\sigma_{k}^{(i-1)}$. Esta aproximação se consegue através do cálculo da probabilidade de pertinência $p^{(i)}(k \mid n)$. Esta operação expressa a probabilidade que um ponto qualquer do vetor de entrada seja gerado por uma das componentes da mistura $f$, mostrada na Equação 2.1. Na Equação 2.5 se observa o cálculo da probabilidade de pertinência.

$$
p^{(i)}(k \mid n)=\frac{p_{k}^{(i)} g\left(x_{n}, m_{k}^{(i)}, \sigma_{k}^{(i)}\right)}{\sum_{m=1}^{K} p_{k}^{(i)} g\left(x_{n}, m_{k}^{(i)}, \sigma_{k}^{(i)}\right)} .
$$

O objetivo do passo Maximização é maximizar a função de verossimilhança, usando a Equação 2.3 ou a Equação 2.4. Neste passo, também são estimados novos valores para os parâmetros que caracterizem o modelo, o qual foi aproximado no passo Expectância. As Equações 2.6, 2.7 e 2.8 indicam como calcular a média $m_{k}^{(i)}$, o desvio padrão $\sigma_{k}^{(i)}$ e a probabilidade de ocorrência $p_{k}^{(i)}$, respectivamente. Note que estas operações dependem da estimativa $p^{(i)}(k \mid n)$, obtida no passo Expectância da mesma iteração. Na equação 2.7, $D$ representa a dimensão dos 
dados.

$$
\begin{gathered}
m_{k}^{(i+1)}=\frac{\sum_{n=1}^{N} p^{(i)}(k \mid n) x_{n}}{\sum_{n=1}^{N} p^{(i)}(k \mid n)} . \\
\sigma_{k}^{(i+1)}=\sqrt{\frac{1}{D} \frac{\sum_{n=1}^{N} p^{(i)}(k \mid n)\left\|x_{n}-m_{k}^{(i+1)}\right\|^{2}}{\sum_{n=1}^{N} p^{(i)}(k \mid n)}} . \\
p_{k}^{(i+1)}=\frac{1}{N} \sum_{n=1}^{N} p^{(i)}(k \mid n) .
\end{gathered}
$$

A função de máxima verossimilhança aumenta em cada iteração garantindo a convergência do método (Borman, 2004). O procedimento do EM é repetido até chegar a um número máximo de iterações ou até que a máxima verossimilhança entre duas iterações sucessivas seja menor que um limiar especificado no começo do algoritmo. Para conseguir uma adequada aproximação da PDF em poucas iterações é necessário considerar algumas limitações do algoritmo EM. Em Nan et al. (2009) se recomenda inicializar os parâmetros do modelo próximos dos valores verdadeiros, devido ao fato de um dos inconvenientes do algoritmo EM ser a possibilidade de encontrar máximos locais, podendo fazer uma indicação errada da melhor estimativa. Outra das limitações do algoritmo é a convergência lenta e a necessidade de estabelecer um critério de parada para detectar se o algoritmo atingiu o máximo global. Estas limitações foram atendidas na implementação do algoritmo EM e as soluções propostas serão explicadas no capítulo 3.

Depois de calcular a PDF a partir de um modelo baseado em mistura de gaussianas, é necessário estabelecer um critério de divergência para estimar as semelhanças entre os modelos construídos. A seguir são descritas algumas das métricas mais utilizadas que se encontram na literatura, especialmente será comentada a divergência KL, além de suas propriedades mais importantes.

\subsection{Medidas de Similaridade}

Empregar GMM para aproximar a PDF de sinais de fala é cada vez mais comum em diferentes áreas do processamento deste tipo de sinais (Dustor e Szware, 2009; Shin et al., 2005; Reynolds e Rose, 1995). Isto se deve a algumas facilidades que caracterizam estes modelos como, por exemplo, a simplicidade de aprendizagem na estimativa dos parâmetros e a flexibi- 
lidade para representar qualquer PDF que descrevem os dados (Moreno et al., 2004). A partir destas vantagens, em diversos algoritmos de fala dedicados à classificação, à seleção de características ou ao reconhecimento de padrões é interessante comparar os modelos estimados para quantificar "quão parecidos" são.

Na literatura, existem diversos coeficientes para calcular semelhanças entre modelos. Estes coeficientes têm sido chamados de distintas formas, (divergência, distância ou medidas) dependendo de como eles satisfazem as propriedades das métricas de distâncias (Seghouane e Amari, 2007; Chan e Vasconcelos, 2005). Calcular a distância entre dois modelos significa avaliar quão distanciados entre si eles estão, enquanto menor seja essa distância mais similares estes serão.

Tradicionalmente, as métricas mais usadas para estimar a similaridade entre modelos foram a distância Euclidiana e a distância Mahalanobis. A matriz de distância da primeira métrica é a identidade e a matriz distância da segunda é a inversa da matriz co-variância dos dados. A distância Euclidiana é independente da distribuição dos dados, enquanto a distância Mahalanobis considera uma distribuição global deles (Li e King, 1999). Em algoritmos dedicados a problemas de classificação, têm se definido algumas funções como alternativa para medir similaridade entre modelos. Entre as mais utilizadas se conhece a função polinomial e a gaussiana (Raykar, 2002). Outras das medidas propostas para estimar distância ou divergência entre GMM foram a Bhattacharyya, que é um caso especial da distância de Chernoff, e a Chi-quadrado (Johnson e Sinanović, 2001). As métricas descritas neste parágrafo são chamadas no resto do texto como métricas tradicionais.

As métricas tradicionais, indicadas na literatura como as mais usadas para medir distância ou similaridade entre modelos, às vezes impõem algumas restrições que se consideram limitações na implementação dos algoritmos. A distância Euclidiana e a Mahalanobis não geram resultados exatos quando os dados estão caracterizados por diferentes tipos de distribuições (Li e King, 1999). As métricas Bhattacharyya e Chi-quadrado para certas distribuições impõem restrições nas características de distribuição dos dados ou são excessivamente custosas de computar. Estas limitações servem como motivação para desenvolver novos trabalhos com o objetivo de introduzir outras métricas ou critérios que estimem a similaridade ou distância entre os modelos baseados em misturas de gaussianas.

Em Li e King (1999) foi formulado um método para estimar a matriz distância entre modelos baseados em GMM, com o objetivo de identificar grupos entre os dados analisados. O 
método é baseado na minimização da divergência KL entre as distribuições dos dados. A nova métrica é comparada com a distância Euclidiana e a Mahalanobis, considerando o desempenho destas medidas. Depois de desenvolver diversos testes, os autores avaliaram a métrica proposta como superior.

Em Raykar (2002), foi introduzida uma nova família de kernels probabilísticos baseada nas medidas de divergência da teoria da informação. No trabalho, um kernel é interpretado como uma função que mede similaridade entre duas PDF. Entre os kernels propostos no trabalho encontram-se o kernel KL, Rényi e Jensen-Shannon, demonstrando através dos resultados que estas métricas apresentam melhor desempenho e exatidão que outras métricas de distância como a Euclidiana.

Apesar da existência de uma variedade de métricas para estimar a divergência entre modelos baseados em mistura de gaussianas, na atualidade a divergência KL é uma ferramenta amplamente usada em diferentes campos da ciência. Aplicar a divergência KL entre GMM é muito natural e frequentemente necessário em campos dedicados ao reconhecimento de fala ou de imagem (Hershey e Olsen, 2007; Seghouane e Amari, 2007; Goldberger et al., 2003; Do, 2003).

Em Goldberger et al. (2003) é apresentado um algoritmo dedicado à recuperação de imagens. A PDF das imagens é estimada usando uma mistura de gaussianas, em que os parâmetros da mistura são calculados empregando o algoritmo EM. O trabalho propõe usar a divergência KL para medir a similaridade entre as misturas de gaussianas que descrevem as PDF das imagens.

Argumentando que a divergência KL se caracteriza por uma base sólida para sistemas estocásticos, em Scalassara et al. (2009a) é usada a divergência KL na diferenciação de vozes normais e patológicas. O trabalho apresenta resultados interessantes na classificação de diferentes doenças vocais.

Em Jensen et al. (2007) apresenta-se uma comparação entre as medidas de distância KL, (EMD) (em inglês Earth Movers Distance) e a distância Euclidiana, também conhecida como L2. O objetivo principal do trabalho foi procurar similaridades entre músicas, além de identificar os diferentes gêneros, nos quais elas pertencem. Avaliando exatidão na classificação, a medida KL se mostra ligeiramente superior à L2, mas esta última medida obedece o teorema de desigualdade triangular, enquanto a KL não (Jensen et al., 2007). 
No trabalho de Haubold e Kender (2008) utiliza-se a divergência KL como medida de distância em algoritmos de agrupamento de fala. $\mathrm{O}$ vetor de fala foi representado usando um vetor de coeficientes cepstrais (MFCC). Nesse trabalho, o autor mostrou que o rendimento da divergência KL diminui quando o comprimento dos segmentos de áudio são muito pequenos ou quando existem diferenças significativas na extensão deles. É necessário considerar estas deficiências da divergência para garantir uma adequada classificação dos sinais.

Devido às vantagens tanto teóricas como computacionais da divergência KL (Johnson e Sinanović, 2001), o coeficiente da teoria da informação é, provavelmente, o mais usado para medir a divergência entre duas PDF (Seghouane e Amari, 2007). Além disso, esta divergência apresenta uma base sólida para ser aplicada tanto em processos estocásticos como em sistemas dinâmicos (Scalassara et al., 2009a). Apesar das vantagens mencionadas anteriormente, o cálculo da divergência KL não é uma tarefa fácil. Além disso, esta métrica depende da estimativa da PDF do sinal que está sendo estudado (Scalassara et al., 2009b).

Nesta seção foram comentadas as medidas de distância que tem sido mais utilizadas para avaliar semelhanças entre mistura de gaussianas. Na Tabela 2.2 é mostrado um resumo destas medidas, assim como os trabalhos em que elas foram empregadas. Em seguida, define-se a divergência KL e suas características principais, dado que neste trabalho este coeficiente será empregado para medir semelhanças entre as palavras.

Tabela 2.2: Medidas de distância mais comummente empregadas para estabelecer semelhanças entre GMM.

\begin{tabular}{|l|l|}
\hline \multicolumn{2}{|c|}{ Medidas de distância empregadas entre GMM } \\
\hline Medidas tradicionais & Medidas da teoria da informação \\
\hline \hline $\begin{array}{l}\text { Euclidiana ou L2 (Jensen et al,. 2007; Li } \\
\text { e King, 1999) }\end{array}$ & $\begin{array}{l}\text { Divergência KL (Haubold e Kender, } \\
\text { 2008; Johnson e Sinanovié, 2001; } \\
\text { Scalassara et al., 2009b) }\end{array}$ \\
\hline Mahalanobis (Li e King, 1999) & Rényi (Raykar, 2002) \\
\hline Bhattacharyya (Johnson e Sinanovié, 2001) & Jensen-Shannon (Raykar, 2002) \\
\hline Chi-quadrado (Johnson e Sinanovié, 2001) & \\
\hline Earth Movers Distance (EMD) (Jensen et al,. 2007) & \\
\hline
\end{tabular}

\subsection{Divergência Kulback-Leibler (KL)}

Um dos principais objetivos da teoria da informação é quantificar as incertezas estatísticas em processos aleatórios, bem como as dependências estatísticas entre múltiplos processos alea- 
tórios. As duas principais grandezas propostas na teoria da informação, definidas para projetar mensagens e sistemas, são a entropia e a divergência Kullback-Leibler (Erdogmus e Principe, 2006).

A entropia é uma grandeza usada para medir a incerteza de uma variável aleatória. Esta define uma medida da quantidade de informação necessária para descrever qualquer variável (Cover e Thomas, 1991). A entropia $H(X)$ foi originalmente definida por Shannon, como medida de informação para uma variável aleatória discreta $X$. Esta grandeza é definida na Equação 2.9, conforme (Cover e Thomas, 1991).

$$
H(X)=-\sum_{X \in \chi} f(x) \log f(x)
$$

$\mathrm{Na}$ Equação 2.9, considera-se a variável aleatória $X$ com um alfabeto de eventos $\chi$, sendo $f(x)$ a PDF associada a essa variável. O logaritmo possui base 2, assim, a entropia é expressa em bits (Cover e Thomas, 1991).

A entropia relativa ou divergência KL $D(f \| g)$ é uma medida de distância entre duas distribuições de probabilidade (Hershey e Olsen, 2007). A divergência KL quantifica a ineficiência em assumir que a distribuição dos dados poderia ser $f$ quando realmente a distribuição é $g$ (Cover e Thomas, 1991). Considerando $f(x)$ e $g(x)$ duas PDFs, a entropia relativa entre elas é definida pela Equação 2.10, sendo $X$ uma variável aleatória discreta, e $\chi$ o alfabeto de eventos dessa variável.

$$
D(f \| g)=\sum_{X \in \chi} f(x) \log \frac{f(x)}{g(x)}
$$

Outra medida da teoria da informação que mede divergência entre modelos é a divergência de Rényi (Chan e Vasconcelos, 2005). Esta divergência de ordem $\alpha$ é definida com a seguinte fórmula:

$$
D_{\alpha}(f \| g)=\frac{1}{\alpha-1} \log \sum_{X \in \chi} f(x)^{\alpha} g(x)^{1-\alpha} .
$$

na qual $\alpha>0$. A divergência de Rényi é uma generalização da divergência KL, e elas são iguais quando $\alpha$ tende a 1. Para $\alpha \rightarrow \infty$, o cálculo da divergência de Rényi considera os eventos de maior probabilidade, enquanto para valores de $\alpha$ próximos de zero considera todos 
os eventos de forma equitativa e com independência de suas probabilidades. Neste estudo, por questões de simplicidade, se usará somente a divergência KL (Chan e Vasconcelos, 2005).

A divergência KL satisfaz três propriedades fundamentais (Hershey e Olsen, 2007):

- Positiva $D(f \| g) \geq 0$ para todo $f$ e $g$

- Similaridade $D(f \| f)=0$

。 Identificação $D(f \| g)=0$ se e somente se $f=g$

Apesar das vantagens da divergência KL, um dos inconvenientes é a sua propriedade de assimetria. A matriz de distância baseada na divergência KL realmente não é uma matriz de distância, pois esta divergência apesar de apresentar algumas características das métricas de distância entre PDFs, como sendo sempre positiva e igual a zero quando $f(x)=g(x)$, não será realmente uma distância. Isso porque $D(f \| g)$ é diferente de $D(g \| f)$, em outras palavras, ela não é simétrica e não satisfaz a desigualdade triangular (Seghouane e Amari, 2007; Johnson e Sinanović, 2001; Cover e Thomas, 1991), o que constitui um requisito essencial para ser considerada uma medida de distância.

Motivados por solucionar este problema de simetria em Seghouane e Amari (2007) e em Johnson e Sinanović (2001) são propostas várias funções para simetrizar a KL. Em Johnson e Sinanović (2001) se recomenda como ideal o uso da distância de Chernoff, mas este método é pouco atrativo devido a sua impossibilidade de ser tratado computacionalmente. Consequentemente, para o autor é preferível a simetrização da divergência KL para aproveitar as vantagens que ela fornece e procurar uma melhor alternativa para avaliar similaridades entre modelos (Johnson e Sinanović, 2001). Na próxima seção, são apresentadas algumas das alternativas proposta para simetrizar a divergência KL.

\subsubsection{Simetrização da divergência $K L$}

Nos últimos anos, diversas funções têm sido propostas para a simetrização da divergência KL (Seghouane e Amari, 2007; Johnson e Sinanović, 2001). Como primeira alternativa, temse a chamada J-divergence ${ }^{8}$, que consiste em calcular a média entre duas divergências KL. A Equação 2.12 define esta operação:

\footnotetext{
${ }^{8}$ Alguns autores definem a J-divergence como uma soma entre as duas PDFs, no lugar da média entre elas.
} 


$$
J(f \| g)=\frac{D(f \| g)+D(g \| f)}{2} .
$$

Em Seghouane e Amari (2007) a função weighted average é considerada como solução do problema da simetrização da divergência KL. Esta operação é definida na Equação 2.13:

$$
W(f \| g)=\eta D(f \| g)+(1-\eta) D(g \| f), \eta \in[0,1]
$$

$\eta=1 / 2$, é um caso especial na Equação 2.13, e corresponde a função J-Divergence, definida pela Expressão 2.12.

Para solucionar o problema da simetrização da divergência KL, foram propostas outras medidas como a média geométrica (Equação 2.14) e a média harmônica (Equação 2.15).

$$
\begin{aligned}
& G(f \| g)=\sqrt{D(f \| g) * D(g \| f)} . \\
& H(f \| g)=\frac{2}{\frac{1}{D(f \| g)}+\frac{1}{D(g \| f)}} .
\end{aligned}
$$

No trabalho de Seghouane e Amari (2007), o principal objetivo foi procurar medidas de distância simétricas, baseadas na divergência KL que pudessem ser usadas como critérios de comparação entre modelos. $\mathrm{O}$ trabalho propõe simetrizar a divergência KL usando a função weighted average, a média Geométrica e a média Harmônica. Concluindo que as três alternativas empregadas são equivalentes já que todas elas podem ser estimadas usando o critério de informação $\mathrm{AIC}^{9}$.

Em Johnson e Sinanović (2001) foi definida uma nova distância entre duas PDFs chamada resistor-average. Esta nova função é simples de calcular e cumpre todas as propriedades da divergência KL. Resistor-average é simétrica e é definida a partir da média Harmônica. Na Equação 2.16 se mostra a operação que descreve esta medida.

\footnotetext{
${ }^{9}$ AIC é o primeiro critério teórico baseado na divergência KL entre duas PDF. Ele é derivado a partir de considerações sobre o comportamento assintótico da divergência KL.
} 


$$
\frac{1}{R(f \| g)}=\frac{1}{D(f \| g)}+\frac{1}{D(g \| f)}
$$

No estudo de Johnson e Sinanović (2001), é comparada a distância resistor-average com a distância de Chernoff, a J-divergence a Bhattacharyya e a média geométrica. O autor usa a distância Chernoff, conhecida como a de maior exatidão na estimativa da distância entre modelos, como uma referência para avaliar o desempenho do resto das métricas propostas. Considerando exatidão na estimativa e simplicidade na avaliação, a melhor estimativa foi obtida usando a função resistor-average. O mesmo trabalho também apresenta outra abordagem para criar uma medida simétrica baseada na divergência KL, a distância Topsoe $T(f \| g)$. Esta métrica é equivalente a $T(f \| p)+T(g \| p)$, em que $p=\frac{1}{2}(f+g)$.

A Figura 2.4, modificada de Johnson e Sinanović (2001), retrata as relações existentes entre algumas das medidas de distância mais usadas na teoria da informação. O foco na figura é a função $-\log (\mu(t))$, em que $\mu(t)=\int\left[f_{x}\right]^{1-t}[g(x)]^{t} d x$. A distância Chernoff $C(f, g)$ é definida como o máximo valor da função anterior no ponto $t^{*}$. A derivada da curva em $t=0$ e $t=1$ é $D(f \| g)$ e $-D(g \| f)$, respectivamente. Os valores destas tangentes correspondem às distâncias KL. As curvas tangenciais se interceptam no ponto $t=t^{* *}$ e esta interceptação corresponde ao valor da distância resistor-average $R(f, g)$; definida na Equação 2.16. A distância Bhattacharyya $B(f, g)$ é igual a $-\log \mu\left(\frac{1}{2}\right)$. A média geométrica $G(f, g)$, definida na Equação 2.14, está situada entre a distância $J$-divergence $J(f, g)$, definida na Equação 2.12, e o máximo valor da divergência KL. $C(f, g)$ representa a distância Chernoff enquanto $D(f \| g)$ representa a divergência KL. Estes testes foram desenvolvidos no trabalho de Johnson e Sinanović (2001).

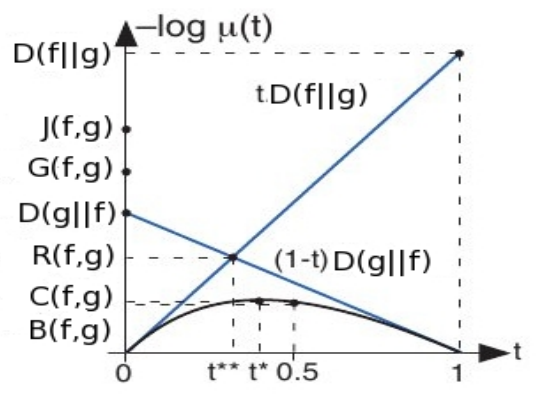

Figura 2.4: Relações entre as métricas de distância, Bhattacharyya, resistor-average, média geométrica, J-Divergence e Chernoff, usadas para simetrizar a divergência KL. Imagem modificada de Johnson e Sinanović (2001). 
Em Jensen et al. (2007) foi necessário simetrizar a divergência KL para estabelecer um critério de comparação entre dois modelos de tipo GMM. A alternativa escolhida para a simetrização deste coeficiente foi a função J-divergence; esta mesma opção foi a empregada em Raykar (2002).

Enquanto a divergência KL ganha aceitação nas comunidades que trabalham com imagem e som, modelos probabilísticos baseados em GMM são bem conhecidos e empregados nestas áreas, resultando atrativa a combinação destas abordagens com a finalidade de construir novas técnicas de classificação e identificação (Moreno et al., 2004).

É simples estimar a divergência KL entre duas funções gaussianas $f_{i}$ e $g_{i}$. Na equação 2.17 é mostrada esta operação (Hershey e Olsen, 2007):

$$
D\left(f_{i}|| g_{i}\right)=\frac{1}{2}\left[\log \frac{\left|\sum g_{i}\right|}{\left|\sum f_{i}\right|}+\operatorname{Tr}\left[\sum_{g_{i}}^{-1} \sum_{f_{i}}\right]-d+\left(\mu_{f_{i}}-\mu_{g_{i}}\right)^{T} \sum_{g_{i}}^{-1}\left(\mu_{f_{i}}-\mu_{g_{i}}\right)\right] .
$$

Considerando que não existe uma expressão para estimar a divergência KL entre modelos baseados em GMM (Hershey e Olsen, 2007; Jensen et al., 2007; Goldberger et al., 2003), a literatura sugere diferentes métodos ou funções para estimá-la, de forma eficiente, entre este tipo de modelos (Hershey e Olsen, 2007). Na próxima seção são abordadas algumas destas alternativas.

\subsubsection{Estimativa da divergência KL entre GMM}

Nesta seção são apresentados os métodos mais conhecidos para estimar a divergência KL entre GMM. Além disso, são mostradas algumas das funções empregadas para substituir a KL, entre dois modelos baseados em mistura de gaussianas.

O simulador de Monte Carlo é o método mais recomendado para estimar a divergência KL entre GMM. Ele consegue uma aproximação bem precisa, principalmente quando trabalha com dados de alta dimensão (Hershey e Olsen, 2007; Goldberger et al., 2003). Neste algoritmo, primeiro é gerado um conjunto de amostras $x_{i=1}^{n}$ para cada mistura $f(x)$ e $g(x)$, para logo estimar, de forma iterativa, a divergência KL para cada amostra gerada $x_{i}$ em $f(x)$ e em $g(x)$. Apesar deste algoritmo ser um dos poucos métodos convergentes, sua execução causa um significativo incremento na complexidade computacional (Goldberger et al., 2003), sendo 
esta a principal desvantagem do método. De acordo com Hershey e Olsen (2007), outra das limitações deste algoritmo é que ele, às vezes, não cumpre a propriedade de positividade da KL. As propriedades mais importantes da KL, foram detalhadas na Seção 2.5.

Em Hershey e Olsen (2007) são propostos dois novos métodos para aproximar a divergência KL entre GMMs. Estas técnicas foram comparadas com outras que aparecem na literatura, a partir dos benefícios que cada uma proporciona. Estes métodos são chamados variational approximation e variational upper bound. Outra técnica comentada em Hershey e Olsen (2007) é unscented transformation, a qual é parecida com o método Monte Carlo (Hershey e Olsen, 2007; Goldberger et al., 2003), mas desta vez as amostras do sinal são escolhidas de forma determinística. Além disso, este método de aproximação é aplicado somente entre mistura de gaussianas (Goldberger et al., 2003). Segundo Hershey e Olsen (2007) esta abordagem satisfaz a propriedade de similaridade, mas geralmente as duas outras propriedades, positividade e identificação, não são mantidas.

Outra alternativa para aproximar a divergência KL entre misturas é o método baseado em aproximação por casamento (em inglês matching based approximation). Este consiste em assumir que não existe uma expressão para medir a divergência entre duas misturas, mas existe uma equação para estimar a divergência entre os componentes individuais que a integram. O primeiro passo deste método é definir uma função que case cada um dos componentes gaussianos que integram a mistura (Goldberger et al., 2003).

Hershey e Olsen (2007) apresentaram uma técnica conhecida como aproximação a uma gaussiana. Este método é motivado também pela existência de uma expressão para calcular a KL entre duas funções gaussianas $f_{i}$ e $g_{i}$. Usa-se a notação $f_{i}$ e $g_{i}$ para referir-se somente a uma gaussiana. O procedimento consiste em substituir cada mistura $f(x)$ e $g(x)$ por um elemento gaussiano $f_{i}$ e $g_{i}$, respectivamente. $\mathrm{O}$ trabalho mostra dois critérios para realizar o casamento das componentes gaussianas. O primeiro método casa as componentes gaussianas, nas quais as médias e as variâncias coincidem. Enquanto o segundo realiza o casamento procurando o par mais próximo, através da operação $D_{\min }=\min _{a, b} D\left(f_{a} \| g_{b}\right)$. O uso deste método constitui uma solução muito simples, obtendo uma aproximação muito pobre. Este método satisfaz as propriedades de positividade e similaridade, mas a propriedade de identidade não é mantida.

Em Goldberger et al. (2003) foram apresentados dois métodos para aproximar a divergência KL entre GMM. O primeiro é baseado no casamento das componentes que integram a mistura, enquanto o segundo baseia-se na unscented transformation. A eficiência dos métodos 
de aproximação foi avaliada usando tanto dados reais como simulados. A melhor aproximação foi alcançada através do método unscented transformation, mas o tempo computacional foi elevado. O método de casamento proposto foi comparado com um método de casamento baseado na distância Mahalanobis, mostrando melhor desempenho.

Outros métodos comentados no trabalho de Hershey e Olsen (2007) são aproximação do produto de gaussianas e matched bound approximation, o último algoritmo não satisfaz nenhuma das propriedades da divergência KL, entretanto o primeiro satisfaz, pelo menos, a propriedade de similaridade. O método de matched bound approximation é uma solução empírica e a aproximação é ruim, quando as componentes gaussianas que se quer multiplicar apresentam baixa probabilidade de ocorrência.

As novas estimativas propostas no trabalho de Hershey e Olsen (2007) são variational approximation e variational upper bound. A primeira alternativa consiste em estimar o limite inferior da verossimilhança do modelo de forma paramétrica, seguindo um enfoque variacional. A segunda alternativa, segue o mesmo enfoque, com o diferencial da estimação do limite superior da divergência KL através de parâmetros. Possivelmente, o melhor limite superior é alcançado procurando os parâmetros que minimizem a divergência KL (Hershey e Olsen, 2007). Enquanto que a primeira alternativa cumpre, apenas, a propriedade de similaridade, a segunda cumpre as três propriedades da divergência.

Numerosas alternativas existem para aproximar a divergência KL entre dois modelos baseados em misturas de gaussianas, algumas com melhor desempenho que o resto (Hershey e Olsen, 2007; Goldberger et al., 2003), mas quando se quer ganhar exatidão na estimativa, o método de Monte Carlo é o que fornece melhores resultados. Se o interesse for em tempo computacional, outros métodos como variational approximation e variational upper bound são preferíveis. Se a simplicidade da expressão for o questionamento, o método indicado é o variational approximation. Embora os métodos aproximação a uma gaussiana e unscented transformation representem uma das alternativas mais comuns, estes não são recomendáveis por existirem outras técnicas que proporcionem melhores soluções (Hershey e Olsen, 2007).

Na Tabela 2.3, é apresentado um resumo dos métodos comentados nesta seção para calcular a divergência KL entre modelos baseados em mistura de gaussianas. Na tabela observam-se as principais propriedades de dita divergência e como estes métodos as cumprem ou não.

Nesta seção, foi apresentada a estimativa da divergência KL, além das principais propriedades que a caracterizam. Foram mostrados alguns trabalhos que usam esta divergência como 
Tabela 2.3: Métodos para estimar a divergência KL entre GMM. Cumprimento das propriedades da divergência KL.

\begin{tabular}{|l|l|l|l|}
\hline \multicolumn{4}{|c|}{ Principais métodos para estimar a divergência KL entre GMM. } \\
\hline & \multicolumn{3}{|c|}{ Propriedades da divergência KL. } \\
\hline Métodos & Positiva & Similaridade & Identificação \\
\hline \hline Monte Carlo & Não & Sim & Sim \\
\hline Variational aproximation & Não & Sim & Não \\
\hline Variational upper bound & Sim & Sim & Sim \\
\hline Unscented transformation & Não & Sim & Não \\
\hline Aproximação por casamento & Sim & Sim & Não \\
\hline Matched bound approximation & Não & Não & Não \\
\hline
\end{tabular}

medida de distância na solução de diversos problemas. A simetrização da KL foi comentada, mostrando algumas das funções propostas como alternativa de simetrização. Por último, o cálculo da divergência KL entre modelos baseados em mistura de gaussianas foi abordado nesta seção. No Capítulo 3 é apresentado o método empregado no presente trabalho para calcular a divergência KL entre GMM. Na Seção 2.6, são explicados os algoritmos de agrupamento hierárquico, os quais serão usados no nosso trabalho, com a finalidade de procurar relações entre algumas das palavras que integram o banco de dados selecionado neste estudo.

\subsection{Agrupamento Hierárquico}

Existem numerosas alternativas para encontrar semelhanças entre elementos e formar grupos (Petridou et al., 2006; Tan et al., 2006; Afifi et al., 2004; Everitt et al., 2001; Kaufman e Rousseeuw, 1990; Anderberg, 1973). No contexto de análise de agrupamento (em inglês, Cluster Analysis), o agrupamento hierárquico representa um conjunto de métodos dedicados à construção de estruturas hierárquicas a partir de um grupo de objetos. O agrupamento hierárquico é um dos métodos mais simples. Estes métodos podem ser divididos em aglomerativos e divisivos. Os métodos aglomerativos começam formando grupos unitários e de forma iterativa se vão mesclando para formar grupos maiores, enquanto os métodos divisivos começam com um único grupo, que contém todos os elementos, e se vão dividindo sucessivamente em grupos menores (Afifi et al., 2004).

Algoritmos hierárquicos são bastante usados na solução de inúmeros problemas práticos. $\mathrm{Na}$ biologia, comumente empregam-se para representar filogenias e taxonomias (Talavera, 
2007). O agrupamento hierárquico também tem sido utilizado em aplicações Web, em que a quantidade de informação processada é excessiva, incitando a construção de algoritmos de agrupamento para organizar a informação seguindo determinados critérios (Tan et al., 2006). Outras áreas em que o agrupamento hierárquico é apropriado são: museologia, sistemas sociais, biblioteconomia e outros (Talavera, 2007).

Este tipo de agrupamento geralmente produz uma saída gráfica conhecida como dendrograma ou árvore binária, que mostra a estrutura hierárquica com as relações entre os grupos e os subgrupos, além da ordem em que cada grupo foi fundido (Tan et al., 2006). Um exemplo de dendrograma é mostrado na Figura 2.5, onde as barras verticais representam a distância entre os grupos e a altura na qual dois grupos foram fundidos.

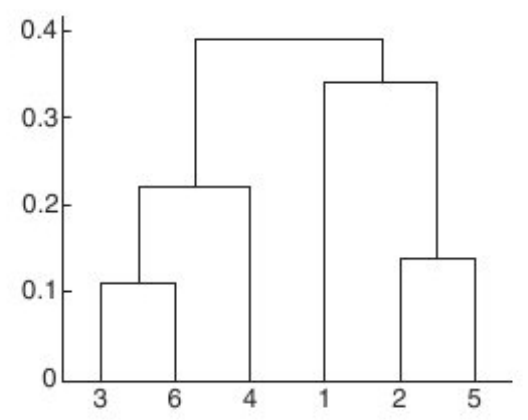

Figura 2.5: Exemplo da representação de um dendrograma, no qual o eixo vertical representa as distâncias entre os grupos e o horizontal identifica cada elemento que integra os grupos.

Os métodos hierárquicos são comumente usados, pois na maioria das vezes produzem resultados razoáveis, além de serem fáceis de calcular. Segundo Talavera (2007) os métodos aglomerativos são atualmente mais usados que os divisivos devido a estes últimos serem computacionalmente exigentes pela enorme quantidade de possíveis divisões que requerem. Neste trabalho, comentaremos apenas os métodos aglomerativos. A seguir são descritos estes métodos comumente usados em diversas áreas.

\subsubsection{Métodos aglomerativos tradicionais}

Os métodos aglomerativos são iniciados com $n$ grupos ( $n=$ número de elementos), em que cada elemento é localizado em um grupo diferente. Usando uma métrica de distância se calcula a matriz de distância entre os elementos individuais. A partir desta matriz, utiliza-se um critério de similaridade para de forma iterativa fundir o par de grupos que apresentem maior 
similaridade. O procedimento termina quando todos os elementos são juntados em um mesmo grupo. Existe uma variedade de métodos aglomerativos que são caracterizados de acordo com o critério utilizado para medir similaridade entre grupos. Entretanto, a maioria dos métodos parecem ser formulações alternativas de três grandes métodos de agrupamento aglomerativo (Anderberg, 1973):

- Métodos de ligação (single link, complete link, average link);

- Métodos de centróide;

- Métodos de soma de erros quadráticos ou variância (método de Ward).

No Algoritmo 1 é descrito o procedimento padrão que os métodos aglomerativos seguem. Formalmente, dado um conjunto de grupos $C=C_{1}, C_{2}, \ldots, C_{n}$, a matriz distância entre os elementos $\Delta=d(i, j)$ é calculada no passo 2 do algoritmo. A escolha desta matriz distância depende do tipo de dado e do problema abordado (Everitt et al., 2001), existindo diversas funções para este cálculo. Na Seção 2.4 são comentadas algumas das métricas mais populares empregadas para a construção da matriz anterior. O principal passo do algoritmo é definir as similaridades entre os grupos e isto ocorre no passo 7 do procedimento, em que a função $\delta\left(C_{i}, C_{j}\right)$ é usada para calcular a distância $\delta\left(C_{i j}, C_{w}\right)$ entre um novo grupo $C_{i j}$ e cada grupo existente $C_{w}$. Os métodos utilizados para medir a distância entre grupos e algumas de suas propriedades serão mostradas a seguir.

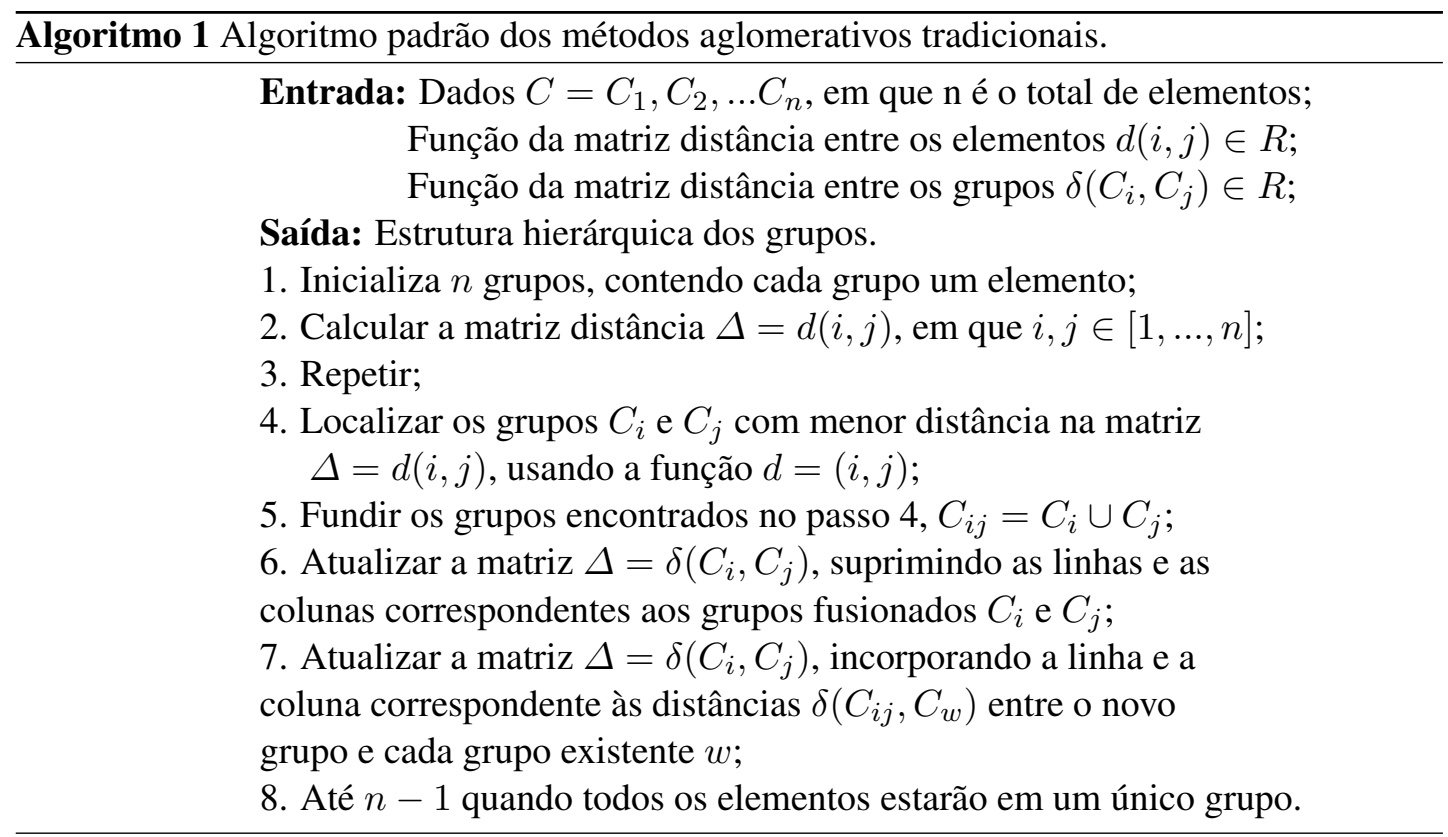


Método de ligação por vizinho mais próximo (em inglês, Single Linkage): Neste método, a distância $\delta\left(C_{i j}, C_{w}\right)$ entre o grupo fundido $C_{i j}$ e qualquer outro grupo existente $C_{w}$ é calculada como a mínima distância entre os elementos dos grupos $i j$ e $w$. A Equação 2.18 mostra o cálculo:

$$
\delta\left(C_{i j}, C_{w}\right)=\operatorname{mim} \delta(i j, w) \mid i \in C_{i j}, w \in C_{w}
$$

Entre as principais características deste método estão (Anderberg, 1973):

- Permite detectar grupos de formas não-elípticas;

- Grupos muito próximos podem não ser identificados;

- Pouca tolerância a ruído e

- Tendência a formar longas cadeias (encadeamento).

Método de ligação por vizinho mais distante (em inglês, Complete Linkage): Neste método, a distância $\delta\left(C_{i j}, C_{w}\right)$ entre o grupo fundido $C_{i j}$ e qualquer outro grupo $C_{w}$ é calculada como a maior distância entre os elementos $i j$ e $w$ de ambos grupos $C_{i j}$ e $C_{w}$. A Equação 2.19 mostra o cálculo:

$$
\delta\left(C_{i j}, C_{w}\right)=\max \delta(i j, w) \mid i \in C_{i j}, w \in C_{w}
$$

Algumas das principais características deste método são (Kaufman e Rousseeuw, 1990):

- Tendência a formar grupos compactos;

- Os ruídos demoram a ser incorporados ao grupo e

- Apresenta bons resultados tanto para distancia Euclidiana quanto para outras.

Método de ligação média (em inglês, Average Linkage): Neste método, a distância $\delta\left(C_{i j}, C_{w}\right)$ entre o grupo fundido $C_{i j}$ e qualquer outro grupo $C_{w}$ é calculada como a distância média de $i j$ e $w$ com respeito a $w$. Este é um método intermediário entre as duas alternativas anteriores (Tan et al., 2006). A Equação 2.20, mostra o cálculo:

$$
\delta\left(C_{i j}, C_{w}\right)=\frac{\sum_{i j \in C_{i j}} \sum_{w \in C_{w}} \delta\left(C_{i j}, C_{w}\right)}{\left|C_{i j}\right| *\left|C_{w}\right|}
$$


Algumas das principais características deste método são (Kaufman e Rousseeuw, 1990):

- Menor sensibilidade a ruídos que outros métodos de ligação;

- Apresenta bons resultados tanto para distâncias Euclidianas quanto para outras e

- Tendência a formar grupos com número de elementos similares.

Método de ligação por centróide (em inglês, Centroid Linkage): Este método, calcula a distância entre o grupo fundido $C_{i j}$ e qualquer outro grupo existente $C_{w}$, como sendo a soma da distância média entre todos os elementos dos grupos. A Equação 2.21, mostra este cálculo:

$$
\delta\left(C_{i j}, C_{w}\right)=\delta\left(\mu_{C_{i j}}, \mu_{C_{w}}\right) \text { onde }: \mu_{C_{i j}}=\frac{\sum_{i j \in C_{i j} i j}}{\mid C_{i j \mid}}
$$

Algumas das principais características deste método são (Talavera, 2007):

- Tolerância à presença de ruído e

- Fenômeno de reversão, isto é, novos grupos podem-se formar em um nível inferior aos grupos existentes, tornando o dendrograma confuso.

Método de ligação de Ward: Neste método, a distância entre dois grupos se calcula como o incremento no erro quadrático, que resulta quando dois grupos são fundidos. A distância entre o grupo fundido $C_{i j}$ e qualquer outro grupo existente $C_{w}$ se calcula de acordo com a Equação 2.22:

$$
\delta\left(C_{i j}, C_{w}\right)=\left(\frac{\left|C_{i j}\right| *\left|C_{w}\right|}{\left|C_{i j}\right|+\left|C_{w}\right|}\right)\left\|\mu_{C_{i j}}-\mu_{C_{w}}\right\|
$$

Algumas das principais características deste método são (Talavera, 2007):

- Pode apresentar resultados insatisfatórios quando o número de elementos em cada grupo é significativamente diferente;

- Tendência a combinar grupos com poucos elementos e

- Sensível a presença de outliers ${ }^{10}$.

\footnotetext{
${ }^{10}$ Outliers são observações numericamente distantes do resto do banco de dados.
} 
Os três primeiros métodos discutidos acima podem ser combinados com qualquer função de distância ou de similaridade para calcular a distância entre os elementos. Dentre as mais utilizadas são conhecidas: a distância Euclidiana, a distância Manhattan, a distância Minkowski, a correlação de Pearson e a distância cosseno. Os demais métodos comentados calculam somente a distância entre os elementos usando a distância Euclidiana (Afifi et al., 2004).

O êxito de um algoritmo hierárquico, depende fundamentalmente da métrica escolhida para estabelecer similaridade entre os elementos (Talavera, 2007). A escolha de uma medida de dissimilaridade que se adeque as propriedades dos dados a analisar é considerada um problema real. Na prática, as medidas de distância tradicionais, como a distância Euclidiana e a distância Manhattan, são as de maior uso nesta classe de algoritmos de agrupamento, desconsiderando a importância de utilizar uma métrica capaz de levar em conta algumas características especiais dos grupos examinados (Weixiang et al., 2009).

Uma alternativa para solucionar este problema é o uso da divergência KL como medida de similaridade para agrupar diversos tipos de dados. Em Weixiang et al. (2009), foi apresentado um algoritmo hierárquico que sugere a divergência KL como medida de distância entre os elementos dos grupos. A motivação desta abordagem está associada com a não linearidade do termo $f(x) \log \left(\frac{f(x)}{g(x)}\right)$, na Equação 2.10, que tende a capturar as diferentes características entre dois vetores (Weixiang et al., 2009). Este algoritmo foi usado em uma aplicação dedicada ao agrupamento de dados biológicos, mostrando a superioridade da divergência selecionada.

Em Petridou et al. (2006), foi proposto o uso da divergência KL combinada com o algoritmo de agrupamento K-means em um sistema dedicado a mineração Web (em inglês, Web Mining). No trabalho se compara esta medida de dissimilaridade com outras métricas tradicionais, como a distância Euclidiana e a distância de Manhattan, também conhecida como distância $L_{1}$, demostrando que o agrupamento obtido empregando a divergência KL é superior ao alcançado com as outras métricas testadas. 


\section{Capítulo 3}

\section{Materiais e Métodos}

Nosso trabalho foi realizado utilizando o banco de vozes do Museu do Índio do Brasil. Este banco de dados possui um acervo de mais de 2000 vocábulos pertencentes a 9 línguas indígenas e um dialeto. Atualmente, estas línguas e o dialeto existem no território brasileiro. Neste capítulo, primeiramente são descritas as palavras selecionadas para serem analisadas, junto com suas características fundamentais. Para a construção do sistema proposto, foi crucial a seleção de algumas das técnicas empregadas para modelar, comparar e agrupar sinais de fala. Após a escolha das palavras para a análise, explica-se o algoritmo implementado, assim como o processo de desenvolvimento e algumas das considerações realizadas para automatizar os métodos matemáticos utilizados.

\subsection{Banco de dados}

Dentre as 180 línguas indígenas que há no território brasileiro, neste trabalho se utilizaram um dialeto e 9 línguas que estão documentadas na base de dados do Museu do Índio. Na Tabela 3.1, são observadas estas línguas, além do tronco linguístico ao qual elas pertencem. Seguindo o agrupamento realizado pelos linguistas, comentado na Seção 2.1, nesta tabela são mostradas as diferentes famílias e dialetos que existem na base de dados do museu. Na Tabela 3.1, percebe-se que na frente de cada língua ou dialeto há um número, o qual é usado como um identificador das línguas dentro do algoritmo que foi implementado e que será detalhado nas próximas seções.

Embora seja significativa a quantidade de palavras armazenadas na base de dados do Museu 
Tabela 3.1: Línguas e dialetos que estão armazenados na base de dados do Museu do Índio. Estas serão analisadas neste trabalho.

\begin{tabular}{|c|c|c|c|}
\hline \multicolumn{4}{|c|}{ Tronco Tupí } \\
\hline Famílias & Tupi-Guarani & Arikém & Mundurukú \\
\hline Línguas & (3) Kamaruyá (5) Kayabí & (4) Karitiána & (8) Mundurukú \\
\hline Dialetos & & & \\
\hline \multicolumn{4}{|c|}{ Tronco Macro-Jê } \\
\hline Famílias & Boróro & Karajá & Jê \\
\hline Línguas & (9)Umutina & (1) Karajá & \\
\hline Dialetos & & & (6) Krahô \\
\hline \multicolumn{4}{|c|}{ Família de Línguas Isoladas } \\
\hline Famílias & Aruak & Karib & Tukano \\
\hline Línguas & (10) Yawalapití & (7) Kuikúru & (2) Tukano \\
\hline Dialetos & & & \\
\hline
\end{tabular}

do Índio, somente existem 6 palavras comuns para as 9 línguas documentadas e o dialeto. No presente estudo por questões de simplicidade, foram escolhidas estas 6 palavras para a análise. Desta forma, nosso trabalho se concentrou no estudo de um total de 60 palavras. Na Tabela 3.2 são mostradas as 6 palavras selecionadas para cada uma das línguas.

Tabela 3.2: Palavras selecionadas no estudo. Para cada uma das línguas que pertencem a base de dados, foram escolhidas estas palavras.

\begin{tabular}{|c|c|}
\hline \multicolumn{2}{|c|}{ Palavras Selecionadas } \\
\hline Água & Olho \\
\hline Criança & Osso \\
\hline Fogo & Sangue \\
\hline
\end{tabular}

Os sinais retirados do banco de dados foram gravados com o uso de um microfone. Foi pedido para cada pessoa dizer uma determinada palavra. Cada palavra foi dita por homens membros das comunidades indígenas, com idades entre 20 e 70 anos. Os sinais de fala foram quantizados, em amplitude, usando 16 bits com formato WAVE mono-canal e frequência de amostragem de $22.050 \mathrm{~Hz}$. A duração das palavras é diferente, variando também o comprimento dos sinais.

Inicialmente as palavras são agrupadas em 6 grupos diferentes. Estes grupos são chamados no resto do trabalho como conjunto de palavras. Cada conjunto contém a mesma palavra dita em diferentes línguas, dessa forma, em cada conjunto estão incluidas 10 palavras. Cada vez que o algoritmo é executado, ele recebe como entrada um conjunto de palavras, isto é, ele 
processa a mesma palavra dita pelas 10 línguas que há na base de dados. A seguir, é explicado o algoritmo implementado para estimar as PDFs dos sinais de fala baseadas em uma mistura de gaussianas. Além disso, são detalhados os procedimentos para estabelecer as semelhanças entre as PDFs e finalmente agrupar os modelos obtidos.

\subsection{Arquitetura do algoritmo proposto}

O sistema proposto para procurar relações entre os sinais de fala foi desenvolvido usando programação orientada a objeto (em inglês, Object Oriented Programing). O software foi desenvolvido empregando $\mathrm{C}++$ e a biblioteca de funções GSL ${ }^{1}$. A GSL é uma biblioteca numérica para $\mathrm{C} / \mathrm{C}++$ que contém funcionalidades embutidas para números randômicos, distribuições estatísticas, matemática de matrizes, números complexos entre outras. Além disto, esta biblioteca é de código aberto e gratuita. A flexibilidade na construção dos algoritmos e a robustez no desempenho, são as principais motivações do emprego de $\mathrm{C}++$ como linguagem de programação neste trabalho.

Para organizar a implementação e a execução do processo de agrupamento dos sinais, o algoritmo foi dividido a partir das diferentes funcionalidades. Foram identificadas quatro etapas fundamentais:

- Pré-processamento dos sinais a serem analisados;

- Estimativa da PDF, baseada em uma mistura de gaussianas;

Cálculo da matriz de distância, aplicando a divergência KL como critério de similaridade entre os modelos;

- Agrupamento das misturas que representam cada palavra;

Na Figura 3.1, é ilustrado o procedimento no qual estão envolvidas as quatro funcionalidades anteriores. Nesta figura se observam as etapas desenvolvidas para a construção do sistema, assim como as principais entradas e saídas. Foram criados quatro módulos para a execução das tarefas do sistema.

O primeiro módulo é o de Pré-processamento, outro para estimar as PDFs das palavras, chamado de módulo PDF, um módulo Medida, para calcular as divergências entre os modelos,

\footnotetext{
${ }^{1}$ http://www.gnu.org/software/gsl/
} 

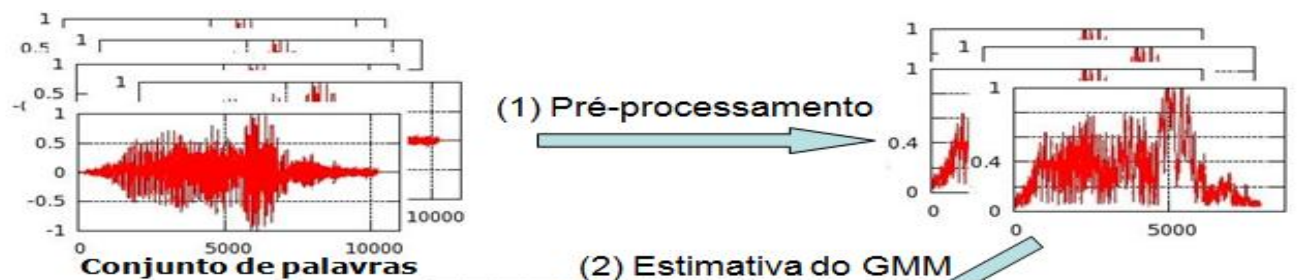

(2) Estimativa do GMM

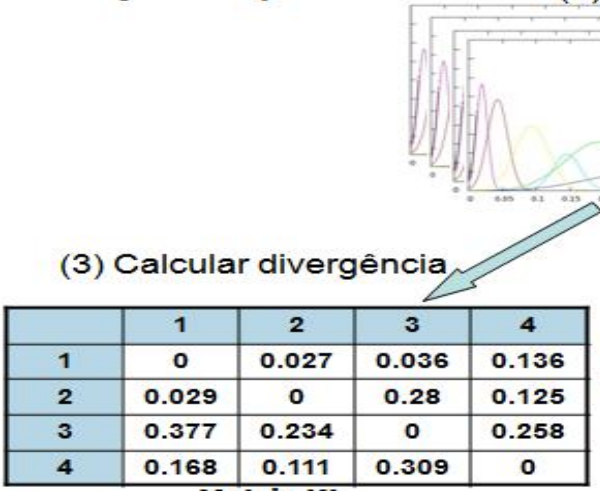

PDF

(4) Agrupamento

Matriz KL

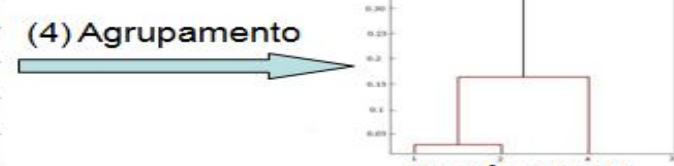

Dendrograma

Figura 3.1: Processo geral do algoritmo proposto para agrupar os modelos baseados em GMM, que descrevem a PDF dos sinais de fala.

e por último o módulo Agrupamento com a função de construir os dendrogramas que mostram as relações entre os modelos. O algoritmo recebe como entrada um conjunto de palavras, definido na Seção 3.1. Este analisa de forma iterativa todas as palavras incluídas no conjunto e para cada conjunto gera como saída, um dendrograma em que se evidenciam as relações entre as 10 palavras que o integram.

Os sinais que integram o conjunto, são pré-processados no módulo Pré-processamento. Neste módulo o sinal é necessariamente preparado para permitir a estimativa da PDF. A saída do primeiro módulo representa a entrada do módulo PDF, no qual a PDF do sinal é estimada tomando como base uma mistura de gaussianas. A função do módulo Medida é calcular a divergência KL entre todas as PDFs estimadas no módulo anterior, para formar a matriz de distância baseada nesta divergência. Esta matriz representa a entrada do módulo Agrupamento, encarregado pela construção dos dendrogramas. Estes dendrogramas ilustram as relações entre os modelos e representam a saída principal do último módulo, além de ser um dos resultados mais importantes do sistema. A seguir se explicam as operações que integram cada um dos módulos definidos. O funcionamento de cada módulo é explicado considerando a análise de um único sinal.

\section{Módulo de Pré-processamento}

Este módulo recebe como entrada um vocábulo pertencente ao banco de vozes analisado. 
O sinal de fala se considera um vetor de $N$ componentes, em que $N$ é o comprimento do sinal e varia entre um sinal e outro. Na Figura 3.2, são mostradas as operações principais desenvolvidas neste módulo.

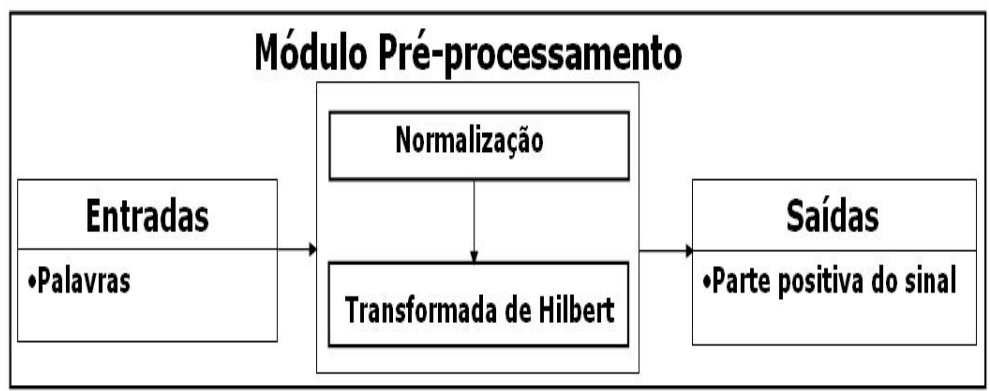

Figura 3.2: Operações realizadas no módulo de Pré-processamento dos sinais de fala.

A operação de normalização, na Figura 3.2 se refere a normalização dos sinais, obtendo valores de amplitudes na faixa de -1 a 1 . Nesta operação, além de normalizar as amplitudes, são eliminados do sinal, os momentos de silêncio existentes tanto no começo como no final do vetor. Estes momentos de silêncio são retirados de forma visual, com o objetivo de não perder amostras com informação relevante para a posterior análise do sinal. A parte a) da Figura 3.3 representa a palavra "água" dita por um membro da comunidade indígena Krahô. Como se pode observar este sinal é simétrico e apresenta um número significativo de amostras próximas a zero.
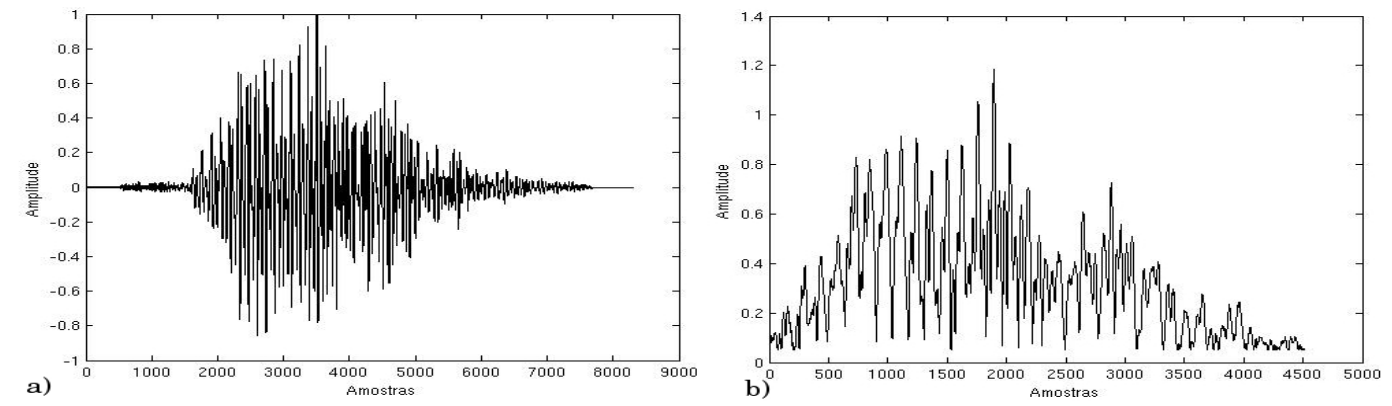

Figura 3.3: Sinal que representa a palavra água dita na língua índigena Kraho.

Após a operação de normalização das amplitudes e a retirada dos momentos de silêncio, é usada a transforma de Hilbert para obter a envoltória do sinal e consequentemente a sua parte positiva. Esta operação é mostrada na Figura 3.2. Para o cálculo da transformada de Hilbert foi empregada a função $x=\operatorname{hilbert}\left(x_{r}\right)$ de Matlab. A saída da função é uma sequência analítica $x=x_{r}+i * x_{i}$, que tem parte real, $x_{r}$, que é o sinal original, e tem parte imaginaria, $x_{i}$, que contêm a transformada de Hilbert. A parte imaginaria é uma versão do sinal original defasada 
$90^{\circ}$. A serie da transformada de Hilbert tem a mesma amplitude e a mesma frequência que o sinal original. Esta transformada é comummente usada para calcular os atributos instantâneos de uma serie de tempo, especialmente a amplitude e a frequência. Na parte b) da Figura 3.3 se ilustra somente as amostras positivas do vetor de fala, usado como exemplo na parte a). O sinal resultante já foi pré-processado, sendo normalizadas suas amplitudes e retirando um conjunto de amostras do início e final do sinal original, para finalmente conseguir um sinal não-simétrico com amplitudes entre 0 e 1 que constitui a entrada principal do módulo PDF.

\section{Estimativa da função de distribuição de probabilidade (Módulo PDF)}

A seguir se apresenta o procedimento para a implementação do algoritmo que estima a PDF, baseada em uma mistura de gaussianas. Este módulo é considerado o mais importante do sistema proposto, devido que tanto a estimativa das similaridades entre as PDFs como o agrupamento dos modelos dependem dele.

Na Figura 3.4, são ilustradas as funcionalidades mais relevantes que conformam o módulo PDF. Nela se observam as entradas e as saídas requeridas pelo módulo, assim como as operações executadas.

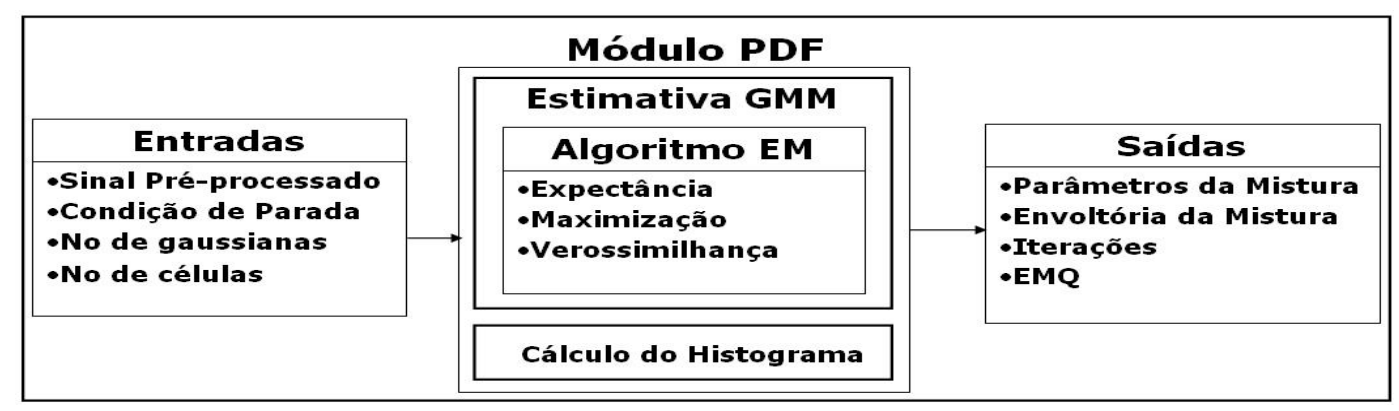

Figura 3.4: Operações do módulo PDF, no qual a PDF dos sinais de fala são estimadas, baseadas em GMM.

O algoritmo EM apresentado na Seção 2.3.1, constitui a base dos métodos implementados neste módulo. Para obter uma boa aproximação da mistura de gaussianas, a partir do método EM, foi necessário considerar as principais limitações deste método numérico. A desvantagem do EM é sua convergência lenta, a necessidade de um critério de parada para detectar se o algoritmo atingiu o máximo global, a escolha de valores iniciais para os parâmetros da distribuição de probabilidade que proporcionem atingir o máximo global em poucas iterações e por último o número máximo de componentes que melhor descrevam o modelo que se quer aproximar. É necessário considerar estas limitações para conseguir um desempenho adequado do algoritmo proposto, assim como a melhor aproximação. 
A escolha apropriada de um critério de parada tem sido muito discutido na literatura (McLachlan e Krishnan, 1997). Em geral, estes critérios se basearam na variação da função de verossimilhança ou do logaritmo dela. A característica comum em todos os critérios propostos é que o algoritmo interrompe a iteração quando o valor do critério escolhido torna-se menor que uma constante especificada inicialmente. Quanto menor for essa constante, mais forte será o critério de parada. Neste trabalho é escolhido como critério de parada a diferença entre duas estimativas sucessivas do logaritmo da função de verossimilhança $\lambda\left(\Theta^{k}\right)$, ou seja

$$
\left|\lambda\left(\Theta^{k+1}\right)-\lambda\left(\Theta^{k}\right)\right|<c
$$

em que $c=10^{-5}$, foi adotado depois de observar o comportamento do algoritmo em várias execuções.

A inicialização do algoritmo EM constitui outro dos fatores de relevância no desempenho do método. A escolha adequada para os valores iniciais dos parâmetros da mistura influencia fortemente na velocidade de convergência do método e na sua capacidade de localizar o máximo global (Marques, 2009). Em Marques (2009) se sugere três métodos de inicialização, Método dos Valores Verdadeiros (MVV), Método dos Valores Iniciais Aleatórios (MVA) e Método dos Momentos (MM).

O primeiro método considera como valores iniciais os mesmos valores usados para gerar a amostra. Espera-se que este método ofereça as melhores estimativas, mas não é usado em um problema real, devido a que, nestes problemas não são conhecidos os parâmetros iniciais que geraram o sinal. Este método é usado pelo autor como um critério de comparação, para avaliar a estimativa dos outros dois métodos propostos. Depois de diversos ensaios, Marques (2009) demonstra que o MM é o método que fornece os melhores resultados. Como alternativa de inicialização, neste trabalho se propõe usar o método MM, proposto em Marques (2009). A seguir é comentado este método além de algumas modificações realizadas.

A inicialização dos parâmetros da mistura se realiza dividindo o sinal de entrada $x_{1}, \ldots, x_{n}$ em K-partes (número máximo de componentes gaussianos). "Devido a seu desempenho e sua simplicidade" (Talavera, 2007), o algoritmo K-Means é empregado para fazer o particionamento do sinal. A k-ésima parte da amostra é denotada usando $\varphi_{k}$. Em cada partição $\varphi_{k}$, é calculada uma estimativa da média e do desvio padrão, como se mostra nas Expressões 3.1. 
A probabilidade de ocorrência, usada para inicializar cada componente gaussiana, é estimada empregando a Expressão 3.2. Estes valores calculados em cada partição $\varphi_{k}$, servem para inicializar as componentes gaussianas que integram a mistura.

$$
\begin{array}{r}
m_{\varphi_{k}}=\sum_{i=0}^{N_{\varphi_{K}}} \frac{x_{i}}{N}, \\
\sigma_{\varphi_{k}}=\frac{\sum_{i=0}^{N_{\varphi_{K}}}\left(x_{i}-m_{\varphi_{k}}\right)^{2}}{N-1},
\end{array}
$$

em que , $m_{\varphi_{k}}, \sigma_{\varphi_{k}}$ são a estimativa da média e do desvio padrão da partição $k$ e $N_{\varphi_{k}}$ representa o total de elementos em cada partição.

$$
p_{\varphi_{k}}=1 / K
$$

em que, $p_{\varphi_{k}}$ é a probabilidade de ocorrência de cada gaussiana e $K$ o número máximo de funções gaussianas na mistura.

Na Figura 3.4, são ilustradas as entradas requeridas por este módulo para o cálculo da PDF baseada em GMM. O vetor que contém o sinal, o qual foi obtido no módulo Pré-processamento, representa a entrada principal deste procedimento. Outras entradas consideradas são o número máximo de componentes gaussianas que vão a integrar a mistura, junto com o critério de parada que seguirá o algoritmo EM.

No nosso trabalho a estimativa da PDF, empregando uma mistura de gaussianas, é desenvolvida usando a definição de GMM, comentada na Seção 2.3. Na implementação se considera, a mistura de gaussianas, a partir da existência de uma ou várias componentes gaussianas. Cada componente é descrita usando os parâmetros, média, desvio padrão e probabilidade de ocorrência. Seguindo o método de inicialização proposto anteriormente, o primeiro passo do algoritmo para estimar a PDF baseado em GMM, concentra-se no cálculo dos valores iniciais dos parâmetros da mistura. Uma vez inicializados os parâmetros, de forma iterativa o algoritmo tenta aproximar o modelo que melhor descreva o sinal, utilizando as Expressões 2.5, 2.6, 2.7 e 2.8, definidas na Subseção 2.3.1.

No Algoritmo 2, é mostrado o pseudocódigo com os procedimentos básicos criados para a implementação da estimativa da PDF, usando o algoritmo EM. Neste pseudocódigo se observa que o algoritmo EM tem sido divido em três funções principais em correspondência com os 
três passos definidos na Subseção 2.3.1. O primeiro passo corresponde a função Verossimilhança, definida na Equação 2.4. Nós trabalhamos com o logaritmo da verossimilhança, em detrimento da verossimilhança diretamente. Depois é empregada a função Expectância, definida pela Equação 2.5, para por último executar a função Maximização. Está última função inclui a avaliação das Equações 2.6, 2.7 e 2.8. A função Verossimilhança, usando o modelo aproximado, avalia a qualidade da mistura em cada uma das iterações do algoritmo. Na primeira execução do algoritmo, esta função verifica o modelo resultante da inicialização dos parâmetros, supõe-se que esta seja a pior aproximação. De forma iterativa o algoritmo estima, usando a função Expectância, um novo modelo da PDF que será maximizado utilizando a função Maximização. Em cada iteração, é calculada a diferença entre o valor atual do coeficiente de máxima log-verossimilhança e o valor do coeficiente calculado na iteração anterior. Esta diferença é comparada com o critério de parada dado como entrada. No caso de se obter uma diferença menor que o limiar indicado como critério de parada, o algoritmo é finalizado, resultando a aproximação do modelo que melhor descreve o vetor de entrada.

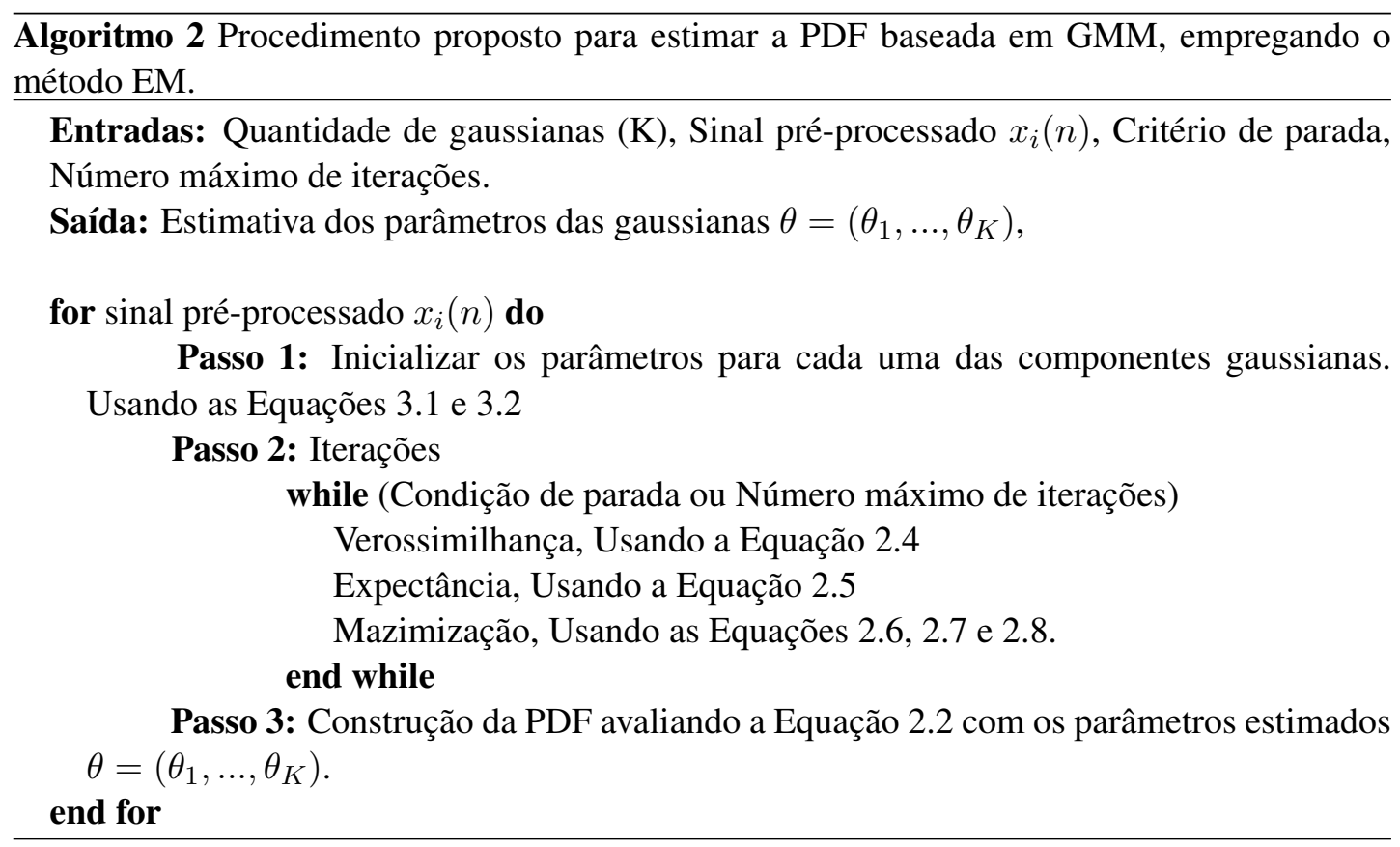

As principais saídas deste módulo são os valores dos parâmetros que caracterizam cada função gaussiana, o logaritmo da função de verossimilhança e o número máximo de iterações. Além disso, este módulo usa Gnuplot ${ }^{2}$ para mostrar alguns resultados de forma gráfica, como é o caso da estimativa da PDF, assim como o resto dos gráficos geradas pelo sistema.

\footnotetext{
${ }^{2}$ http://www.gnuplot.info/
} 
A PDF no presente trabalho é estimada usando uma abordagem semiparamétrica baseada em GMM. Dada a importância da estimativa da PDF é imprescindível verificar esta aproximação, para ter certeza da veracidade dos resultados. Com a finalidade de verificar a exatidão e a confiança do cálculo da PDF baseada em GMM, a PDF é também estimada usando uma abordagem não-paramétrica baseada no cálculo do histograma do sinal.

Uma abordagem computacional é proposta para estimar o histograma com tamanho de célula fixa. Como se mostra na Figura 3.4, as entradas necessárias para construir o histograma são o sinal pré-processado e o número de células. A partir do cálculo da frequência de aparição de cada amostra do sinal é construído, de forma iterativa, o vetor que contém as probabilidades de ocorrência das amostras. O histograma será normalizado para que a soma sob a curva seja 1.

Neste módulo, também é implementado um procedimento para extrair a envoltória da mistura. Esta aproximação constitui outra das saídas do módulo PDF. Com a finalidade de avaliar a estimativa da PDF baseada em mistura de gaussianas, a envoltória da mistura é usada para compará-la com o histograma calculado. Esta comparação se realiza através do cálculo do erro quadrático médio (EQM). O histograma e o EQM também formam parte das saídas do módulo PDF, como se ilustra na Figura 3.4.

\section{Módulo Medida}

No presente trabalho a divergência KL é proposta para medir similaridade entre modelos baseados em misturas de gaussianas. O módulo Medida é o encarregado para procurar similaridades ou diferenças entre as misturas, usando este coeficiente. A saída do módulo é a matriz de distância baseada na divergência KL. A Figura 3.5 mostra o procedimento adotado neste bloco.

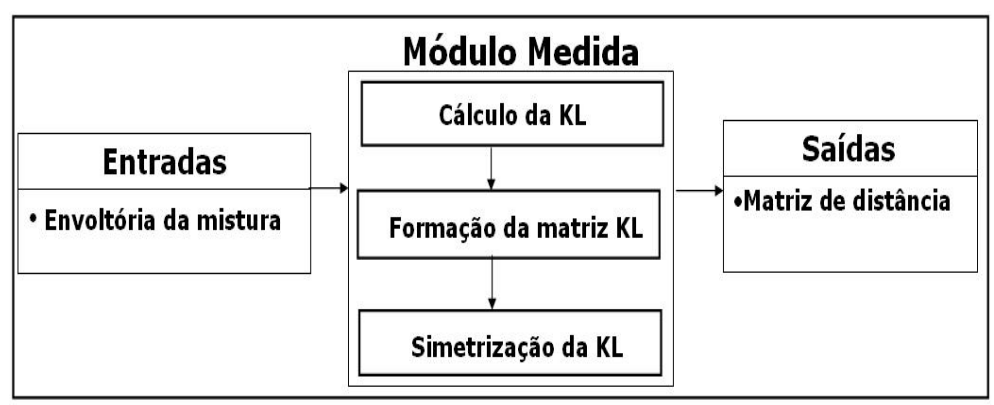

Figura 3.5: Operações do módulo responsável por estimar as similaridades entre as misturas e construir a matriz de distância.

Estimar a divergência KL entre GMM é um problema que não é analiticamente tratado. 
Devido a este inconveniente a solução não é trivial. Na Subseção 2.5.2, foram comentadas algumas das soluções para esta problemática. Neste trabalho, propõe-se construir um método computacional que estime a divergência KL entre dois modelos baseados em misturas de gaussianas, utilizando a envoltória da mistura.

No módulo PDF, é calculada a envoltória da mistura de gaussianas. Esta envoltória é representada por um vetor, o qual é empregado para estimar a divergência KL. Os vetores $f(x)$ e $g(x)$ constituem as envoltórias de duas misturas. Cada um destes vetores são divididos em um reticulado com $i$ células igualmente espaçadas $\Delta i$. Em cada célula se considera a ocorrência $f\left(x_{i}\right)$ e $g\left(x_{i}\right)$ de cada vetor $f(x)$ e $g(x)$ respectivamente. Reescrevendo a Equação 2.10, a divergência KL é calculada usando as envoltórias como se mostra na Equação 3.3.

$$
D(f \| g)=\sum_{i=0}^{N} f\left(x_{i}\right) \log \frac{f\left(x_{i}\right)}{g\left(x_{i}\right)}
$$

em que $N$ é o número total de células.

Para atender às limitações da divergência KL, comentadas em Haubold e Kender (2008) todas as envoltórias das misturas foram construídas com o mesmo número de amostras e o comprimento dos vetores se consideram adequados para realizar este cálculo.

De acordo com a Figura 3.5, a principal entrada deste módulo é um conjunto de vetores que representam as envoltórias das PDFs, as quais foram estimadas no módulo PDF. Usando a Equação 3.3, calcula-se a divergência KL entre todos estes vetores de entrada e de forma iterativa estes valores são agrupados em uma matriz quadrada não simétrica, chamada de matriz KL. O número máximo de linhas e colunas desta matriz corresponde ao total de vetores recebidos como entrada. O cálculo da divergência KL, utilizando as envoltórias das misturas, cumpre com as propriedades desta divergência, que foram mencionadas na Seção 2.5, obtendo uma matriz assimétrica, com todos os valores positivos e os elementos da diagonal principal iguais a zero.

Na Seção 2.5.1 foram comentados alguns dos trabalhos dedicados a procurar funções para simetrizar a divergência KL. Comparando as diversas técnicas que têm sido propostas, é possível distinguir vantagens entre elas, além de identificar algumas limitações. A função J-divergence, definida na Equação 2.12, é uma das mais comuns na literatura, apesar de calcular uma das piores aproximações. Em Sepúlveda et al. (2010) é utilizada esta função para simetrizar a divergência, destacando que fixar o valor de $\eta=1 / 2$ é satisfatório sempre que 
a matriz KL seja quase simétrica, caso contrário, os resultados de aproximação poderiam ser inadequados.

Dentre as funções estudadas a única que cumpre com as três propriedades fundamentais da divergência KL é a função resistor-average, definida pela Equação 2.16. Considerando a exatidão na estimativa, este método é comparado com a distância de Chernoff, avaliada nos textos, como o método que consegue a melhor aproximação. Além disso, a operação resistoraverage é simples de calcular em termos computacionais. Por estas razões a adotamos como critério de simetrização da divergência KL. Neste módulo, após o cálculo da matriz KL, é usada a função resistor average para simetrizar esta matriz, obtendo finalmente uma verdadeira matriz de distância, que constitui a saída fundamental do módulo.

\section{Módulo Agrupamento}

O objetivo deste módulo é construir uma estrutura que evidencia as possíveis relações entre as palavras. Para isso, decidiu-se implementar um algoritmo baseado em agrupamento hierárquico. Este módulo foi desenvolvido em Matlab, empregando as funções que esta ferramenta disponibiliza. $\mathrm{O}$ algoritmo de agrupamento implementado segue o mesmo procedimento mostrado no Algoritmo 1. Seguindo as especificações do Algoritmo 1, neste estudo os elementos que se desejam agrupar são as PDFs estimadas no módulo PDF e a matriz entre os elementos é formada mediante a estimativa da divergência KL. Para medir a distância entre os grupos é usada a função $Z=\operatorname{linkage}(y$, methods) do matlab, em que $y$ é a matriz KL entre as PDFs e methods é o método de ligação média, comentado na Subseção 2.6. A escolha do método de ligação média está relacionada ao fato dele ser um método estável que apresenta bons resultados tanto para distância Euclidiana quanto para outros tipos de distância, além de ser uma alternativa intermediaria entre os métodos de ligação por vizinho mais distante e ligação por vizinho mais próximo. As relações entre os modelos baseados em mistura de gaussianas são ilustradas através de dendrogramas.

\subsection{Experimentos}

Para realizar os experimentos foram construídos sinais simulados com o objetivo de verificar os métodos implementados. Foi priorizado o planejamento de experimentos para testar o funcionamento do algoritmo EM e consequentemente a estimativa da PDF, devido a importância desta aproximação no algoritmo geral. O modelo baseado em GMM também foi testado 
comparando-o com o histograma, através do EQM, da divergência KL e de outras medidas de distância que foram propostas. Para avaliar a estimativa da divergência KL foram calculadas as medidas de distância mais comuns em aplicações dedicadas ao processamento de sinais de fala, por exemplo, a distância Bhattacharyya. A seguir são detalhados cada um dos experimentos realizados.

\subsubsection{Experimentos na estimativa de PDF}

Considerando uma variável aleatória $X$, que foi gerada a partir da mistura de duas distribuições gaussianas, $X-N\left(m_{1}, \sigma_{1}\right)+N\left(m_{2}, \sigma_{2}\right)$, neste estudo foram realizados três experimentos com o objetivo de avaliar a qualidade da PDF estimada, baseado em GMM e usando EM. O algoritmo foi testado quando as componentes da mistura estão "bem superpostas", "bem separadas"e "moderadamente separadas". Estes experimentos baseiam-se nos testes realizados em Marques (2009). O primeiro experimento considerou os seguintes parâmetros para gerar o sinal simulado,

$$
m_{1}=5, m_{2}=15, \sigma_{1}=3, \sigma_{2}=4, p_{1}=0.5, p_{2}=0.5,
$$

O segundo experimento considerou os seguintes parâmetros,

$$
m_{1}=5, m_{2}=40, \sigma_{1}=3, \sigma_{2}=4, p_{1}=0.5, p_{2}=0.5,
$$

O último experimento considerou os seguintes parâmetros,

$$
m_{1}=5, m_{2}=20, \sigma_{1}=3, \sigma_{2}=4, p_{1}=0.5, p_{2}=0.5 .
$$

Cada simulação teve 1000 repetições, no caso de não atingir o critério de parada de $10^{-5}$. Os três experimentos foram simulados com amostras de tamanho 500, 1000 e 5000. Na Figura 3.6, são mostrados os histogramas dos sinais com 1000 amostras gerados a partir da mistura de duas distribuições normais descritas pelos parâmetros especificados anteriormente.

A partir da mistura de duas gaussianas obtida em cada experimento, o método da estimativa da PDF foi avaliado em 3 aspectos:

1) Analise dos parâmetros calculados, isto foi realizado observando os valores obtidos para cada parâmetro, média, desvio padrão e probabilidade de ocorrência das gaussianas esti- 

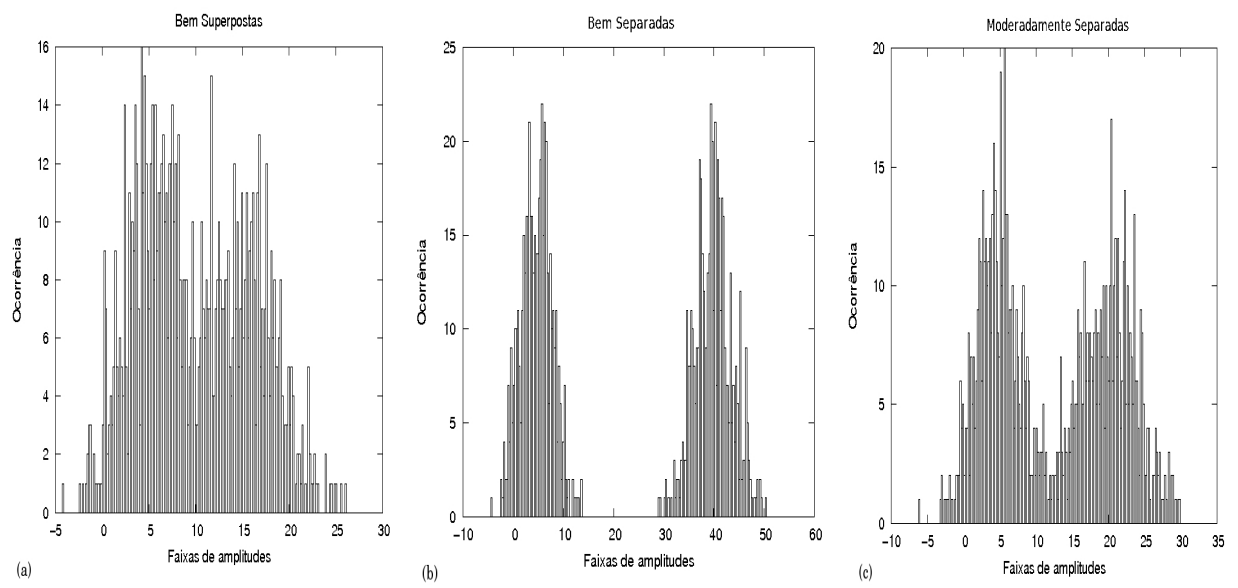

Figura 3.6: Histograma dos sinais gerados a partir de duas distribuições gaussianas. (a) Histograma do primeiro experimento (Bem Superpostas). (b) Histograma do segundo experimento (Bem Separadas). (c) Histograma do terceiro experimento (Moderadamente Separadas).

madas em cada um dos experimentos elaborados.

2) Avaliação do número de gaussianas que integram a mistura, aqui se usou o critério BIC (Bayesian Information Criterion) (Schwarz, 1978). Este critério é proposto para avaliar a quantidade de componentes gaussianos que deveriam caracterizar a mistura. $\mathrm{O}$ modelo que apresentar maior BIC será aquele que melhor modelará o sinal de fala. O BIC para uma mistura $f(X, \Theta)$ é definido como:

$$
B I C_{f(X, \Theta)}=2 \lambda(X, \Theta)-K \log (N)
$$

em que $\lambda(X, \Theta)$ é o logaritmo da verossimilhança da mistura $f(X, \Theta)$, $K$ é o número máximo de gaussianas presentes no modelo, enquanto $N$ é o comprimento do sinal.

3) Comparação com a PDF estimada usando o método do histograma. A construção do histograma é outro dos métodos empregados para avaliar a estimativa do GMM. Usando o EQM as duas aproximações são comparadas. Quanto menor for o valor do erro, melhor serão as estimativas. Também se propõe comparar o histograma e o GMM calculando a divergência KL. Espera-se que se as duas estimativas forem bem parecidas, o valor obtido seja próximo de zero. Usar a KL como critério de validação não só é útil para comprovar a aproximação dos modelos, como também serve para verificar se o método proposto para o cálculo desta divergência cumpre com as propriedades de identificação e de similaridade da KL, comentadas na Subseção 2.5. 


\subsubsection{Experimentos do cálculo da distância entre os modelos}

A divergência KL é responsável neste trabalho pela estimativa das similaridades entre os modelos aproximados. Por esse motivo é necessário ter certeza da qualidade do método proposto. Um dos fatores de interesse para avaliar os resultados gerados a partir do método que estima a KL é o cumprimento das propriedades desta divergência. Observar a matriz de distância obtida em cada execução do algoritmo serve para verificar se o método implementado cumpre com estas propriedades. Outro fator para avaliar o cálculo desta divergência consiste em comprovar a exatidão dos resultados e consequentemente os agrupamentos obtidos para cada conjunto de palavras.

No algoritmo de agrupamento, as relações entre os modelos são obtidas a partir da matriz de distância baseada na divergência KL. Estas relações, mostradas através dos dendrogramas, poderiam ser produto da métrica de distância empregada para avaliar as semelhanças entre os modelos, ou poderiam estar sujeitas aos modelos que foram estimados e que representam as PDFs das palavras. Por isso, propõe-se calcular a distância entre as PDFs baseadas em GMM empregando algumas das métricas de distância apresentadas na literatura, além da divergência KL. Desta forma, as relações entre as palavras estariam sujeitas a um conjunto de medidas de distância e não somente a divergência KL. Estas métricas poderiam confirmar a classificação realizada pela divergência KL, além de oferecer novas relações. Procura-se empregar medidas que tenham sido utilizadas em aplicações similares as abordadas no presente trabalho, sem considerar as medidas tradicionais, cujas limitações foram mencionadas na Seção 2.4.

Embora existam diversas medidas de distância, as métricas mais empregadas para sinais de fala são a distância Bhattacharyya e a distância KL (Jensen et al., 2007; Sfikas et al., 2005; Goldberger et al., 2003; Salvi, 2003; Johnson e Sinanović, 2001). A distância Bhattacharyya é um caso particular da distância Chernoff. A distância Chernoff é apontada nos textos (Johnson e Sinanović, 2001) como a medida de distância que consegue as aproximações mais exatas. O cálculo desta medida é mostrado na Equação 3.5. O principal problema da distância Chernoff é que ela em termos computacionais é difícil de ser calculada. Por isso, empregam-se outras alternativas como substituição desta medida, daí o uso da distância Bhattacharyya, a qual é definida na Equação 3.6. Pode-se observar que na Equação 3.6 o parâmetro $t$ é igual a 1/2. Em Pereira et al. (2004) as duas métricas anteriores foram testadas quanto à proximidade de seus resultados e foi verificado, empiricamente, que realmente a Bhattacharyya é uma aproximação adequada da Chernoff. Em Salvi (2003) a distância de Bhattacharyya é utilizada como critério 
comparativo para agrupar as diferentes pronúncias da língua sueca. A distância anterior é também empregada em Sfikas et al. (2005) para medir similaridades entre modelos baseados em mistura de gaussianas que representam as PDFs de diferentes imagens. Seguindo a utilidade da distância Bhattacharyya, neste trabalho é proposta como outra alternativa para avaliar as semelhanças entre as palavras que pertencem às línguas indígenas sob análise.

$$
\begin{gathered}
C(f, g)=\max _{0 \geq t \leq 1}-\log \mu(t), \\
\text { onde } \mu(t)=\sum\left[f\left(x_{i}\right)^{1-t}\right] *\left[g\left(x_{i}\right)^{t}\right] \\
B(f, g)=-\log \mu\left(\frac{1}{2}\right),
\end{gathered}
$$

em que $\mu$ é a função definida na Equação 3.5, que representa a distância de Chernoff.

Além das duas métricas de distância mais comummente empregadas em aplicações de fala, neste estudo se propõe utilizar outras medidas de distância. Em Cha (2007) são apresentadas várias medidas de distância aplicadas para medir similaridade entre PDFs. O autor classificou estas medidas em diferentes grupos seguindo um critério de semelhanças entre as sintaxes das mesmas. Alguns dos grupos identificados em Cha (2007) são: a família Minkowski, a família de acordes quadrados (em inglês, Squared-chord family), a família Chi-quadrado e a família entropia de Shannon. Na família Minkowski estão incluídas a distância Euclidiana e a Manhattan, além de outras funções. A distância Bhattacharyya está incluída na família de acordes quadrados. A família entropia de Shannon agrupa medidas relacionados com o conceito de incerteza probabilística de Shannon. Uma das medidas deste grupo é a divergência KL, além da divergência Jensen-Shannon que será empregada no presente trabalho para medir similaridade entre as PDFs. A divergência de Jensen-Shannon é uma medida simétrica e positiva que pode ser interpretada como a distância média entre duas PDFs. A Equação 3.7 mostra o cálculo desta divergência. A outra medida que será empregada neste estudo é a divergência Chi-quadrado de Pearson que, como seu nome indica, pertence ao grupo Chi-quadrado. As medidas deste grupo personificam a distância Euclidiana quadrada, sendo a mais importante a divergência Chi-quadrado de Pearson, dado que o resto das divergências são derivações desta. A divergência Chi-quadrado de Pearson não é simétrica e seu cálculo é mostrado na Equação 3.8 . 


$$
\begin{gathered}
D_{j s}(f, g)=\frac{1}{2}\left[\sum_{i=1}^{N} f(x) \log \left(\frac{2 f(x)}{f(x)+g(x)}\right)+\sum_{i=1}^{N} g(x) \log \left(\frac{2 g(x)}{f(x)+g(x)}\right)\right] \\
D_{p}(f, g)=\sum_{i=1}^{N} \frac{(f(x)-g(x))^{2}}{g(x)}
\end{gathered}
$$

Finalmente, a última medida que será implementada neste estudo foi proposta por Sfikas et al. (2005). Em Sfikas et al. (2005) além de utilizar a distância Bhattacharyya e a divergência KL para comparar GMMs que descreviam as PDFs de várias imagens, o autor definiu uma nova medida de distância, chamada distância $\mathrm{C} 2$ e definida na Equação 3.9. Esta métrica é zero quando $f(x)$ e $g(x)$ são iguais, é simétrica e positiva. A distância C2 é a última medida de distância que será utilizada neste estudo para mostrar as relações entre as palavras das línguas indígenas brasileiras.

$$
C 2(f, g)=-\log \frac{2 \sum_{i=0}^{N} f(x) g(x)}{\sum_{i=0}^{N} f(x)^{2}+g(x)^{2}} .
$$

As métricas mencionadas anteriormente serão estimadas empregando a envoltória da mistura e seguindo o mesmo procedimento definido para a divergência KL. No caso da divergência Chi-quadrado de Pearson, que não é simétrica, será simetrizada utilizando a mesma função definida para a divergência KL. Espera-se que os resultados obtidos com a distância JensenShannon sejam similares aos da divergência KL, isso pelo fato destas duas medidas pertencerem à mesma família. Já os resultados alcançados com as medidas Chi-quadrado de Pearson, Bhattacharyya e C2 poderiam ser diferentes. Após definidos os critérios de similaridade entre os modelos, no próximo capítulo serão mostrados os resultados alcançados. 


\section{Capítulo 4}

\section{Resultados e Discussões}

Neste capítulo, são mostrados os resultados obtidos a partir do algoritmo implementado. Primeiramente, são apresentados os resultados proporcionados pelos sinais simulados. Estes sinais junto com os ensaios preparados foram definidos no Capítulo 3. Na segunda parte do capítulo são apresentados os resultados fornecidos a partir da análise do conjunto de palavras que pertencem às línguas indígenas brasileiras. Nestes resultados são incluídas as estimativas da PDF baseada em mistura de gaussianas de cada palavra, além de mostrar as relações encontradas entre os diferentes modelos calculados. Estes resultados estão sujeitos ao algoritmo implementado e se consideram inconclusivos e não refutam nenhuma das classificações feitas pelos linguistas na literatura. Nosso objetivo é mostrar possíveis relações entre os modelos estimados.

\subsection{Resultados dos sinais simulados}

Todas as simulações foram desenvolvidas usando o algoritmo construído no presente trabalho. Nos experimentos definidos na Seção 3.3, geraram-se vários sinais aleatórios a partir de duas misturas de gaussianas, especificadas por diferentes parâmetros. Na Figura 3.6 são ilustrados os histogramas dos sinais aleatórios com tamanho de 1000 amostras, os quais foram calculados em cada um dos 3 ensaios. Estes sinais serão empregados nesta seção para descrever os resultados alcançados. Depois da execução dos experimentos, verificou-se que os parâmetros estimados utilizando o algoritmo EM são próximos dos parâmetros originais. $\mathrm{Na}$ implementação do algoritmo EM foram consideradas suas principais limitações: a inicialização dos parâmetros, o critério de convergência e a condição de parada. Em geral, comprovou-se 
que os melhores resultados foram obtidos com aqueles sinais que apresentavam maior número de amostras. Mas os ensaios preparados com amostras de tamanho 500, 1000 e 5000, apresentaram resultados próximos dos parâmetros reais.

Os parâmetros definidos para descrever cada gaussiana que integra a mistura são a média, o desvio padrão e a probabilidade de ocorrência. Estes parâmetros, calculados por meio do algoritmo EM, são ilustrados na Tabela 4.1. Nela são observados os parâmetros originais para cada experimento, seguidos dos valores aproximados para todas as misturas estimadas. Os valores obtidos são muito próximos dos seus respectivos parâmetros originais, tanto nas amostras menores quanto nas maiores. Após uma análise detalhada, percebe-se que os melhores resultados foram fornecidos com sinais de comprimento 1000 e 5000. A melhor estimativa foi alcançada para componentes gaussianas, moderadamente separadas e bem separadas.

Tabela 4.1: Parâmetros (Média, desvio padrão e probabilidade de ocorrência) estimados para cada gaussiana que integra a mistura dos sinais simulados de comprimento igual a 1000 amostras, nos 3 experimentos desenvolvidos.

\begin{tabular}{r|r|r|r|r|r|r}
\hline & \multicolumn{7}{|c}{ Experimento 1 } \\
\hline \hline Comprimento & $m_{1}=5$ & $m_{2}=15$ & $\sigma_{1}=3$ & $\sigma_{2}=4$ & $p_{1}=0,5$ & $p_{2}=0,5$ \\
\hline 500 & 4,91 & 15,26 & 3,07 & 4,56 & 0,51 & 0,48 \\
\hline 1000 & 5,13 & 14,95 & 2,96 & 3,96 & 0,49 & 0,5 \\
\hline 5000 & 4,98 & 14,67 & 2,89 & 4,09 & 0,48 & 0,51 \\
\hline & \multicolumn{7}{|c}{ Experimento 2 } \\
\hline \hline Comprimento & $m_{1}=5$ & $m_{2}=40$ & $\sigma_{1}=3$ & $\sigma_{2}=4$ & $p_{1}=0,5$ & $p_{2}=0,5$ \\
\hline 500 & 4,96 & 39,96 & 3 & 4,04 & 0,5 & 0,5 \\
\hline 1000 & 4,72 & 39,95 & 3,1 & 3,74 & 0,5 & 0,5 \\
\hline 5000 & 5,02 & 40,13 & 2,97 & 3,98 & 0,5 & 0,5 \\
\hline \multicolumn{7}{|c|}{ Experimento 3 } \\
\hline Comprimento & $m_{1}=5$ & $m_{2}=20$ & $\sigma_{1}=3$ & $\sigma_{2}=4$ & $p_{1}=0,5$ & $p_{2}=0,5$ \\
\hline 500 & 4,79 & 19,66 & 2,74 & 4,24 & 0,48 & 0,51 \\
\hline 1000 & 4,7 & 20,02 & 3,01 & 3,99 & 0,49 & 0,5 \\
\hline 5000 & 4,89 & 20,03 & 2,94 & 3,86 & 0,49 & 0,5 \\
\hline \multicolumn{7}{|c|}{}
\end{tabular}

Na parte a) da Figura 4.1, são ilustradas as PDFs, baseadas em mistura de gaussianas, obtidas para cada um dos sinais simulados, de comprimento 1000 amostras. Estas PDFs foram construídas a partir dos parâmetros calculados usando o algoritmo EM, os quais se observam na Tabela 4.1. Cada gráfico desta figura mostra claramente as duas componentes gaussianas que geraram o sinal original, assim como os parâmetros que as descrevem. Com o objetivo de verificar visualmente as semelhanças entre o histograma e a envoltória da PDF dos sinais aleatórios, na parte b) da Figura 4.1, são mostrados os histogramas e as curvas que representam 
a envoltória dos três modelos estimados. Esta figura indica que as curvas das envoltórias, ficaram bem ajustadas aos respectivos histogramas.

O cálculo da PDF, baseada em mistura de gaussianas, foi avaliada usando o EQM, a divergência KL, a distância Chi-quadrado de Pearson, a distância Bhattacharyya, a distância C2 e a divergência Jensen-Shannon. Estas métricas são estimadas entre o histograma e a envoltória dos sinais simulados com o objetivo de corroborar o ajuste das misturas com seus respectivos histogramas, além de avaliar o cumprimento da propriedade de similaridade das medidas de distância propostas. A Tabela 4.2 apresenta o cálculo das medidas de distância e do EQM entre as duas estimativas anteriores. Os melhores ajustes foram alcançados com a distância de Bhattacharyya, com a divergência KL e com o EQM, enquanto o pior ajuste foi o da divergência Chi-quadrado de Pearson. Os valores obtidos para cada medida indicam que a curva da envoltória da mistura se ajusta satisfatoriamente ao histograma dos dados, mostrando que as duas abordagens utilizadas para estimar a PDF dos sinais, geram resultados similares, o que é confirmado observando a parte b) da Figura 4.1.

Tabela 4.2: Valores do erro quadrático médio, da divergência KL, da distância de Bhattacharyya, da divergência Chi-quadrado de Pearson, da distância Jensen-Shannon e da distância C2 entre o histograma e a envoltória da mistura, obtidos pelo sistema implementado neste trabalho.

\begin{tabular}{c|c|c|c}
\hline & Bem Superpostas & Bem Separadas & Moderadamente Separadas \\
\hline \hline EMQ & $5,63 * \mathrm{e}-6$ & $4,91 * \mathrm{e}-6$ & $4,63 * \mathrm{e}-6$ \\
\hline KL & 0,038 & 0,04 & 0,041 \\
\hline Bhattacharyya & 0,030 & 0,026 & 0,027 \\
\hline Chi-quadrado de Pearson & 0,17 & 0,14 & 0,14 \\
\hline Jensen-Shannon & 0,059 & 0,050 & 0,052 \\
\hline C2 & 0,087 & 0,068 & 0,084 \\
\hline
\end{tabular}

Com o objetivo de determinar o número ótimo de gaussianas que integram a mistura que melhor descreve o sinal foi selecionado o critério BIC. A Figura 4.2 mostra a curva do BIC resultante para as misturas dos sinais simulados, usados como exemplo nesta seção. Nesta figura, pode-se observar que o máximo valor do BIC correspondente ao modelo gerado a partir de duas gaussianas é exatamente 2. Este resultado confirma a estimativa da PDF, baseada em GMM e a eficiência do algoritmo EM na aproximação dos parâmetros. 
(a)

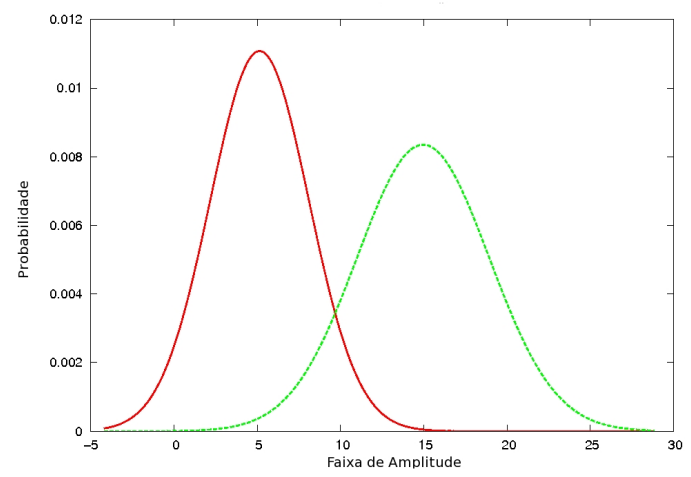

(b)

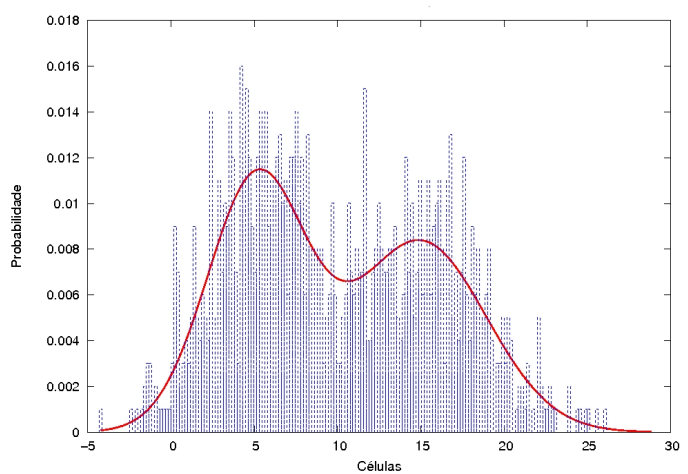

Experimento 2-Bem Separadas $\left(m_{1}=5, m_{2}=40\right)$
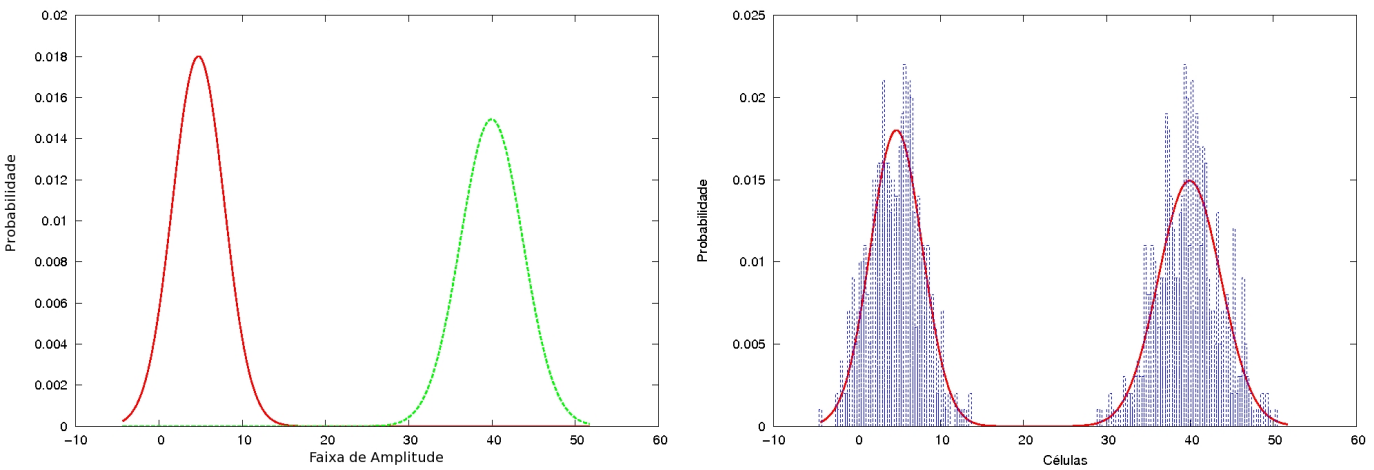

Experimento 3-Moderadamente Separadas $\left(m_{1}=5, m_{2}=20\right)$
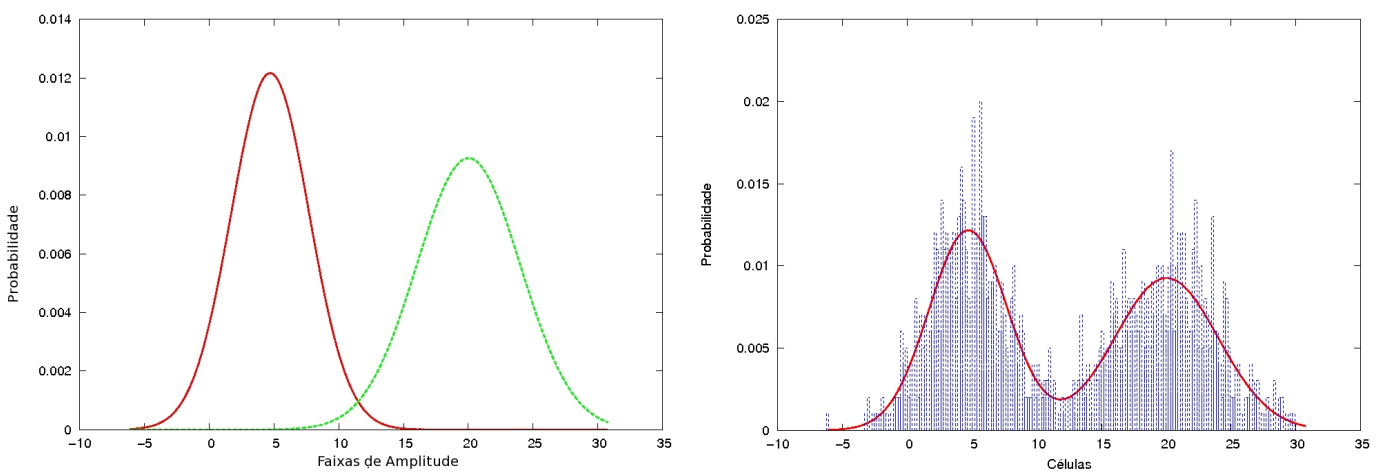

Figura 4.1: Estimativa da PDF baseada em GMM, envoltória da mistura e o histograma dos sinais simulados de comprimento 1000 amostras, gerados em cada um dos experimentos desenvolvidos. (a)Estimativa da PDF baseada em GMM. (b) Envoltória da mistura e histograma do sinal gerado. 


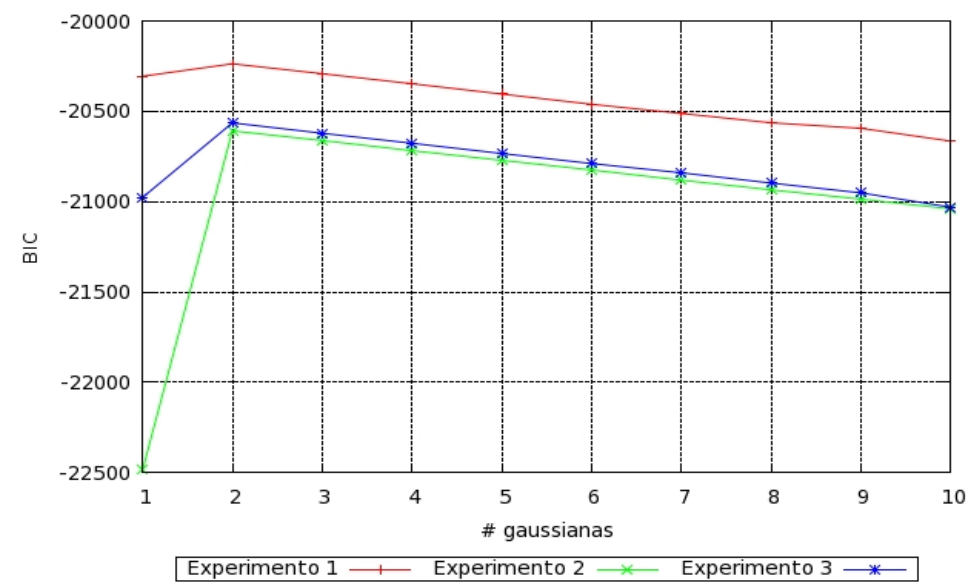

Figura 4.2: Evolução do critério BIC na seleção do número ótimo de gaussianas que integram a mistura dos sinais simulados.

\subsection{Resultados das palavras das línguas indígenas.}

\section{Resultados da estimativa da PDF}

A PDF das palavras pertencentes às línguas indígenas brasileiras foi estimada usando uma mistura de gaussianas. Esta mistura é construída mediante o algoritmo EM, que é inicializado de forma diferente para cada um dos sinais. O número total de gaussianas, que integram a mistura, é estimado pelo algoritmo para cada palavra, obtendo o modelo que melhor descreve a PDF do sinal. Em geral, este número está incidindo na faixa de 6 a 15 componentes, tendo maior ocorrência os modelos caracterizados por 7 ou 9 gaussianas. $\mathrm{O}$ algoritmo EM reconhece o modelo que melhor descreve a PDF do sinal através do cálculo do coeficiente de verossimilhança. Após a estimativa deste modelo é empregado o critério BIC com a finalidade de avaliar o número total de gaussianas que deve caracterizar o modelo estimado. Desta forma, existe outra medida para conferir a veracidade da PDF estimada.

Nas Figuras 4.3, 4.4, 4.5, 4.6, 4.7 e 4.8, são mostradas as PDFs estimadas para cada uma das palavras analisadas. Em cada figura se observa a PDF de uma mesma palavra, dita pelas 10 línguas indígenas escolhidas. Por exemplo, a Figura 4.3 mostra a PDF, baseada em GMM, da palavra água, falada nas 10 línguas diferentes. Nas Figuras 4.3, 4.4, 4.5, 4.6, 4.7 e 4.8, percebese que cada mistura é identificada por um número e pelo nome da língua na qual pertence a palavra. Este número foi definido na Tabela 3.1 e foi utilizado no algoritmo para identificar cada uma das línguas estudadas. Além das misturas de gaussianas, nestes gráficos, mostram-se as envoltórias de cada PDF, isso para ter uma ideia geral da forma que segue cada estimativa. 

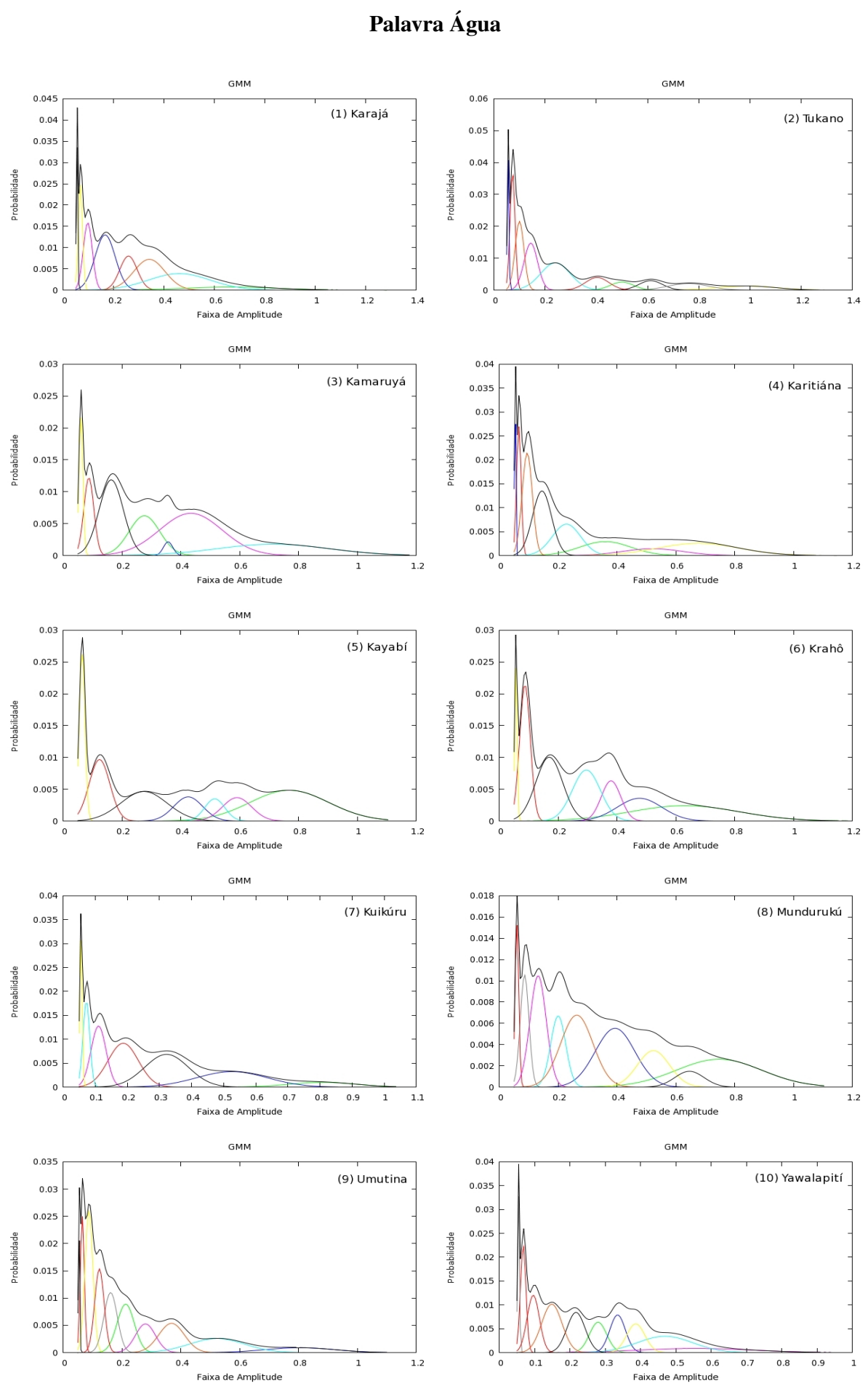

Figura 4.3: Estimativa da PDF baseada em GMM da palavra água, dita em 10 línguas indígenas diferentes. Estas línguas estão incluídas na base de dados do Museu do Índio e foram mencionadas na Seção 3.1. Cada PDF está identificada por um número, que se corresponde com o número definido no Quadro 3.1 e pelo nome da língua. 
Palavra Criança
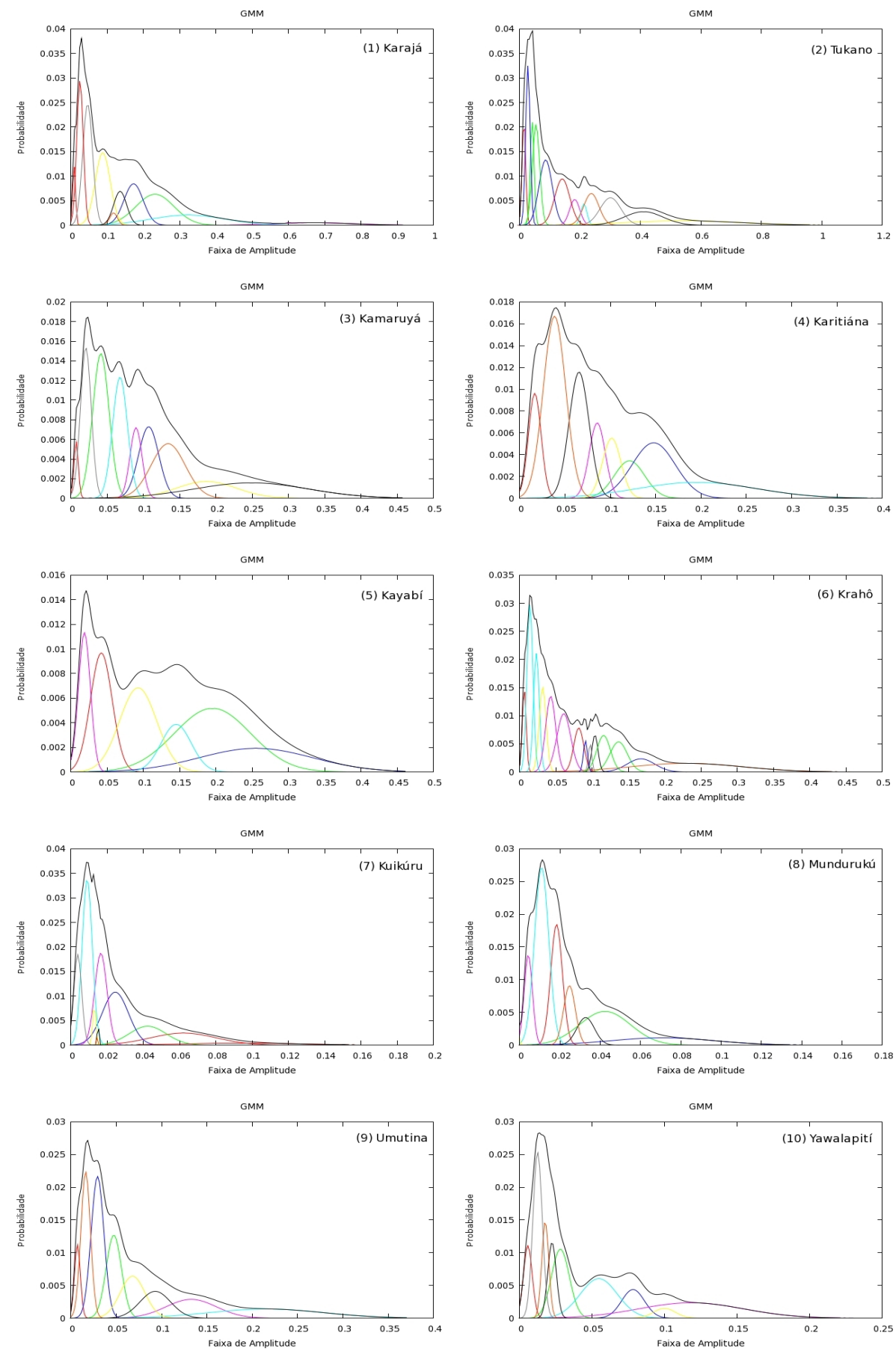

Figura 4.4: Estimativa da PDF baseada em GMM da palavra criança, dita em 10 línguas indígenas diferentes. Estas línguas estão incluídas na base de dados do Museu do Índio e foram mencionadas na Seção 3.1. Cada PDF está identificada por um número, que se corresponde com o número definido no Quadro 3.1 e pelo nome da língua. 


\section{Palavra Fogo}
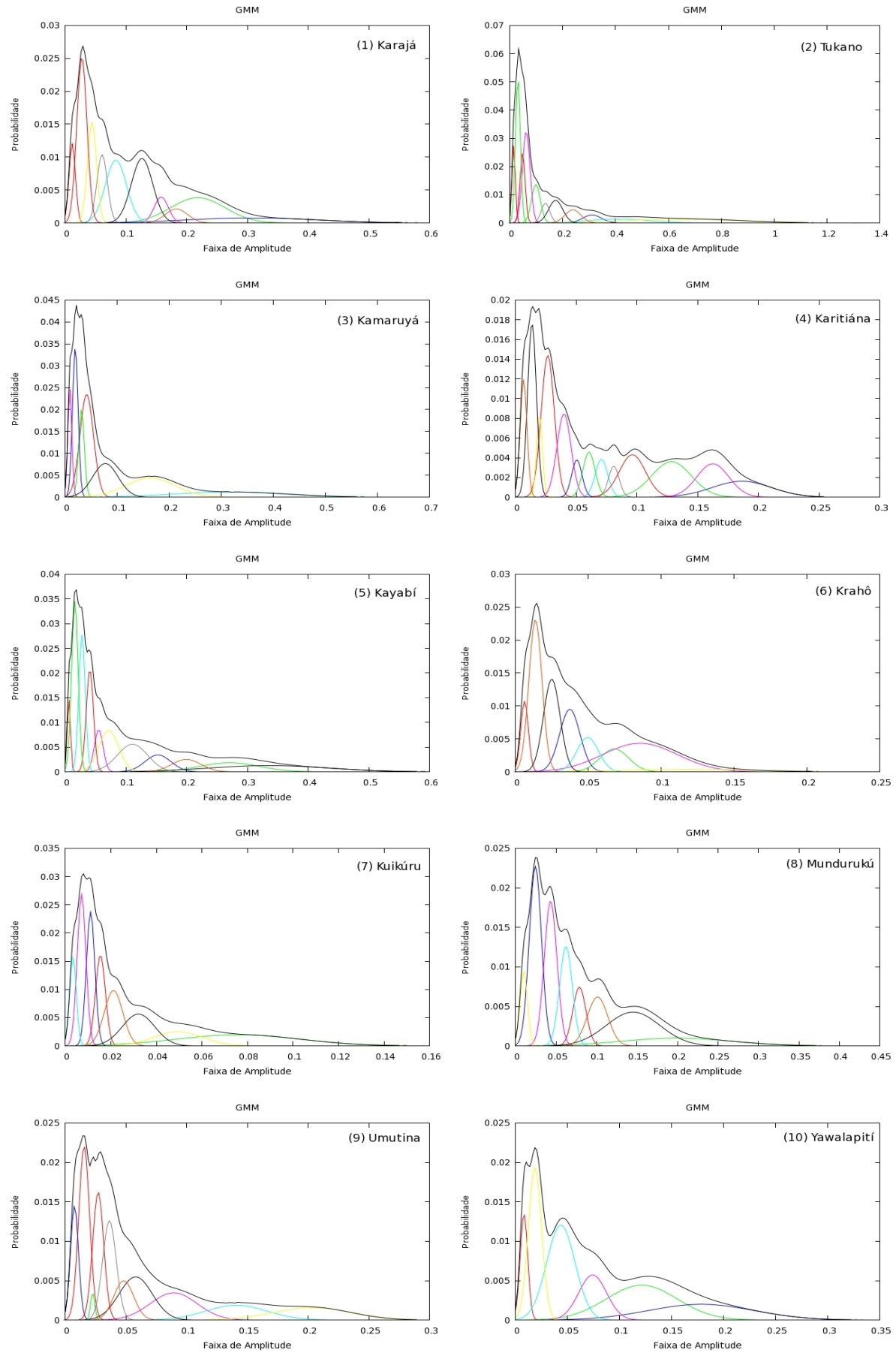

Figura 4.5: Estimativa da PDF baseada em GMM da palavra fogo, dita em 10 línguas indígenas diferentes. Estas línguas estão incluídas na base de dados do Museu do Índio e foram mencionadas na Seção 3.1. Cada PDF está identificada por um número, que se corresponde com o número definido no Quadro 3.1 e pelo nome da língua. 


\section{Palavra Olho}
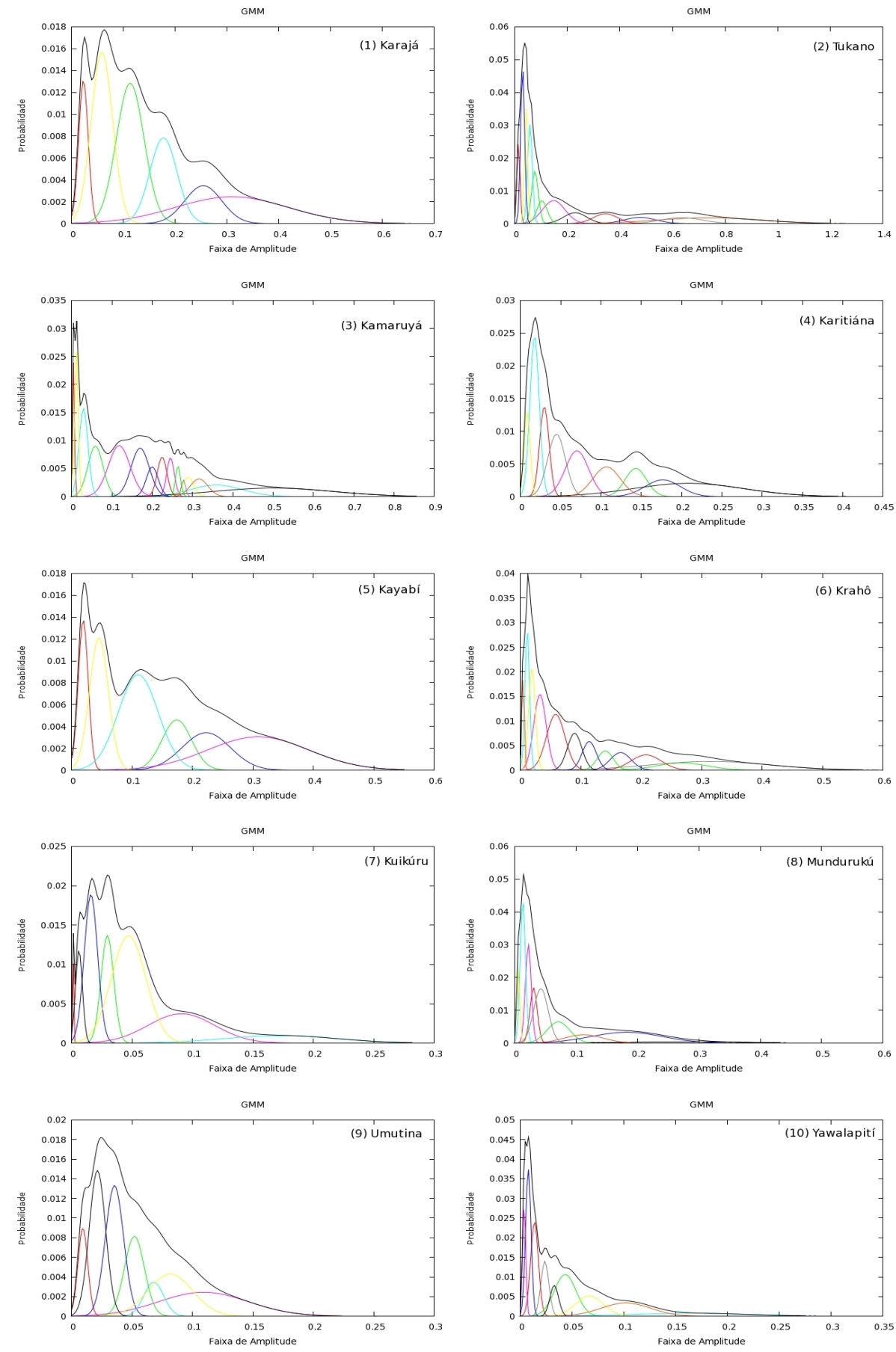

Figura 4.6: Estimativa da PDF baseada em GMM da palavra olho, dita em 10 línguas indígenas diferentes. Estas línguas estão incluídas na base de dados do Museu do Índio e foram mencionadas na Seção 3.1. Cada PDF está identificada por um número, que se corresponde com o número definido no Quadro 3.1 e pelo nome da língua. 
Palavra Osso
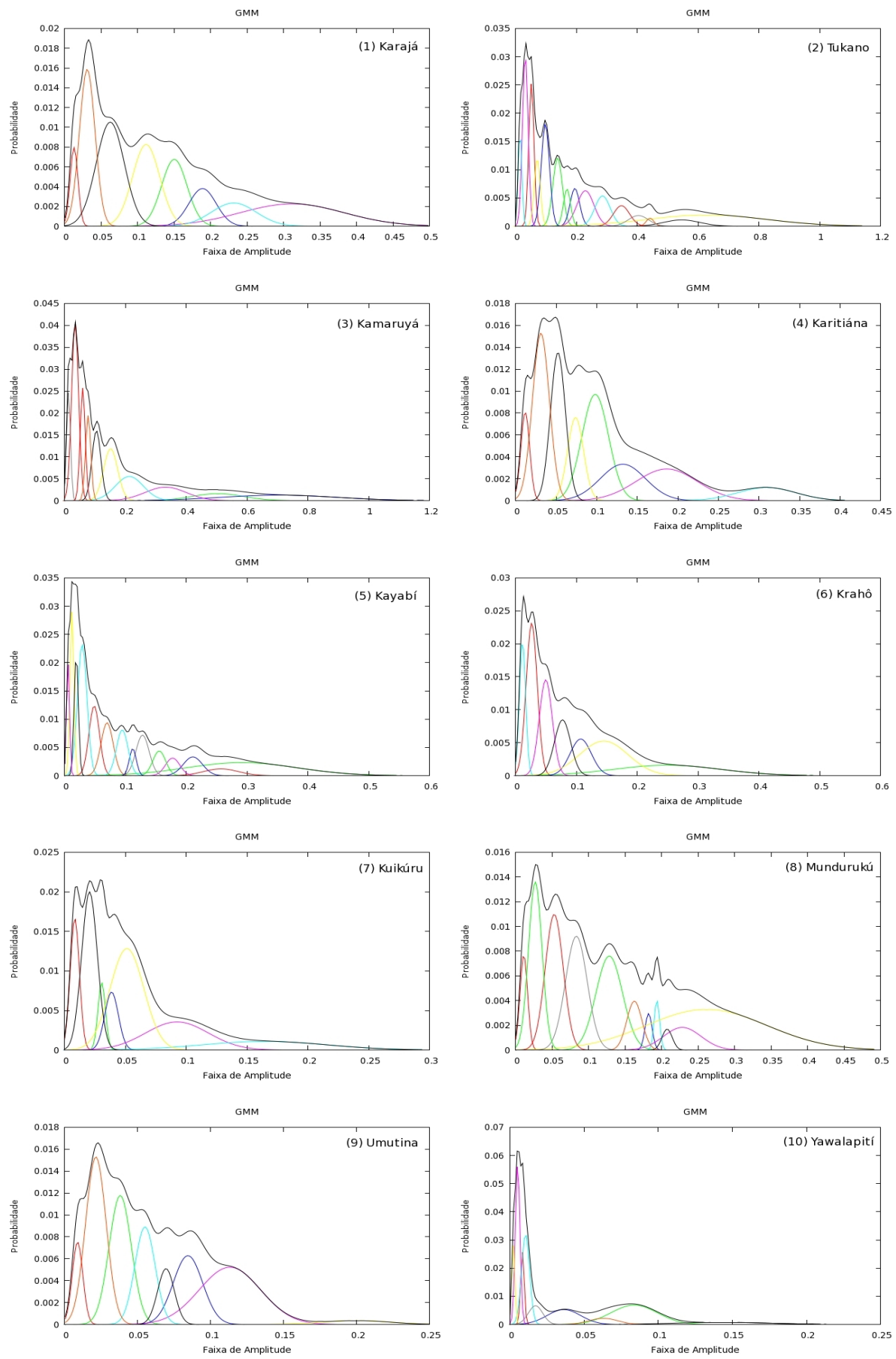

Figura 4.7: Estimativa da PDF baseada em GMM da palavra osso, dita em 10 línguas indígenas diferentes. Estas línguas estão incluídas na base de dados do Museu do Índio e foram mencionadas na Seção 3.1. Cada PDF está identificada por um número, que se corresponde com o número definido no Quadro 3.1 e pelo nome da língua. 


\section{Palavra Sangue}
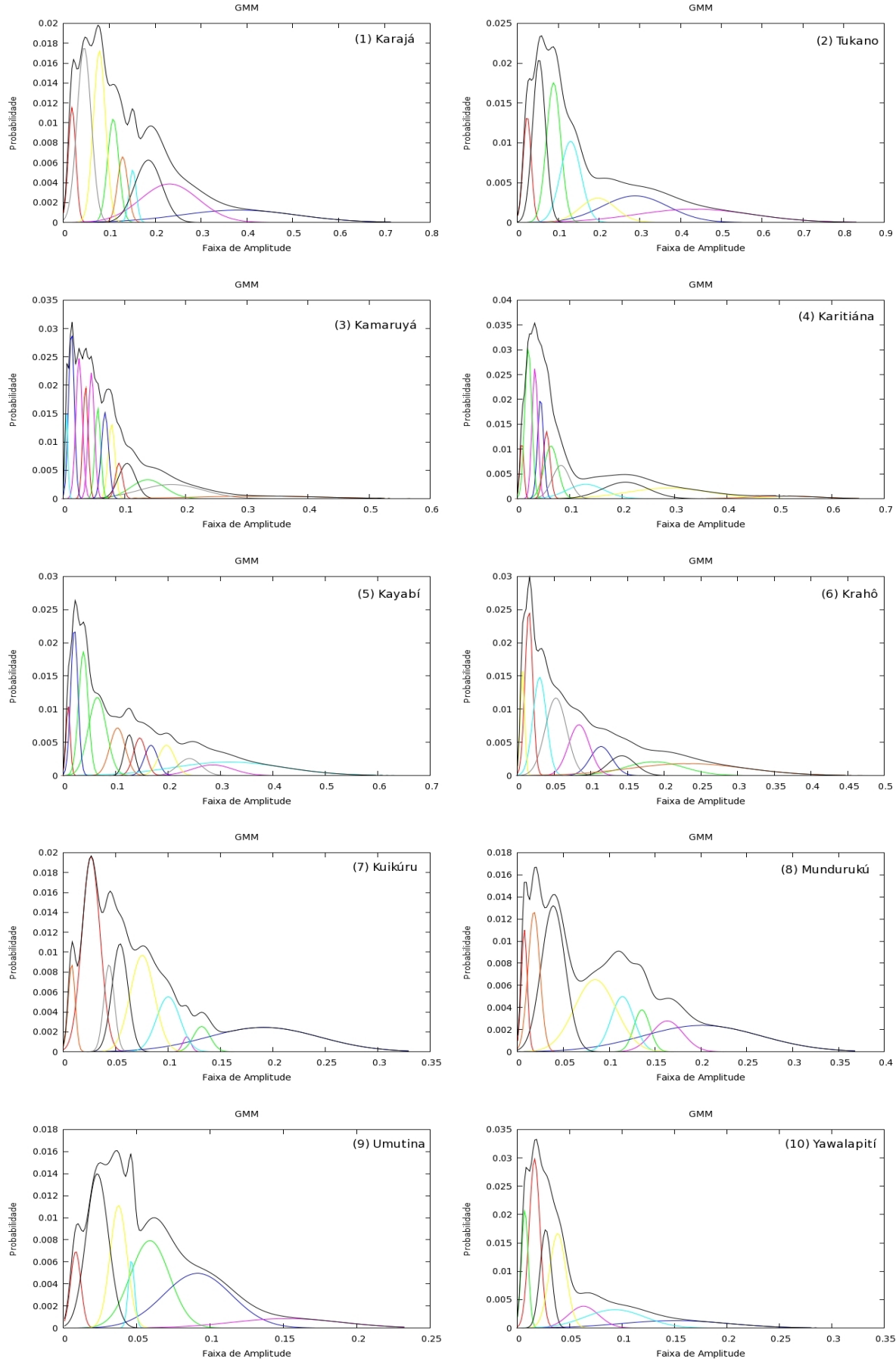

Figura 4.8: Estimativa da PDF baseada em GMM da palavra sangue, dita em 10 línguas indígenas diferentes. Estas línguas estão incluídas na base de dados do Museu do Índio e foram mencionadas na Seção 3.1. Cada PDF está identificada por um número, que se corresponde com o número definido no Quadro 3.1 e pelo nome da língua. 
Além da representação gráfica de cada PDF, outro resultado interessante são os valores dos parâmetros que descrevem cada uma das componentes gaussianas que integram as misturas, contudo não serão colocados no texto, para ganhar claridade na representação dos resultados. Os experimentos desenvolvidos com sinais simulados, na Seção 4.1, confirmam que o método implementado consegue estimar parâmetros próximos aos originais de cada gaussiana. A partir deste resultado e supondo que os sinais que descrevem as palavras indígenas foram gerados por um processo aleatório que combinava um conjunto de funções gaussianas, considera-se que as estimativas das PDF, dos sinais empregados como análise, também proporcionem valores próximos dos originais.

Similarmente aos sinais simulados, as PDFs para as palavras analisadas também foram estimadas usando o método de histograma. Esta última estimativa foi comparada com a envoltória da PDF, baseada em GMM. A comparação foi realizada empregando somente, o EQM e a divergência KL. Estas medidas proporcionaram valores do erro na faixa entre $10^{-5}$ e $10^{-6}$, enquanto os valores da divergência KL, foram registrados perto do zero, verificando as similaridades entre as duas estimativas das PDFs.

\section{Resultados das medidas de distância}

Respondendo a um dos principais objetivos do presente trabalho, foi necessário definir um critério para estabelecer as semelhanças entre os modelos estimados. O coeficiente selecionado para medir as similaridades entre os modelos que descrevem um conjunto de palavras foi a divergência KL. Para isso foi implementado um algoritmo de agrupamento, que através de um dendrograma mostra as distâncias entre as PDFs estimadas para cada conjunto de palavras. Dada a dificuldade para calcular a divergência KL entre modelos baseados em mistura de gaussianas, neste trabalho se estima esta métrica usando as envoltórias das misturas. Estas envoltórias são mostradas nas Figuras 4.3, 4.4, 4.5, 4.6, 4.7 e 4.8. O algoritmo de agrupamento proporciona um dendrograma por cada conjunto de palavras. Lembrando que o conjunto de palavras está integrado por uma mesma palavra dita em 10 línguas indígenas diferentes e foi definido na Seção 3.1 .

As Figuras 4.3, 4.4, 4.5, 4.6, 4.7 e 4.8 mostram as PDFs estimadas para as palavras água, criança, fogo, olho, osso e sangue, ditas por 10 línguas diferentes. Os dendrogramas que apresentam as semelhanças entre as PDFs, são mostrados nas Figuras 4.9, 4.10, 4.11, 4.12, 4.13 e 4.14, respectivamente. Os dendrogramas anteriores foram cálculados empregrando a divergência KL. Nestes gráficos de agrupamento, deseja-se ilustrar as misturas que se apresentam 
mais relacionadas, a partir da medida de distância entre elas. As PDFs baseadas em GMM se identificam nos dendrogramas, mediante números. Na Tabela 3.1 se define um número para cada língua ou dialeto indígena e os gráficos das misturas utilizam este número para identificar a língua a qual a palavra pertence.

Observando as Figuras 4.3, 4.4, 4.5, 4.6, 4.7 e 4.8 é possível identificar algumas semelhanças ou diferenças entre as PDFs baseadas em misturas de gaussianas. Após o cálculo dos dendrogramas de cada conjunto de palavras, estas semelhanças e diferenças, são confirmadas. Considera-se que em geral as relações ilustradas nos dendrogramas estão intimamente relacionadas com as formas das misturas, é dizer, relacionadas com a quantidade de componentes gaussianas, assim como com as características dos parâmetros que descrevem cada um dos modelos.

Para avaliar a classificação realizada pelo algoritmo de agrupamento, usando a divergência KL, neste estudo são empregadas as seguintes medidas: a distância Bhattacharyya, a divergência Chi-quadrado de Pearson, a distância Jensen-Shannon e a distância C2. O objetivo de empregar estas medidas de distância é obter diferentes classificações para cada um dos critérios de similaridade propostos que de forma mais robusta permita conhecer se os agrupamentos entre as diferentes palavras dependem das medidas de distância ou dos modelos estimados para cada palavra. Nas Figuras 4.15, 4.16, 4.17, 4.18, 4.19 e 4.20 se mostram os dendrogramas obtidos utilizando a distância Bhattacharyya. Nas Figuras 4.21, 4.22, 4.23, 4.24, 4.25 e 4.26 são observados os agrupamentos alcançados empregando a divergência Chi-quadrado de Pearson. Nas Figuras 4.27, 4.28, 4.29, 4.30, 4.31 e 4.32 se mostram os agrupamentos realizados pela distância Jensen-Shannon. Finalmente, nas Figuras 4.33, 4.34, 4.35, 4.36, 4.37 e 4.38 são mostradas as relações obtidas a partir da distância C2.

Uma observação detalhada dos dendrogramas obtidos para cada uma das medidas de distância confirma que os agrupamentos são similares aos alcançados a partir da divergência KL. A distância que mostrou agrupamentos menos similares foi a distância C2. Por exemplo, nos dendrogramas da palavra criança se identificam semelhanças entre as línguas identificadas pelos números 3 e 4 , no dendrograma da distância C2 para esta palavra se observa que além de agrupar as línguas 3 e 4 a língua 5 foi incluída no agrupamento. Este agrupamento se considera interessante dado que as três línguas pertencem ao mesmo tronco linguístico. Isso também acontece, no caso da palavra olho, em que a única medida que agrupa as línguas 3,4 e 5 é a distância C2. Nos diversos agrupamentos da palavra fogo encontram-se relacionadas as pala- 
Dendrogramas da divergência $\mathrm{KL}$

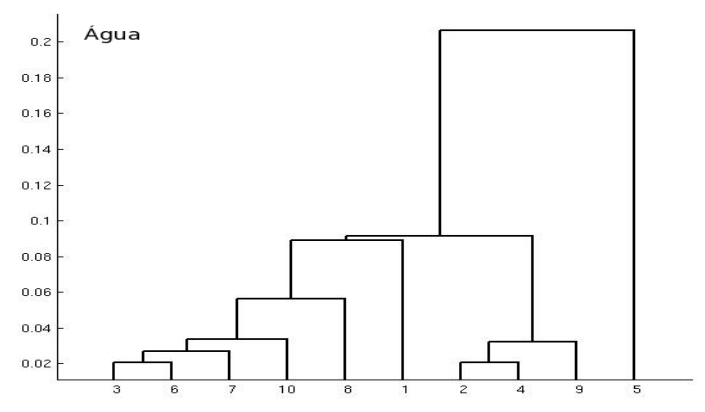

Figura 4.9: Dendrograma que ilustra as relações entre os modelos que integram o lote da palavra água.

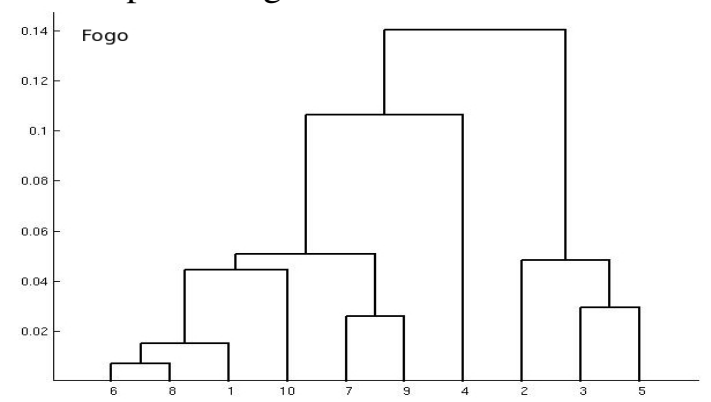

Figura 4.11: Dendrograma que ilustra as relações entre os modelos que integram o lote da palavra fogo.

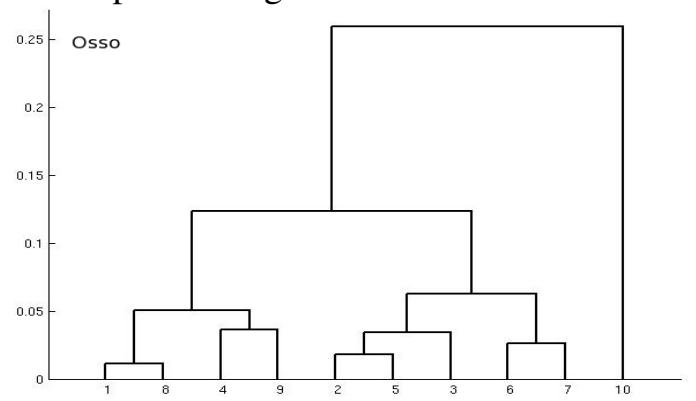

Figura 4.13: Dendrograma que ilustra as relações entre os modelos que integram o lote da palavra osso.

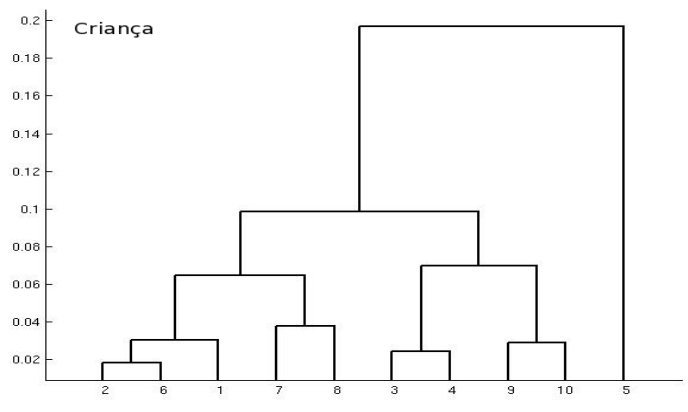

Figura 4.10: Dendrograma que ilustra as relações entre os modelos que integram o lote da palavra criança.

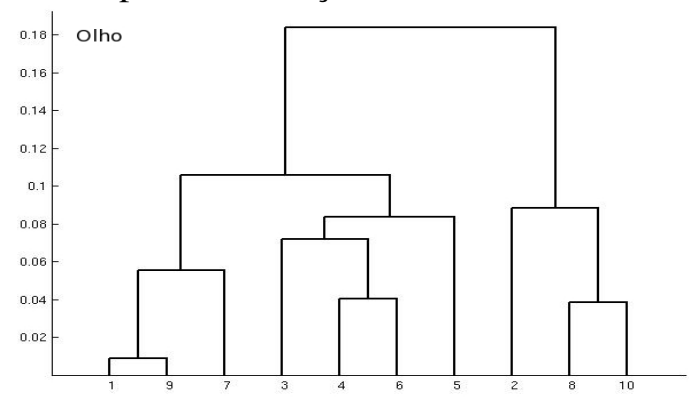

Figura 4.12: Dendrograma que ilustra as relações entre os modelos que integram o lote da palavra olho.

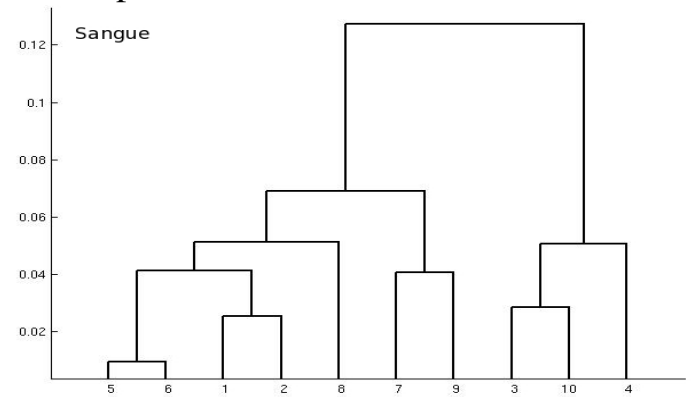

Figura 4.14: Dendrograma que ilustra as relações entre os modelos que integram o lote da palavra sangue. 
vras que pertencem à língua 7 e 9 . Este agrupamento não é observado no dendrograma obtido a partir da distância C2 para a mesma palavra. Os resultados alcançados com a distância C2 são interessantes dado que ela poderia ser considerada como um critério complementar à classificação da divergência KL. As semelhanças entre os agrupamentos resultantes era esperada para o caso da distância Jensen-Shannon dado que pertence a mesma família que a divergência KL. No caso das outras medidas de distância as similaridades dos agrupamentos poderiam estar relacionados com o método computacional empregado para estimar as distâncias entre os modelos mas de qualquer forma poderia-se afirmar que os agrupamentos dependem dos modelos estimados e não das métricas de distância utilizadas.

\section{Semelhanças entre as línguas indígenas}

A abordagem empregada neste trabalho interessa-se por representar palavras de línguas indígenas através de um modelo probabilístico que permita estabelecer similaridades e diferenças entre os modelos estimados. Segundo nosso critério valorativo é necessário fazer um estudo, integrando diversas técnicas de processamento digital da fala, para conceber resultados mais definitivos. Os resultados das línguas indígenas apresentados a seguir estão sujeitos aos métodos matemáticos implementados e por esse motivo, não refutam nenhuma das classificações feitas pelos linguistas. Nosso interesse é mostrar relações entre algumas palavras que pertencem a línguas indígenas no Brasil, obtidas com o algoritmo implementado e sem julgar as relações já estabelecidas pelos estudos linguísticos.

Uma observação detalhada das Figuras 4.3, 4.4, 4.5, 4.6, 4.7 e 4.8 permite identificar alguns padrões na forma da mistura de algumas palavras que pertencem a uma determinada língua. Este é o caso dos modelos que representam as palavras da língua Tukano. As PDFs destas palavras estão quase sempre caraterizadas por misturas em que os valores dos parâmetros (média e desvio padrão) são pequenos e concentrados. Acontece a mesma coisa com as PDFs das palavras que integram a língua Kayabí, desta vez as misturas destas palavras se caracterizam por parâmetros com valores mais espalhados, mostrando altos valores de desvio padrão para cada componente gaussiana. Todas as palavras de outras línguas não evidenciam o mesmo comportamento padrão, por exemplo as palavras da língua indígena Mundurukú estão descritas por um comportamento irregular dos parâmetros, em outras palavras não é possível estabelecer um padrão para os modelos das palavras que integram esta família.

Há algumas famílias de línguas indígenas em que as PDFs das palavras, em geral, se caracterizam por misturas com muitos componentes gaussianos. Um exemplo concreto são as PDFs 
Dendrogramas da distância de Bhattacharyya

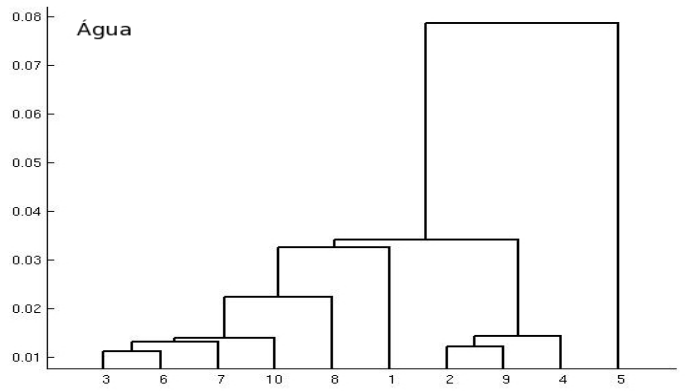

Figura 4.15: Dendrograma que ilustra as relações entre os modelos que integram o lote da palavra água.

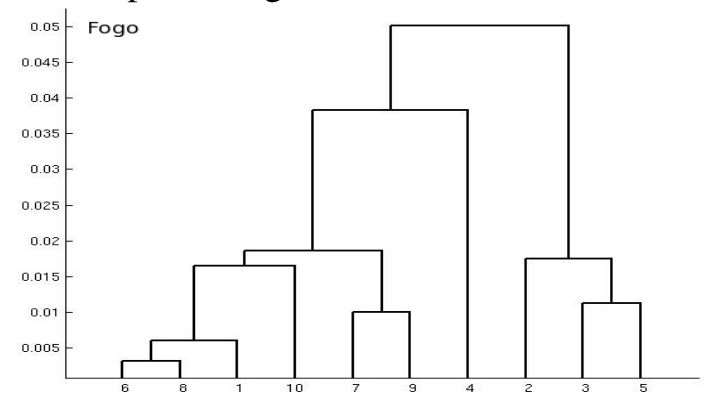

Figura 4.17: Dendrograma que ilustra as relações entre os modelos que integram o lote da palavra fogo.

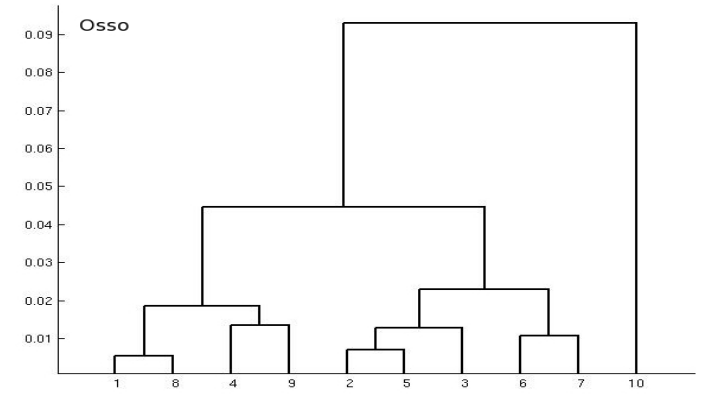

Figura 4.19: Dendrograma que ilustra as relações entre os modelos que integram o lote da palavra osso.

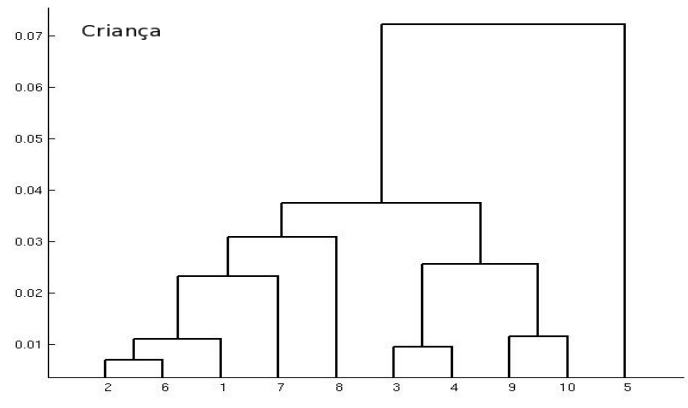

Figura 4.16: Dendrograma que ilustra as relações entre os modelos que integram o lote da palavra criança.

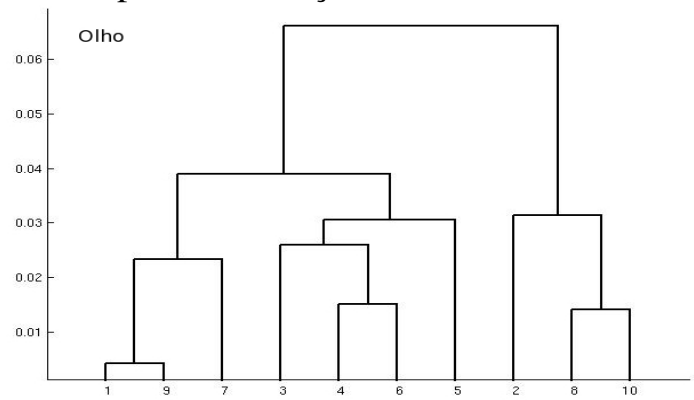

Figura 4.18: Dendrograma que ilustra as relações entre os modelos que integram o lote da palavra olho.

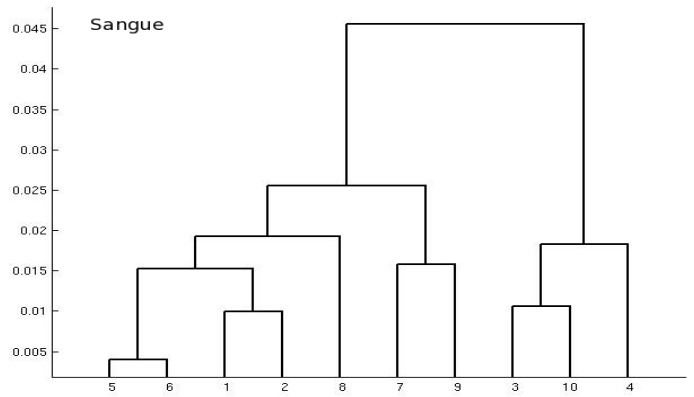

Figura 4.20: Dendrograma que ilustra as relações entre os modelos que integram o lote da palavra sangue. 


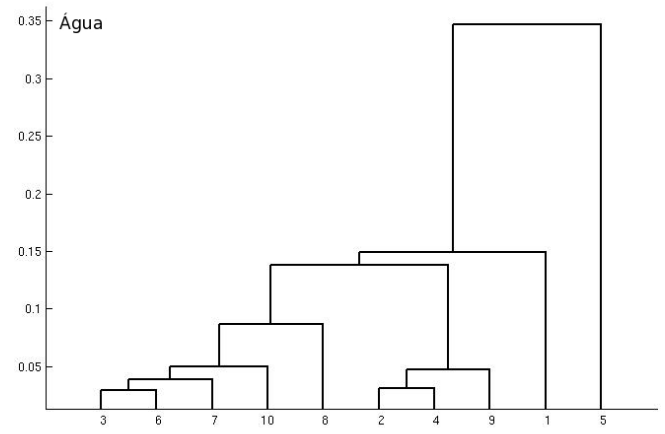

Figura 4.21: Dendrograma que ilustra as relações entre os modelos que integram o lote da palavra água.

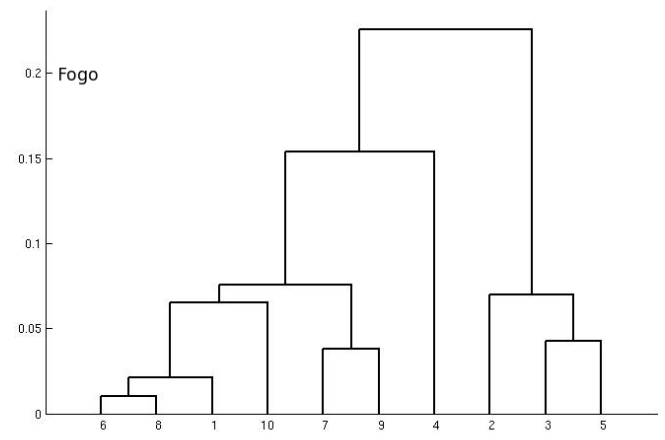

Figura 4.23: Dendrograma que ilustra as relações entre os modelos que integram o lote da palavra fogo.

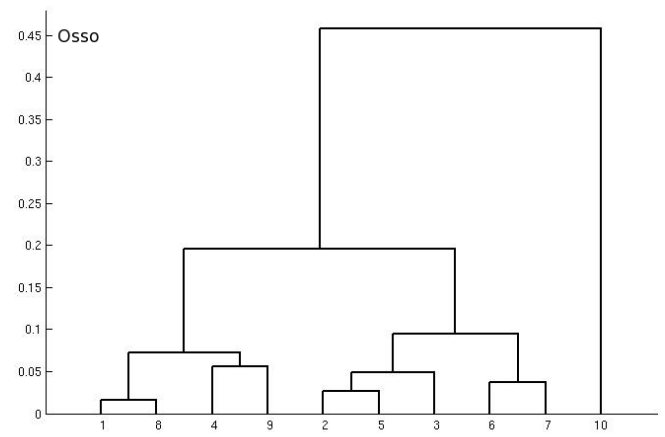

Figura 4.25: Dendrograma que ilustra as relações entre os modelos que integram o lote da palavra osso.

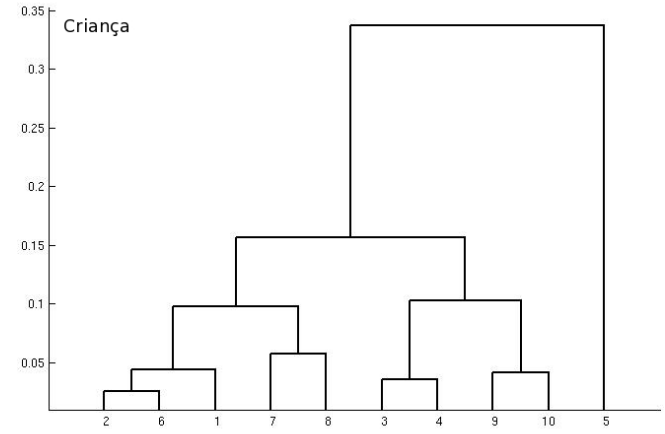

Figura 4.22: Dendrograma que ilustra as relações entre os modelos que integram o lote da palavra criança.

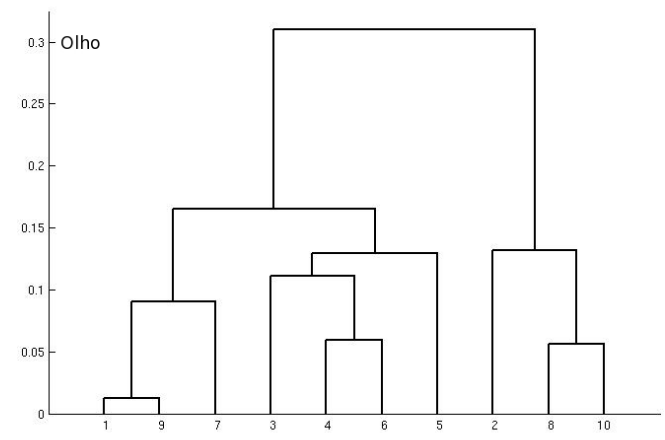

Figura 4.24: Dendrograma que ilustra as relações entre os modelos que integram o lote da palavra olho.

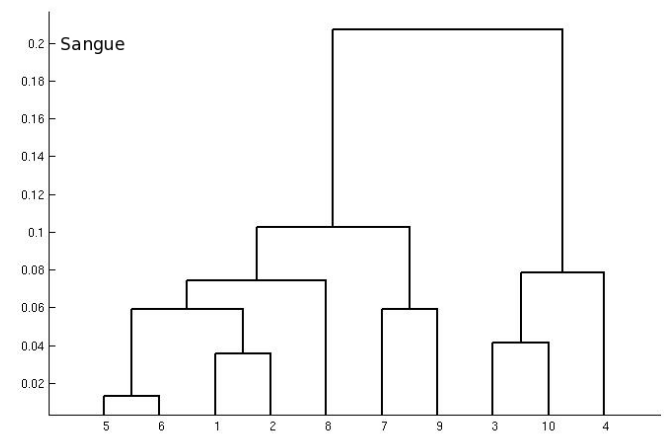

Figura 4.26: Dendrograma que ilustra as relações entre os modelos que integram o lote da palavra sangue. 


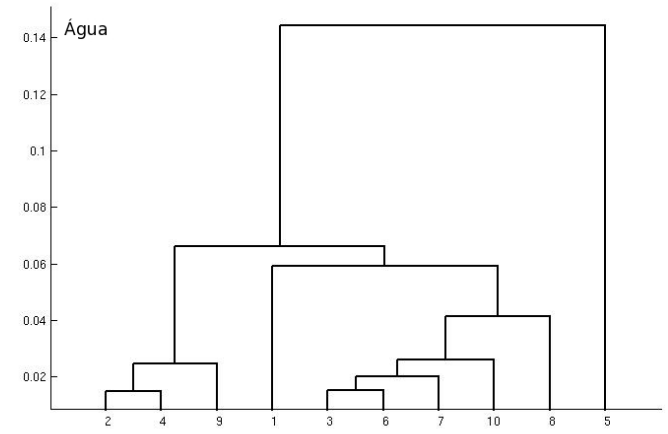

Figura 4.27: Dendrograma que ilustra as relações entre os modelos que integram o lote da palavra água.

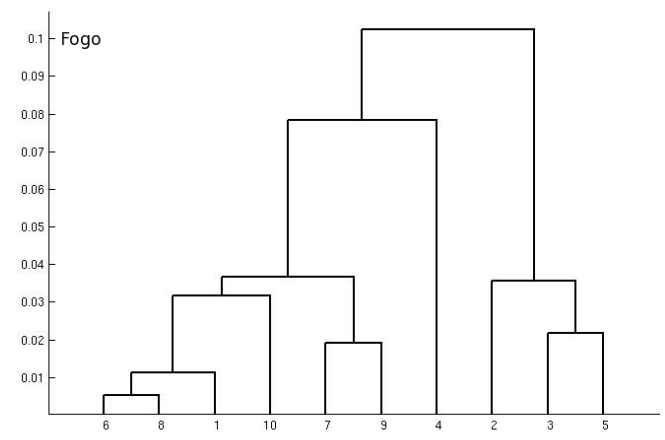

Figura 4.29: Dendrograma que ilustra as relações entre os modelos que integram o lote da palavra fogo.

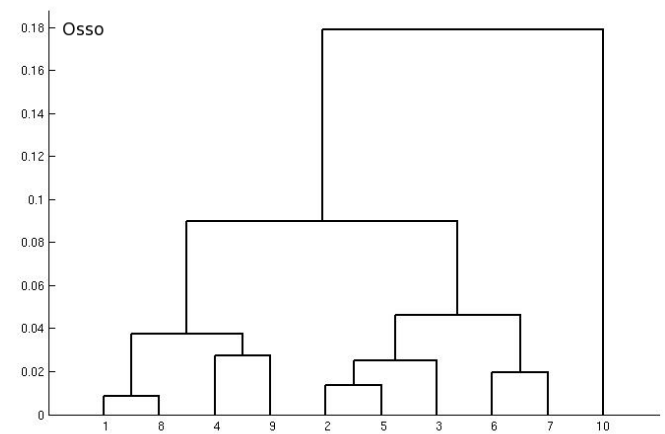

Figura 4.31: Dendrograma que ilustra as relações entre os modelos que integram o lote da palavra osso.

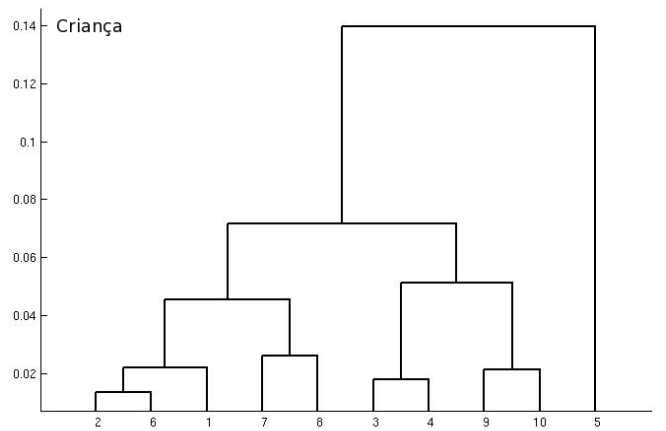

Figura 4.28: Dendrograma que ilustra as relações entre os modelos que integram o lote da palavra criança.

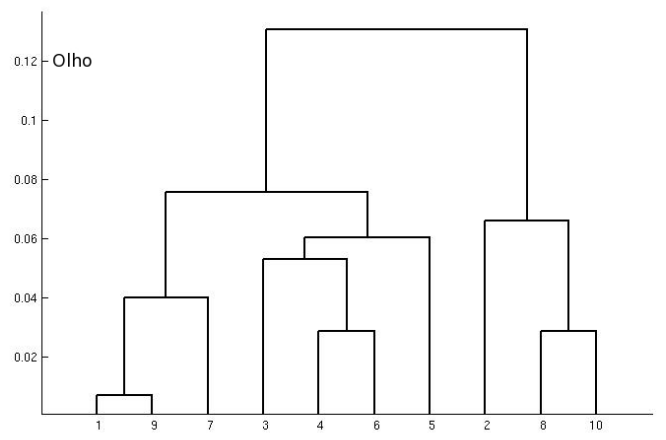

Figura 4.30: Dendrograma que ilustra as relações entre os modelos que integram o lote da palavra olho.

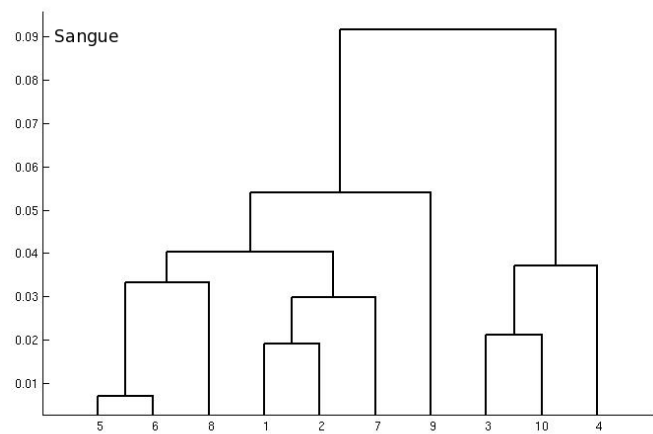

Figura 4.32: Dendrograma que ilustra as relações entre os modelos que integram o lote da palavra sangue. 
Dendrogramas da distância C2

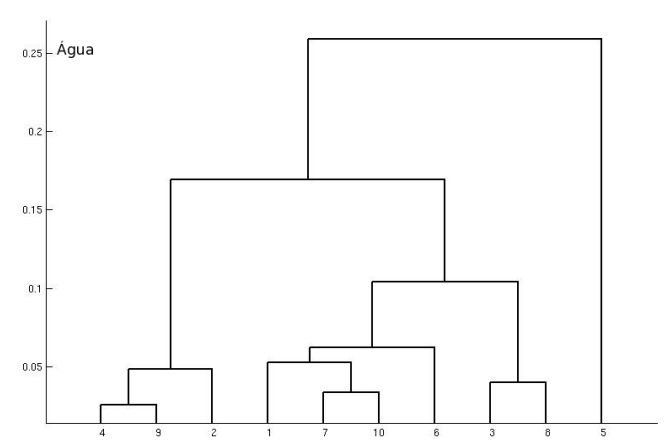

Figura 4.33: Dendrograma que ilustra as relações entre os modelos que integram o lote da palavra água.

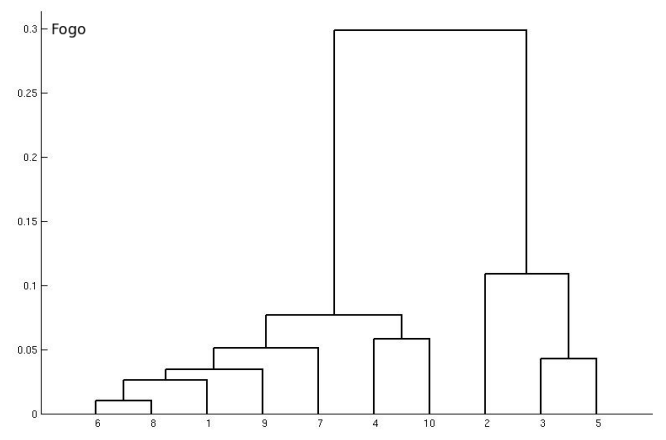

Figura 4.35: Dendrograma que ilustra as relações entre os modelos que integram o lote da palavra fogo.

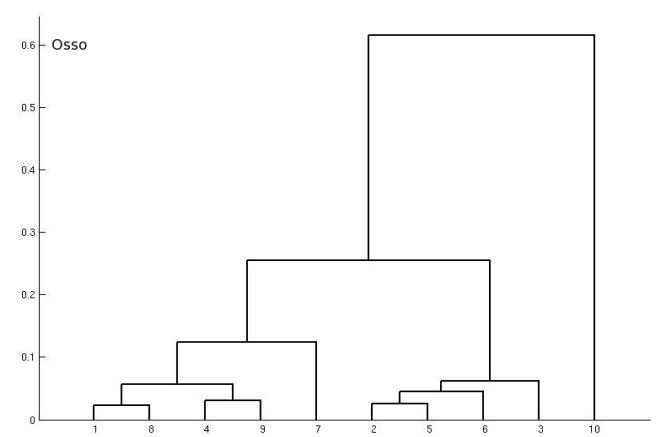

Figura 4.37: Dendrograma que ilustra as relações entre os modelos que integram o lote da palavra osso.

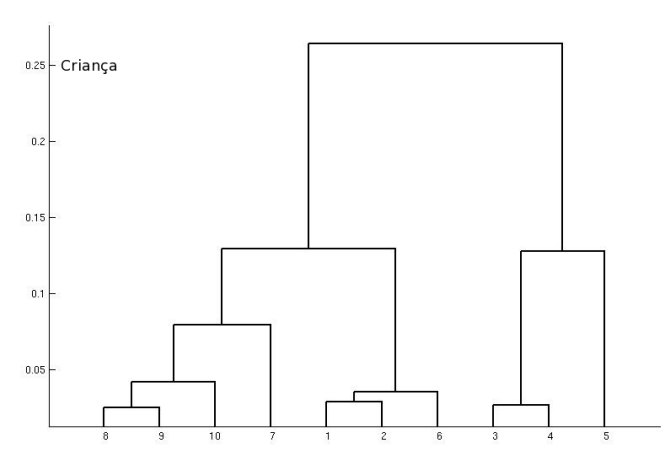

Figura 4.34: Dendrograma que ilustra as relações entre os modelos que integram o lote da palavra criança.

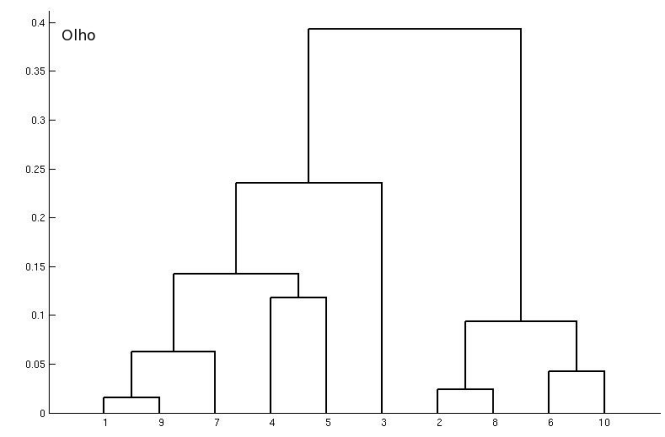

Figura 4.36: Dendrograma que ilustra as relações entre os modelos que integram o lote da palavra olho.

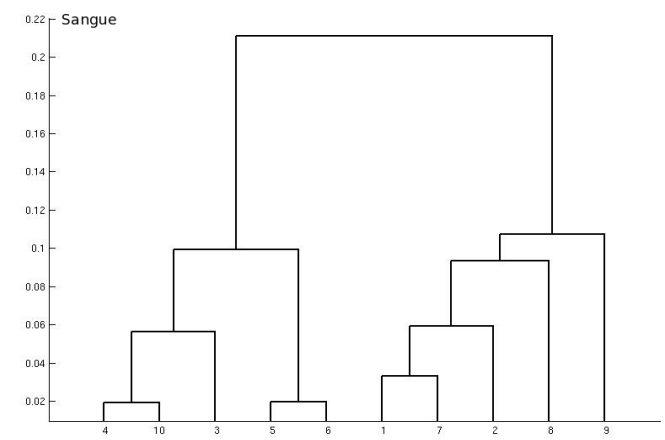

Figura 4.38: Dendrograma que ilustra as relações entre os modelos que integram o lote da palavra sangue. 
das palavras que pertencem a algumas das línguas que integram o tronco Tupí, como é o caso das línguas Kamaruyá, Kayabí e Karitiana. Nas Figuras 4.3, 4.4, 4.5, 4.6, 4.7 e 4.8 pode-se observar que a maior parte das vezes as PDFs destas famílias apresentam este comportamento. Um caso mais interessante ainda é o da língua Tukano, na qual as PDFs estão sempre caraterizadas por muitos componentes. Na maior parte das vezes estas estimativas apresentaram entre 11 e 15 gaussianas.

Dado que os agrupamentos das palavras foram similares para todas as métricas de distância, as relações entre as línguas indígenas comentadas nesta seção serão analisadas considerando os agrupamentos obtidos com a divergência KL. Dado que a distância C2 mostrou agrupamentos diferentes para algumas palavras, estes agrupamentos serão considerados sempre que confirmem a classificação dos linguistas. Por isso, a distância C2 será utilizada como outro critério de classificação, além da divergência KL. Na maioria dos dendrogramas construídos, os quais mostram relações entre as palavras das línguas indígenas, há uma tendência a formar-se grupos entre os troncos linguísticos (Figuras 2.1 e 2.2). Em outras palavras, observam-se agrupamentos em que estão incluídos modelos que descrevem as palavras das línguas dos troncos Tupí ou Macro-Jê. Isto pode ser observado nas Figuras 4.10 e 4.11. Na Figura 4.10 se observa um agrupamento entre as línguas Kamaruyá (3) e Karitiána (4), que pertencem ao tronco linguístico Tupí e um segundo agrupamento entre as línguas Karajá (1) e Krahô (6), as quais formam parte do tronco Macro-Jê. Na Figura 4.34 pode-se observar o mesmo agrupamento que em 4.10, com a diferença que no grupo do tronco Tupí foi incluída a língua Kayabí (5), a qual pertence a este mesmo tronco, na classificação realizada pelos linguistas. Neste caso, será considerado o agrupamento da distância C2 no lugar da divergência KL.

Seguindo as classificações obtidas neste trabalho, acontece frequentemente que nos grupos integrados por palavras de determinado tronco, também são incluídas as palavras que pertencem as línguas isoladas. Desta forma, aparecem grupos entre as palavras do tronco Tupí por exemplo, com alguma palavra pertencente a determinada língua isolada, isso se ilustra no dendrograma da Figura 4.10, em que no agrupamento do tronco Macro-Jê foi incluída a língua Tukano (2), a qual é classificada como uma língua isolada.

Outro resultado interessante, proporcionado pelo algoritmo de agrupamento, é que poucas vezes se mostram grupos em que estejam incluídos somente modelos de palavras que pertencem a línguas isoladas. Segundo nosso algoritmo existe uma tendência a formar grupos entre as palavras das línguas isoladas e as palavras que pertencem a algum dos troncos existentes. 
Isso pode ser observado na Figura 4.12, em que estão relacionadas as línguas Umutina (9) e Karajá (1), ambas pertencentes ao tronco Macro-Jê e a língua Kuikúru (7) que é classificada como uma língua isolada.

Em vários dos agrupamentos realizados se observam que muitas vezes aparecem as línguas Kamaruyá (3), Kayabí (5) e Karitiána (4) no mesmo grupo, segundo a classificação dos linguistas estas três línguas pertencem ao mesmo tronco linguístico, o Tupí. Isso pode ser observado nas Figuras 4.11 e 4.12. Outras das famílias de línguas que aparecem com frequência no mesmo grupos são as línguas Umutina (9) e Kuikúru (7), este resultado é interessante devido a que ambas línguas pertencem a famílias diferentes, mas acontece de forma repetida o fato delas aparecerem juntas. A primeira língua pertence ao tronco Macro-Jê, enquanto a segunda é classificada como uma língua isolada.

A língua Tukano (2) aparece nos dendrogramas mostrados nas Figuras 4.9, 4.10, 4.11, 4.12, 4.13 e 4.14, em diferentes grupos cada vez. As palavras desta língua, poderiam ser consideradas as mais parecidas com o resto das palavras. Contrariamente acontece com as palavras da língua Kayabí (5), que apresentam uma tendência a ficar isolada do resto dos grupos, isso se ilustra nas Figuras 4.9 e 4.10, ou formar grupos com as línguas que integram seu mesmo tronco linguístico, observado nas Figuras 4.34 e 4.36.

Os resultados mostrados nesta seção confirmam em alguns momentos as classificações realizadas pelos linguístas. Além destas relações já conhecidas na literatura, novos agrupamentos são observados. De qualquer forma todos os agrupamentos aqui mostrados são de interesse para o presente estudo. 


\section{Capítulo 5}

\section{Conclusões e Sugestões}

O objetivo principal do presente trabalho foi construir um modelo capaz de caracterizar determinadas palavras e que possibilitará o emprego de métricas de distância para estabelecer semelhanças e diferenças entre os modelos estimados. Para isso foi implementado um algoritmo para estimar as PDFs dos sinais, baseadas em GMM, comparar os modelos e estabelecer relações entre as PDFs que caracterizaram as palavras. Um conjunto de palavras de línguas indígenas brasileiras foram analisadas, através do emprego do algoritmo implementado. A PDF das palavras indígenas foi estimada usando um modelo baseado em mistura de gaussianas, enquanto a divergência KL foi escolhida para calcular as semelhanças entre estes modelos.

Diversos testes realizados com sinais simulados confirmaram que o método de estimativa da PDF baseada em mistura de gaussianas demonstrou a capacidade de gerar as PDFs com exatidão. Considera-se que a precisão das misturas de gaussianas foi produto da implementação do algoritmo EM. Providenciar soluções para cada uma das limitações do algoritmo EM, determinaram o sucesso da estimativa das misturas. O método proposto para inicializar os parâmetros contribuiu para conseguir uma boa e rápida aprendizagem dos modelos, em outras palavras, obter modelos com verossimilhança alta. Um ponto importante na estimativa da mistura, que melhor modela os dados, foi o emprego do critério BIC. Este critério foi crucial na determinação do número de componentes que integraram o GMM. Este fator é considerado um dois mais importantes na exatidão da PDF.

Considera-se que a estimativa da PDF baseada em mistura de gaussianas consegue fazer uma caracterização adequada de cada palavra. Em geral, a estimativa se mostrou capaz de caracterizar de forma individual determinadas palavras. Tal é assim, que algumas das PDFs, das 
palavras analisadas, apresentaram um comportamento padrão, podendo ser identificadas por este tipo de aproximação. A flexibilidade do número de gaussianas que integraram as misturas, sugere ser um fator decisivo para ressaltar as características individuais de cada palavra.

A divergência KL se mostrou como uma medida de distância robusta na determinação das semelhanças entre as PDFs estimadas. O método computacional desenvolvido para calcular esta divergência, utilizando as envoltórias das misturas, se comportou estável, conseguindo exatidão na estimativa, além do cumprimento de todas as propriedades da divergência KL. A função resistor-average, empregada para simetrizar a divergência KL, garantiu precisão e eficiência na simetrização da matriz KL.

Os dendrogramas construídos a partir da estimativa da divergência KL evidenciaram claramente relações entre as PDFs. Com o cálculo destas estruturas de agrupamento utilizando outros coeficientes de similaridade, como a distância Bhattacharyya, a divergência Chi-quadrado de Pearson, a distância Jensen-Shannon e a distância C2, foi comprovado que os agrupamentos obtidos para cada medida foram similares. Este resultado é interessante porque confirma que as relações entre os modelos dependem das características dos próprios modelos, não das métricas de distância selecionadas, comprovando-se que o método empregado para o cálculo da divergência KL, consegue respeitar as estimativas das PDF e que a maioria das relações ilustradas nos dendrogramas são produto dos parâmetros que descrevem as misturas.

Os agrupamentos obtidos a partir da distância C2 foram os menos similares com respeito aos outros. Apesar disso, em todos os casos foram consistentes com a classificação realizada pela divergência KL e em alguns momentos mostrou classificações mais parecidas com as realizadas pelos linguistas. Por isso, a distância $\mathrm{C} 2$ foi considerada como um complemento da divergência KL. Nesse caso, propomos empregar neste estudo, as duas métricas de distância, considerando os agrupamentos similares para as duas medidas e aquelas relações que sendo diferentes, confirmem a classificação realizada pelos linguistas.

Embora os resultados obtidos para as palavras que integram as 10 línguas indígenas brasileiras se consideram inconclusivos, as relações estabelecidas, a partir de nosso algoritmo, foram interessantes. Para conseguir resultados mais definitivos relacionados com as classificações das línguas indígenas é necessário um estudo mais detalhado em que sejam integradas um conjunto de técnicas de processamento de sinais de fala. O objetivo principal de nosso trabalho foi alcançado, já que se conseguiu construir um modelo probabilístico que descreve cada palavra das línguas indígenas e que permite estabelecer comparações entre estes modelos, 
através de métricas de distância.

Encontrar padrões nas PDFs de algumas das palavras que pertencem a determinada família de línguas se considera um resultado promissor porque sugere a possibilidade de estudar diferentes comportamentos para cada uma das famílias. Neste estudo, não é possível generalizar esta ideia, devido ao fato de utilizar um reduzido número de palavras. É válido ressaltar que em muitas ocasiões, os agrupamentos ilustrados nos dendrogramas incluíam palavras que pertenciam à mesma família linguística, confirmando a classificação de troncos linguísticos realizada por Rodrigues (1986), além de dar credibilidade ao método matemático e ao algoritmo proposto neste trabalho.

Outra questão importante é a tendência a formar grupos em que estejam incluídas palavras dos troncos linguísticos e palavras que pertencem a línguas isoladas. Dificilmente, encontraram-se grupos em que foram agrupadas palavras pertencentes somente a línguas isoladas. De forma empírica se sugere que estas relações poderiam estar acontecendo pelo fato de que, as línguas dos troncos linguísticos são mais consolidadas e faladas por maior número de povos. Esta poderia ser uma influência para que as línguas isoladas sejam cada vez mais parecidas com aquelas que pertencem a um tronco linguístico mais consolidado.

Todas as afirmações anteriores são consideradas como um conjunto de questões, que servem de motivação para continuar pesquisando nestas áreas. O presente trabalho se considera um estudo inicial que abre caminho para inúmeras pesquisas, em que será preciso a integração de diversas áreas da ciência e a concepção de uma equipe multidisciplinar com o objetivo de acrescentar conhecimentos a respeito das línguas indígenas brasileiras e do mundo em geral.

\subsection{Trabalhos futuros}

Este trabalho foi uma das primeiras abordagens na análise de línguas indígenas brasileiras, portanto existem muitas possibilidades a serem consideradas. Alguma delas são:

Aumentar o número de palavras nas análises para conseguir resultados mais definitivos;

Realizar outro tipo de comparações, por exemplo, entre as palavras que pertencem a mesma língua;

Realizar um estudo para avaliar a existência de padrões entre os modelos que descrevem as línguas; 
- Embora o modelo baseado em GMM comportou-se adequado para a estimativa das PDFs dos sinais, recomenda-se empregar outro tipo de modelo, que se apresentam na literatura como promissórios na caraterização dos sinais de fala;

- Empregar outras medidas de distância entre os modelos baseados em GMM, por exemplo estimar a informação mutua;

- Procurar outros métodos para estimar as distâncias propostas neste trabalho entre GMM;

- Realizar uma análise temporal dos sinais, considera-se que esse tipo de análise acrescentaria consideravelmente os critérios de classificação das palavras. 


\section{Referências Bibliográficas}

Afifi, A., Clark, V., e May, S. (2004). Cluster Analysis. In Computer-Aided Multivariate Analysis, Fourth Edition, pp. 417-442. Chapman Hall/CRC, Florida.

Anderberg, M. R. (1973). Cluster Analysis for Applications. New York:Academic.

Archambeau, C. e Verleysen, M. (2003). Fully Nonparametric Probability Density Function Estimation with Finite Gaussian Mixture Models. In 5th International Conference on Advances in Pattern Recognition (ICAPR'2003), pp. 81-84.

Azzalini, A. e Capitanio, A. (1999). A Statistical Applications of Themultivariate Skewnormal Distribution. Journal of the Royal Statistical Society, Serie B, 61:579-602.

Borman, S. (2004). The Expectation Maximization Algorithm - A Short Tutorial. University of Notre Dame, USA.

Cha, S. (2007). Comprehensive Survey on Distance/Similarity Measures between Probability Density Functions. International Journal of Mathematical Models and Methods in Applied Sciences, 1(4):300-307.

Chan, A. e Vasconcelos, N. (2005). A Family of Probabilistic Kernels Based on Information Divergence. Technical report, University of California., San Diego.

Chang, J. H., Kim, N., e Mitra, S. K. (2006). Voice Activity Detection Based on Multiple Statistical Models. IEEE Transactions on Signal Processing, 54:1965-1976.

Chen, T., Huang, C., Chang, E., e Wang, J. (2001). Automatic Accent Identification Using Gaussian Mixture Models. In IEEE Workshop on Automatic Speech Recognition and Understanding (ASRU 2001), pp. 343-346.

Cover, T. M. e Thomas, J. A. (1991). Elements of Information Theory. John Wiley and Sons, Inc., New York. 
Cristófaro-Silva, T. (2002). Morte de Língua ou Mudança Linguística?- Uma Revisão Bibliográfica. Revista do Museu Antropológico, 5-6(1):55-73.

Crystal, D. (2000). Language Death. Cambridge University Press, Cambridge, UK.

Cândido, G. V. e Ribeiro, L. A. A. (2007). O Comportamento Fonológico dos Segmentos Secundários Vocálicos nas Línguas Indígenas Brasileiras. In II Jornada de Pesquisa e PósGraduação.

Do, M. N. (2003). Fast Approximation of Kullback-Leibler Distance for Dependence Trees and Hidden Markov Models. IEEE Signal Processing Letters, 10(4):115-118.

Dustor, A. e Szware, P. (2009). Application of GMM Models to Spoken Language Recognition. In 16th International Conference Mixed Desing of Integrated Circuits and Systems (MIXDES'2009), pp. 603-606.

Erdogmus, D. e Principe, J. C. (2006). From Linear Adaptive Filtering to Nonlinear Information Processing. IEEE Signal Processing Magazine, 23(6):14-33.

Everitt, B. S., Landau, S., e Leese, M. (2001). Cluster Analysis, $4^{\text {th }}$ edition. Oxford University Press Inc., New York.

Francheto, B. (1999). As Línguas Indígenas. In Índios no Brasil 2, Coleção Cadernos da TV Escola, Ministério da Educação, Secretaria de Educação à Distância, pp. 5-20.

Gazor, S. e Zhang, W. (2003a). A Soft Voice Activity Detector Based on a Laplacian Gaussian Model. IEEE Transactioons on Speech and Audio Processing, 11(5):498-505.

Gazor, S. e Zhang, W. (2003b). Speech Probability Distribution. IEEE Signal Processing Letters, 10(7):204-207.

Goldberger, J., Gordon, S., e Greenspan, H. (2003). An Efficient Image Similarity Measure Based on Approximations of KL-Divergence Between Two Gaussian Mixtures. In Ninth IEEE International Conference on Computer Vision, vol. 1, pp. 487-493.

Gopinath, D. P., Veena, S. G., e Achuthsankar, S. N. (2008). Modeling of Vowel Duration in Malayalam Speech Using Probability Distribution. In Speech Prosody 2008, pp. 99-102.

Gray, A. G. e Moore, A. W. (2003). Nonparametric Density Estimation: Toward Computational Tractability. In SIAM International Conference on Data Mining (SDM), pp. 203-211. 
Haubold, A. e Kender, J. (2008). Accommodating Sample Size Effect on Similarity Measures in Speaker Clustering. In IEEE International Conference on Multimedia and Expo (ICME 2008), vol. 1-4, pp. 1525-1528.

Hershey, J. R. e Olsen, P. A. (2007). Approximating the Kullback Leibler Divergence between Gaussian Mixture Models. In IEEE International Conference on Acoustics, Speech and Signal Processing (ICASSP'2007), vol. 4, pp. 317-320.

Huber, M., Bailey, T., Durrant-Whyte, H., e Hanebeck, U. (2008). On Entropy Approximation for Gaussian Mixture Random Vectors. In IEEE International Conference on Multisensor Fusion and Integration for Intelligent Systems (MFI'2008), pp. 181-188.

Jensen, J. H., Ellis, D. P., Christensen, M. G., e Jensen, S. H. (2007). Evaluation of Distance Measures between Gaussian Mixture Models of MFFCS. Technical report, Autrian Computer Society (OCG).

Johnson, D. H. e Sinanović, S. (2001). Symmetrizing the Kullback-Leibler Distance. IEEE Transactions on Information Theory.

Kaufman, L. e Rousseeuw, P. J. (1990). Finding Groups in Data: An Introduction to Cluster Analysis. Wiley, New York.

Kroeker, B. (2003). Aspectos da Língua Nambikuara. Sociedade Internacional de LinguísticaSIL, 2:1-101.

Ku, Y. G. e Kawasumi, M. (2008). Semiparametric Approach to Nonstationary Signal Analysis. In IEEE International Conference on Signal Processing, Comunications and Networking (ICAPR'2003), pp. 158-162.

Lan, T., Erdogmus, D., Ozertem, U., e Huang, Y. (2006). Estimating Mutual Information Using Gaussian Mixture Model for Feature Ranking and Selection. In International Joint Conference on Neural Networks (IJCNN'06), pp. 5034-5039.

Li, X. Q. e King, I. (1999). Gaussian Mixture Distance for Information Retrieval. In Proceedings of the International Joint Conference on Neural Networks, vol. 4, pp. 2544-2549.

Maia, M. (2006). A Revitalização de Línguas Indígenas e seu Desafio para a Educação Intercultural Bilíngue. In VII Congreso Latinoamericano de Educación Intercultural Bilíngue. 
Maia, M., Franchetto, B., Leite, Y. F., Soares, M. F., e Vieira, M. D. (1998). Comparative Aspects of Grammar in Brazilian Indigenous Languages. DELTA: Documentação de Estudos em Linguística Teórica e Aplicada, 14:349-375.

Marques, L. V. (2009). Um Estudo sobre a Inicialização do Algoritmo EM Aplicado à Misturas Finitas de Normais Assimétricas. Dissertação de Mestrado, Universidade Federal do Amazonas-UFAM, Manaus.

Martin, R. e Breithaupt, C. (2003). Speech Enhancement in the DFT Domain Using Laplacian Speech Priors. In International Workshop on Acoustic Echo and Noise Control (IWAENC2003), pp. 87-90.

McLachlan, G. e Krishnan, T. (1997). The EM Algorithm and Extensions. Wiley-Interscience Publication, University of Queensland, Brisbane.

McLachlan, G. e Peel, D. (2000). Finite Mixture Models. Wiley-Interscience Publication, University of Queensland, Brisbane.

Moreno, P., Ho, P., e Vasconcelos, N. (2004). A Kullback-Leibler Divergence Based Kernel for SVM Classification in Multimedia Applications. In 17th Annual Conference on Neural Information Processing Systems (NIPS), vol. 16, pp. 1385-1392.

Nan, F., Wang, Y., Li, F., e Yang, W. (2009). A Better Method than Tail-fitting Algorithm for Jitter Separation Based on Gaussian Mixture Model. Journal of Electronic Testing: Theory and Applications (JETTA), pp. 1-6.

Nasser, S., Alkhaldi, R., e Vert, G. (2006). A Modified Fuzzy K-means Clustering Using Expectation Maximization. In IEEE International Conference on Fuzzy Systems, pp. 231235.

Nolazco, J. A., Salgado, L. R., e Peña, M. (2005). Speaker Dependent ASRs for Huastec and Western Huastec Nahuatl Languages. Lecture Notes in Computer Science, II(3523):595602.

Olson, K. S. e Mielke, J. (2007). Acoustic Properties of the Kagayanen Vowel Space. In 16th International Congress of Phonetic Sciences (ICPhS XVI), pp. 845-848.

Parker, S. (2007). An Acoustic Analysis of Cusco Quechua. Revista de la Facultad de Humanidades y Lenguas Modernas, Universidad Ricardo Palma, (3):1-12. 
Pereira, R. N., Gubitoso, M. D., e Zanotto, P. (2004). BlastPhen Agrupamento por Similaridade com Genomas Completos. Technical report, Universidade de São Paulo, São Paulo.

Petridou, S. G., Koutsonikola, V., Vakali, A. I., e Papadimitriou, G. I. (2006). A DivergenceOriented Approach for Web Users Clustering. Lecture Notes in Computer Science, pp. 12291238.

Raykar, V. C. (2002). Probability Density Function Estimation by Different Methods. Technical report, University of Maryland., USA.

Reynolds, D. A. e Rose, R. C. (1995). Robust Text-Independent Speaker Identification Using Gaussian Mixture Models. IEEE Transactions on speech and audio processing, 3(1):72-83.

Rodrigues, A. D. (1986). Línguas Brasileiras - para o Conhecimento das Línguas Indígenas. Edições Loyola, São Paulo.

Salvi, G. (2003). Accent Clustering in Swedish Using the Bhattacharyya Distance. In Proceedings of the International Congress of Phonetic Sciences (ICPhS, pp. 1149-1152.

Scalassara, P. R. (2009). Utilização de Medidas de Previsibilidade em Sinais de Voz para Discriminação de Patologias de Laringe. Tese de Doutorado, EESC-USP, São Carlos.

Scalassara, P. R., Dajer, M. E., Maciel, C. D., e Guido, R. C. (2009a). Relative Entropy Measures Applied to Healthy and Pathological Voice Characterization. Applied Mathematics and Computation, 207:95-108.

Scalassara, P. R., Maciel, C. D., Pereira, J. C., e Oliveira, S. (2009b). Problems with Nonparametric Entropy Estimation of Voice Signals. In 20th International Congress of Mechanical Engineering (COBEM'2009), vol. 1, p. 1677.

Schwarz, G. (1978). Estimating the Dimension of a Model. Annal of Statistics, 6(1):461-464.

Seghouane, A. K. e Amari, S. I. (2007). The AIC Criterion and Symmetrizing the KullbackLeibler Divergence. IEEE Transactions on Neural Networks, 18(1):97-106.

Seki, L. (2000). Línguas Indígenas no Brasil No Limiar do Século XXI. Impulso, 12(27):157170.

Sepúlveda, L., Maciel, C., Pereira, J. C., Scalassara, P., e Petronio, A. (2010). Divergence of Languages Among Brazilian Indigenous Peoples. In 17th International Workshop on Systems, Signals and Image Processing (IWSSIP 2010), pp. 364-367. 
Sfikas, G., Constantinopoulos, C., Likas, A., e Galatsanos, N. (2005). An Analytic Distance Metric for Gaussian Mixture Models with Application in Image Retrieval. In Duch, W., Kacprzyk, J., Oja, E., e Zadrozny, S. (Eds.), Artificial Neural Networks: Formal Models and Their Applications - ICANN 2005, vol. 3697 of Lecture Notes in Computer Science, pp. 835-840. Springer Berlin / Heidelberg.

Shin, J., Chang, J., e Kim, N. S. (2005). Statistical Modeling of Speech Signals Based on Generalized Gamma Distribution. IEEE Signal Processing Letters, 12(3):258-261.

Talavera, E. V. (2007). Métodos Bayesianos Aplicados em Taxonomia Molecular. Dissertação de Mestrado, EESC-USP, São Carlos.

Tan, P., Steinbach, M., e Kumar, V. (2006). Cluster Analysis: Basic Concepts and Algorithms. In Introduction to Data Mining, pp. 361-391. Addison-Wesley, Minnesota.

Tomasi, C. (2004). Estimating Gaussian Mixture Densities with EM - A Tutorial. Technical report, Duke University.

Viola, P., Schraudolph, N. N., e Sejnowski, T. J. (1996). Empirical Entropy Manipulation for Real-World Problems. In Advances in Neural Information Processing Systems (NIPS*96), pp. 851-857.

Weixiang, L., Tianfu, W., Siping, C., e Aifa, T. (2009). Hierarchical Clustering of Gene Expression Data with Divergence Measure. In 3rd International Conference on Bioinformatics and Biomedical Engineering (iCBBE 2009), pp. 1-3. 